\title{
ADSORÇÃO DE BORO EM PODZÓLICO E LATOSSOLOS PAULISTAS
}

\author{
LUÍS REYNALDO FERRACCIÚ ALLEONI \\ Engenheiro Agrônomo
}

Orientador: Dr. OTÁVIO ANTONIO DE CAMARGO

Tese apresentada à Escola Superior de Agricultura "Luiz de Queiroz", da Universidade de São Paulo, para obtenção do título de Doutor em Agronomia, Área de Concentração: Solos e Nutrição de Plantas.

PIRACICABA

Estado de São Paulo - Brasil

Maio - 1996 
Dados Internacionais de Catalogação na Publicaçăo (CIP)

DIVISÃO DE BIBLIOTECA E DOCUMENTAÇĀO - Campus "Luiz de Queiroz"/USP

Alleoni, Luis Reynaldo Ferracciú

Adsorçāo de boro em podzólico e latossolos paulistas / Luis Reynaldo

Ferracciú Alleoni. - - Piracicaba, 1996.

$127 p$.

Tese (doutorado) - - Escola Superior de Agricultura Luiz de Queiroz, 1996.

Bibliografia.

1. Boro em solo - Adsorçāo 2. Latossolo - São Paulo (Estado) 3. Solo Quimica I. Titulo

CDD 631.41 


\title{
ADSORÇÃO DE BORO EM PODZÓLICO E LATOSSOLOS PAULISTAS
}

\author{
Luís Reynaldo Ferracciú Alleoni
}

Aprovada em 28/05/1996

\section{Comissão Julgadora:}

Dr. Otávio Antonio de Camargo

IAC

Prof. Dr. Jorge de Castro Kiehl

ESALQ/USP

Prof. Dr. José Carlos Chitolina

ESALQ/USP

Prof. Dr. Geraldo Aparecido de Aquino Guedes

U.F. Lavras

Dr. Ronaldo Severiano Berton

IAC

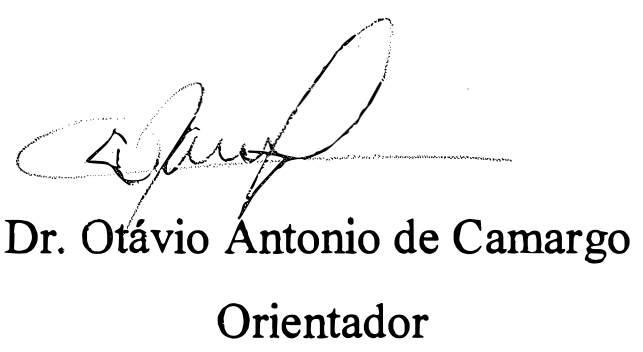


भi भina Cláudia, minba esposa, pelo apoio e compreensão em todos as momentos, e ao (à) nasso (a) filbo (a). que está por vir. 


\section{AGRADECIMENTOS}

- Ao Dr. Otávio Antonio de Camargo, pela orientação desta tese e pelo exemplo de profissional e amigo demonstrado continuamente nesses sete anos de contato;

- À Escola Superior de Agricultura "Luiz de Queiroz, nas pessoas dos Profs. Drs. Geraldo Victorino de França e Francisco Antonio Monteiro, coordenadores do Curso de Pós-Graduação em Solos e Nutrição de Plantas, pela oportunidade oferecida;

- Ao Conselho Nacional de Pesquisa e Desenvolvimento Científico (CNPq), pela bolsa de estudo concedida;

- Ao Prof. Vincenzo de Palma, Chefe do Departamento de Fitotecnia da Universidade de Marlia, e aos Pesquisadores Científicos do Instituto Agronômico de Campinas Drs. Edivaldo Cia, Chefe da Seção de Algodão, Marcos Guimarães de Andrade Landell, Coordenador do Programa Cana, e Léo Zimback, Chefe da Estação Experimental de Piracicaba, pela liberação de minhas atividades, em tempo parcial, a fim de realizar o curso de pós-graduação;

- Ao Pesquisador Científico José Maria Aires da Silva Valadares, da Seção de Pedologia do Instituto Agronômico de Campinas, pela realização das análises químicas e fisicas de rotina e pela obtenção do teor de boro solúvel;

- Ao Prof. Dr. José Carlos Chitolina e à Técnica de Laboratório Gertrudes Cláudia Barbieri Fomazier, do Departamento de Química da ESALQ, pela cessão do Laboratório de Físico-Química e pelo auxilio na obtenção do boro adsorvido, respectivamente;

- Aos químicos Mônica Ferreira de Abreu e Cláudio José Cuelbas, da Seção de Fertilidade do Solo e Nutrição de Plantas, do Instituto Agronômico de Campinas, pelo auxilio na determinação de boro por indução de plasma;

- A todos os demais que, de uma forma ou de outra, contribuíram para a realização deste trabalho. 


\section{SUMÁRIO}

\section{Página}

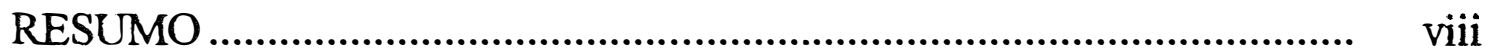

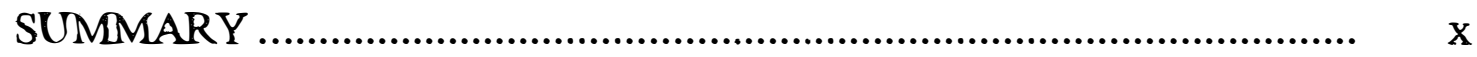

1. INTRODUÇÃO ..................................................................... 1

2. REVISÃO DE LITERATURA...................................................... 4

2.1. Geoquímica e formas de ocorrência ............................................... 4

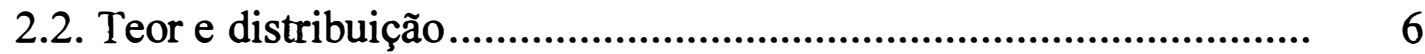

2.3. Interação boro-solo .................................................................. 7

2.3.1. Adsorção de boro em minerais de argila ................................ 8

2.3.2. Adsorção de boro em óxidos e hidróxidos de Fe e de Al....... 9

2.3.3. Adsorção de boro na matéria orgânica.................................... 10

2.3.4. Efeito do $\mathrm{pH}$ na adsorção de boro......................................... 12

2.3.5. Efeito da calagem na adsorção de boro.................................. 13

2.3.6. Energia livre ..................................................................... 15

2.4. Isotermas de adsorção................................................................. 15

2.4.1. Equação de Langmuir......................................................... 16

2.4.2. Equação de Freundlich .................................................... 18

3. MATERIAL E MÉTODOS............................................................ 21

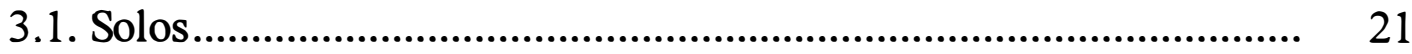

3.2. Caracterização química, física e mineralógica............................... 21

3.2.1. Análises químicas................................................................ 22

3.2.2. Determinação do boro solúvel em $\mathrm{CaCl}_{2} 0,01 \mathrm{~mol} / \mathrm{L}$ a quente 23

3.2.3. Análises físicas.................................................................... 23

3.2.4. Análise mineralógica qualitativa.......................................... 24 
3.3. Adsorção de boro............................................................................ 24

3.4. Análises estatísticas ..................................................................... 26

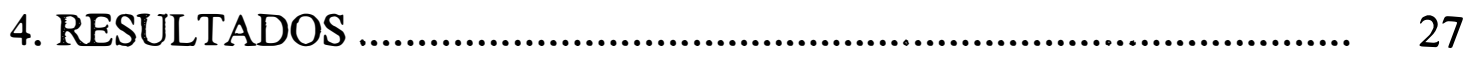

4.1. Análises químicas ..................................................................... 27

4.1.1. Análises químicas ........................................................ 27

4.1.2. Análises químicas complementares.................................... $\quad 30$

4.2. Análises físicas ........................................................................... 32

4.3. Análises mineralógicas .......................................................... 34

4.4. Correlações simples entre as quantidades de boro solúvel (Bs) em solução de $\mathrm{CaCl}_{2}, 0,01 \mathrm{~mol} / \mathrm{L}$ a quente e alguns atributos dos solos 40

4.5. Adsorção de boro................................................................................ 43

4.5.1. Efeito da adição de carbonato de cálcio............................... 47

4.5.2. Representação gráfica da adsorção de boro nos solos .......... 47

4.5.3. Correlações entre boro adsorvido e atributos dos solos........ 51

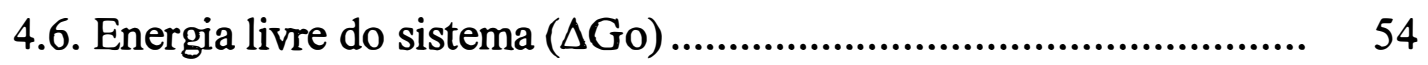

4.7. Modelos de Langmuir e de Freundlich.......................................... 56

4.7.1. Correlações entre constantes de Langmuir e de Freundlich e atributos dos solos .................................................... 58

4.7.2. Representação gráfica dos modelos de Langmuir e de Freundlich, e sua comparação com os valores obtidos em laboratório ........................................................................ 62

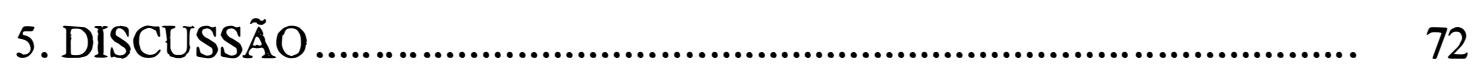

5.1. Boro solúvel em $\mathrm{CaCl}_{2} \quad 0,01 \mathrm{~mol} / \mathrm{L}$ a quente ............................... 72

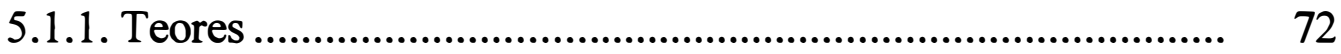

5.1.2. Boro solúvel $x$ atributos químicos dos solos ........................ 74

5.1.2.1. Boro solúvel $\mathrm{x}$ pH ................................................ 74

5.1.2.2. Boro solúvel $x$ carbono orgânico ............................. 75

5.1.2.3. Boro solúvel $x$ cátions trocáveis .............................. 77 
5.1.2.4. Boro solúvel x óxidos ............................................ 77

5.1.3. Boro solúvel $x$ atributos físicos dos solos ........................... 78

5.1.4. Análise de regressão múltipla ............................................ 80

5.2. Boro adsorvido ..................................................................... 82

5.2.1. Quantidade adsorvida ................................................... 82

5.2.2. Correlações entre boro adsorvido e atributos químicos dos

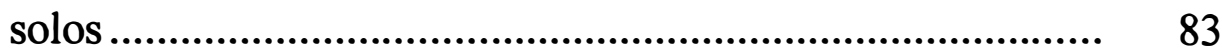

5.2.2.1. Boro adsorvido $\mathrm{xH}$.......................................... 83

5.2.2.2. Efeito da aplicação de $\mathrm{CaCO}_{3}$................................ 85

5.2.2.3. Boro adsorvido $x$ carbono orgânico........................ 87

5.2.2.4. Boro adsorvido $x$ óxidos de ferro e de alumínio...... 89

5.2.3. Correlações entre boro adsorvido e atributos físicos dos

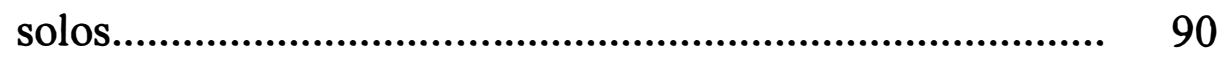

5.3. Modelos de Langmuir e Freundlich ............................................ 93

5.3.1. Adequação dos modelos aos resultados ................................ 93

5.3.2. Correlações entre as constantes dos modelos e atributos dos

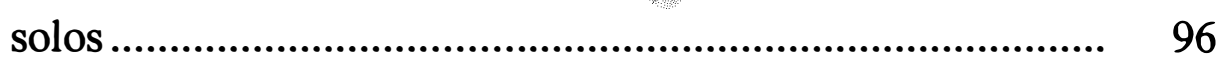

5.3.2.1. Adsorção máxima .................................................... 96

5.3.2.2. Demais correlações ............................................... 99

6. CONCLUSÕES ...................................................................... 101

REFERÊNCIAS BIBLIOGRÁFICAS ............................................. 103

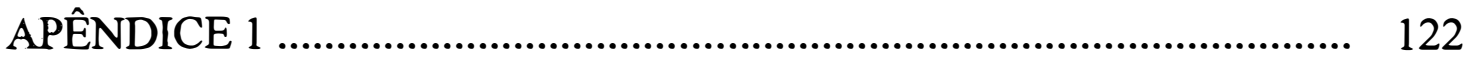

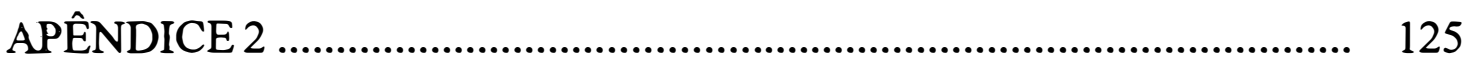




\title{
ADSORÇÃO DE BORO EM PODZÓLICO E LATOSSOLOS
}

\section{PAULISTAS}

\author{
Autor: LUÍS REYNALDO FERRACCIÚ ALLEONI \\ Orientador: DR. OTÁVIO ANTONIO DE CAMARGO
}

\section{RESUMO}

Este trabalho teve por objetivo estudar a adsorção de boro em cinco solos representativos do Estado de São Paulo: latossolo roxo distrófico textura argilosa; latossolo vermelho-escuro álico textura média; latossolo vermelhoamarelo álico textura média; latossolo vermelho-escuro álico textura argilosa, e podzólico vermelho-amarelo eutrófico textura arenosa/média.

Avaliou-se, através de correlações lineares simples e análises de regressão múltipla, o efeito dos atributos químicos do solo fornecidos pela análise de rotina para fins de fertilidade, dos teores totais, livres e mal cristalizados de óxidos de ferro e de alumínio, e dos atributos físicos dos solos (areia, silte, argila e superfície específica) nos teores de boro solúvel extraído com $\mathrm{CaCl}_{2}$, $01 \mathrm{~mol} / \mathrm{L}$ a quente, e de boro adsorvido ao solo. Foi também quantificada a influência da correção da acidez do solo, via carbonato de cálcio, na adsorção do elemento. Estudou-se, finalmente, a adequação das isotermas de Langmuir e Freundlich no estudo da adsorção do boro.

$\mathrm{O}$ boro solúvel em $\mathrm{CaCl}_{2}$ 0,01mol/L a quente apresentou alta correlação com a superfície específica e com os teores de areia e de argila dos solos. As correlações com os atributos químicos foram mais baixas, sendo estatisticamente significativas somente com a CTC e o teor total de óxido de 
alumínio dos cinco solos e com o teor de carbono orgânico dos latossolos. $\mathrm{Na}$ análise conjunta, alumínio total, cálcio trocável e alumínio trocável foram as variáveis que se correlacionaram significativamente com boro solúvel, explicando $85 \%$ de sua variação.

A adição de carbonato de cálcio promoveu aumento na quantidade de boro adsorvido por todos os solos, sendo mais pronunciado o efeito nos latossolos de textura média. Os mais altos coeficientes de correlação entre boro adsorvido e os atributos químicos foram com os teores totais e mal cristalizados de alumínio. Analogamente ao que ocorreu com o boro solúvel, as correlações com areia, argila e superfície específica foram altamente significativas. $\mathrm{Na}$ regressão múltipla, os teores de argila, de óxido de alumínio livre e de boro solúvel correlacionaram-se significativamente com o boro adsorvido pelos solos, com alto coeficiente de determinação $(0,93)$.

As isotermas de Langmuir e de Freundlich ajustaram-se bem à adsorção de boro aos solos, com somatórios de desvios um pouco menores para 0 modelo de Freundlich. Os maiores desvios entre os valores obtidos em laboratório e os estimados pelos modelos apareceram nos solos de textura argilosa. Nesses solos foram encontradas as maiores estimativas de adsorção máxima pelo modelo de Langmuir, cujos valores estavam altamente correlacionados com os teores de ferro e de alumínio totais, livres e amorfos, e com todos os atributos físicos, inclusive o teor de silte. $\mathrm{Na}$ análise conjunta, o teor de óxido de ferro livre foi o principal responsável pela variação nos valores de adsorção máxima, respondendo por $94 \%$ do modelo. No caso da capacidade tampão máxima (CTM), resultado do produto das constantes $\mathrm{K} \mathrm{e} \mathrm{b}$ de Langmuir, os óxidos de alumínio, nas formas totais, livres e mal cristalizadas, representaram $95 \%$ da variação de seus valores na análise de regressão múltipla. 
BORON ADSORPTION IN ULTISOL AND OXISOLS OF THE STATE OF SÃO PAULO, BRAZIL

\author{
Author: LUÍS REYNALDO FERRACCIÚ ALLEONI \\ Adviser: DR. OTÁVIO ANTONIO DE CAMARGO
}

SUMMARY

This work was carried out in order to study boron adsorption by samples of three Hapludox, one Acrudox and one Hapludult, all representative soils from the State of São Paulo, Brazil. Simple linear correlation and more complex relationships, trough the stepwise regression program, were obtained between both soluble boron extracted with hot- $\mathrm{CaCl}_{2} 0,01 \mathrm{~mol} / \mathrm{L}$ (HCB) solution and adsorbed boron, and chemical atributtes (the usual components of routine soil fertility analysis, and the contents of total, free and amorphous iron and aluminum oxides), the usualy physical attributes of the soils (sand, silt and clay content) and the specific surface. The effect of correcting the soil acidity, with calcium carbonate, on the adsorption of boron was also quantified. Finally, the Langmuir and Freundlich isotherms were employed to study the boron adsorption.

Hot- $\mathrm{CaCl}_{2}$ solution extractactable boron was highly correlated with sand and clay contents and with specific surface area. Correlations with chemical attributes were not as high, being statistically significant only for CEC and total aluminum oxide in all the five soils and for organic carbon in the four Oxisols. Multiple regression analysis showed that total aluminum oxide and exchangeable calcium and aluminum were correlated with $\mathrm{HCB}$, explaining $85 \%$ of its variation. 
Calcium carbonate promoted an increase in the amount of adsorbed boron in all soils, but the most outstanding effect was observed in the coarser textured Oxisols. The highest correlation coefficients between the adsorbed boron and chemical attributtes appeared with the content of total and amorphous aluminum oxide. High coefficients were also found with sand and clay contents and specific surface. In the multiple regression, clay content, free aluminum oxide and $\mathrm{HCB}$ could explain $93 \%$ of the variance in adsorbed boron.

Both Langmuir and Freundlich isotherms fitted well to the adsorbed data, but Freundlich model exhibited lower sum of deviation. Highest deviations between the values obtained in laboratory and those predicted by both models occured in the clayey textured Oxisols. Highest values for maximum adsorption predicted by the Langmuir isotherm were found in these soils, which were significantly correlated with contents of total, free and amorphous iron and aluminum oxides, as well with the physical attributes. Ninety four percent of the variation in the maximum adsorption could be related to the free iron content. In the other side, total, free and amorphous aluminum oxide content, in a multiple regression equation, could explain $95 \%$ of variance of maximum buffer capacity, determined by the product of the $\mathrm{K}$ and $\mathrm{b}$ constants of Langmuir equation. 


\section{INTRODUÇÃO}

- O boro é um elemento essencial ao crescimento das plantas, participando como constituinte de diversos compostos e ativadores de enzimas, e de diversos processos, como absorção iônica, transporte de carboidratos, síntese de lignina, celulose, ácidos nucléicos e proteínas. Atribui-se ao boro uma influência marcante nos atributos de formação e qualidade dos produtos agrícolas, tais como germinação do grão de pólen e crescimento do tubo polínico, pegamento da florada, esterilidade masculina e chochamento de grãos.

O Estado de São Paulo apresenta uma gama muito grande de solos com diferentes texturas e graus de fertilidade. Em muitos casos, a deficiência de boro tem sido uma séria limitação para o pleno desenvolvimento de diversas culturas de interesse econômico. Assim sendo, podem ser destacados alguns sintomas de deficiência de boro: morte de gemas apicais e aparecimento de folhas novas encarquilhadas no algodoeiro; internódios curtos, folhas menores, deformadas ou não, e superbrotamento no cafeeiro; espigas de milho com falha na granação; cavidades negras no interior do caule de couve-flor; lesões negras e rachaduras nos frutos do tomateiro; morte de brotos e tubérculos pequenos de batata etc.

Além da deficiência de boro em alguns solos, é importante destacar que o intervalo entre os teores que causam deficiência e toxicidade é muito pequeno, o que complica o quadro de entendimento de sua disponibilidade. Assim, alguns sintomas típicos de toxicidade de boro podem aparecer em algumas 
culturas, tais como a clorose reticulada do cafeeiro e a queima das margens das folhas do algodoeiro (zonas de acumulação de boro).

As recomendações de adubação, em solos com deficiência de boro, apontam para doses maiores do elemento em solos com acidez corrigida (na grande maioria das vezes pela calagem) e solos com altos teores de argila e matéria orgânica. Tal procedimento é devido à adsorção do boro aos colóides do solo, principalmente em pHs próximos e acima da neutralidade. Entretanto, as quantidades recomendadas são baseadas, principalmente, na experiência dos técnicos que formulam as tabelas de recomendação, muitas vezes sem o conhecimento adequado dos processos químicos que determinam a menor disponibilidade do elemento sob determinadas condições.

Reveste-se, então, de importância e compreensão apropriada o estudo do comportamento do boro, no que diz respeito aos mecanismos de interação com as partículas dos solos, principalmente com relação à sua adsorção, a fim de que se possam quantificar os fatores que influenciam sua disponibilidade para as plantas, oferecendo subsídios para a previsão da existência ou não de possível deficiência ou toxicidade. À medida que os resultados obtidos puderem ser ajustados a um modelo matemático, diversas simulações poderão ser feitas, sem que seja necessária a instalação de experimentos de campo para cada condição específica a ser estudada.

Os objetivos do trabalho a ser desenvolvido são estudar:

- os teores de boro solúvel em solução de $\mathrm{CaCl}_{2} 0,01 \mathrm{~mol} / \mathrm{L}$ a quente nos horizontes A e B de alguns solos paulistas, geográfica e economicamente importantes, e suas relações com alguns atributos químicos e físicos destes solos;

- a adsorção de boro nos horizontes A e B dos solos citados, e sua relação com alguns de seus atributos químicos e físicos;

- os efeitos da correção da acidez do solo, via adição de carbonato de cálcio, na adsorção do elemento. 
- a aplicação dos modelos de Langmuir e Freundlich na adsorção do boro.

Parte-se da hipótese que:

- os teores de boro solúvel e adsorvido estão relacionados aos atributos físicos e químicos dos solos, principalmente os teores de carbono orgânico, óxidos de ferro e de alumínio e a textura do solo;

- a aplicação de carbonato de cálcio promove aumento na adosrção de boro nos solos;

- os modelos de Langmuir e de Freundlich ajustam-se bem à adsorção de boro aos solos, dentro da faixa de concentração do elemento utilizada. 


\section{REVISÃO DE LITERATURA}

\subsection{Geoquímica e formas de ocorrência}

O boro é um elemento não-metal do grupo $3 \mathrm{~A}$, de raio iônico pequeno, e que não forma cátion do tipo $\mathrm{B}^{3+}$. Apresenta comportamento semelhante ao dos não-metais, sendo mais parecido com o silício do que com o alumínio, como poderia se esperar devido à sua posição na tabela periódica (COTTON \& WILKINSON, 1972), sendo muito grande a semelhança entre o ácido silícico e o ácido bórico (RAIJ, 1991). Os óxidos $\mathrm{B}_{2} \mathrm{O}_{3}$ e $\mathrm{SiO}_{2}$ são similares em sua natureza acídica e ambos formam vidros que se cristalizam com dificuldade. Em solução, as formas mais importantes são o ácido bórico $\left(\mathrm{H}_{3} \mathrm{BO}_{3}\right)$ e o ânion $\mathrm{H}_{2} \mathrm{BO}_{3}{ }^{-}$. Trata-se de um ácido muito fraco e sua dissociação parcial somente ocorre em valores elevados de $\mathrm{pH}\left(\mathrm{pK}_{1}=9,14 ; \mathrm{pK}_{2}=12,74\right.$ e $\mathrm{pK}_{3}=$ $13,80)$.

O boro é essencialmente litófilo (tende a se acumular na camada silicatada extema da Terra), ocorrendo nos minerais sempre combinado com o oxigênio, em coordenação triangular, formando boratos, ou em coordenação tetraédrica, substituindo parcialmente o silício nos borossilicatos (MARCONI et al., 1980). Entretanto, isto ocorre raramente, devido à grande diferença entre os raios iônicos dos dois elementos ( $\mathrm{B}-0,023 \mathrm{~nm} ; \mathrm{Si}-0,043 \mathrm{~nm}$ ). O boro participa da estrutura de elevado número de minerais, embora poucos apresentem alguma importância, quer pelo seu valor econômico, quer pela quantidade presente nas rochas. Nas rochas ígneas seu teor é baixo, pois seu raio iônico é muito menor do 
que o dos outros elementos mais abundantes em silicatos que ocorrem nestas rochas (RAIJ, 1991). No entanto, sua concentração é maior em granitos do que em basalto, diferentemente dos demais micronutrientes.

A geoquímica do elemento é influenciada sensivelmente pela sedimentação. Os teores nos sedimentos marinhos podem chegar a ser de dez a quinze vezes maiores do que nos sedimentos continentais e nas rochas ígneas e metamórficas (RANKAMA \& SAHAMA, 1962). Nos sedimentos continentais, os teores mais elevados de boro encontram-se nos folhelhos, cerca de $100 \mu \mathrm{g} / \mathrm{g}$, enquanto que nos arenitos eles estão em torno de $35 \mu \mathrm{g} / \mathrm{g}$ (KRAUSKOPF, 1972).

A turmalina $\left[\mathrm{H}_{2} \mathrm{MgNa}_{9} \mathrm{Al}_{3}(\mathrm{BO})_{2} \mathrm{SiO}_{4} \mathrm{O}_{20}\right]$ é o principal mineral que contém boro, respondendo por quase $95 \%$ do conteúdo total do elemento nos solos bem drenados de regiões úmidas (DANTAS, 1991). Além da turmalina, são importantes minerais de boro $\mathrm{o}$ bórax $\left(\mathrm{Na}_{2} \mathrm{~B}_{4} \mathrm{O}_{7} \cdot 10 \mathrm{H}_{2} \mathrm{O}\right)$, a quernita $\left(\mathrm{Na}_{2} \mathrm{~B}_{4} \mathrm{O}_{7} \cdot 4 \mathrm{H}_{2} \mathrm{O}\right)$, a colemanita $\left(\mathrm{CaB}_{6} \mathrm{O}_{11} \cdot 5 \mathrm{H}_{2} \mathrm{O}\right)$ e a ulexita $\left(\mathrm{Ca}_{2} \mathrm{~B}_{6} \mathrm{O}_{11} \cdot 5 \mathrm{H}_{2} \mathrm{O}\right)$, que são pouco resistentes ao intemperismo, permanecendo intactos somente em condições de aridez (RAIJ, 1991).

No solo, a matéria orgânica concentra a maior parte do boro que irá suprir as exigências das plantas (MALAVOLTA, 1980). O boro é liberado para a solução do solo após a mineralização da matéria orgânica, podendo, a partir daí, seguir vários caminhos, tais como ser absorvido pelas plantas, ser perdido por lixiviação ou ser adsorvido pelos colóides do solo (BERGER \& PRATT, 1963).

As formas inorgânicas mais comuns do boro são o ácido bórico e o ânion $\mathrm{B}(\mathrm{OH})_{4}^{-}$, sendo que o ácido bórico, $\mathrm{B}(\mathrm{OH})_{3}$, é a forma predominante nos valores mais comuns de $\mathrm{pH}$ dos solos, enquanto o $\mathrm{B}(\mathrm{OH})_{4}^{-}$predomina somente em pHs acima de 9,2 (LINDSAY, 1972). 


\subsection{Teor e distribuição}

O boro do solo é quantificado nas formas total e disponível. Os teores de boro total variam acentuadamente, dependendo do tipo de mineral presente no solo e dos teores de matéria orgânica (DANTAS, 1991). As concentrações variam de 2 a $100 \mu \mathrm{g} / \mathrm{g}$, sendo mais comuns valores na faixa de 7 a $80 \mu \mathrm{g} / \mathrm{g}$ (KRAUSKOPF, 1973).

Para solos paulistas, teores de boro total estiveram na faixa de 31,3 a $54,0 \mu \mathrm{g} / \mathrm{g}$ para o horizonte $\mathrm{A}$, de 31,2 a $67,5 \mu \mathrm{g} / \mathrm{g}$ para o horizonte B e de 18,7 a $56,0 \mu \mathrm{g} / \mathrm{g}$ para o horizonte C (BRASIL SOBRINHO, 1965). Os valores foram maiores em solos podzolizados de Lins e Marília (atualmente classificados como podzólicos vermelho-amarelos, com diferentes graus de fertilidade, abruptos ou não), derivados do arenito Bauru. Os valores mais baixos foram obtidos nos latossolos roxos e latossolos vermelho-escuros orto (atualmente classificados como latossolos vermelho-escuros distróficos, álicos ou ácricos de textura argilosa ou muito argilosa), derivados de rochas básicas e de sedimentos modernos, respectivamente. SANTOS et al. (1980) encontraram 53 e $48 \mu \mathrm{g} / \mathrm{g}$ de boro total em horizontes superficiais de um latossolo vermelho-amarelo e de um latossolo vermelho-escuro, respectivamente. CASAGRANDE (1978), por sua vez, obteve de 9,8 a 34,2 $\mu \mathrm{g} / \mathrm{g}$ em solos da região de Piracicaba, SP.

Diversos autores constataram que o teor de boro total não constitui parâmetro adequado para predizer sua disponibilidade para as plantas (BERGER \& TRUOG, 1940; BRASIL SOBRINHO, 1965; WEAR, 1965). Em trabalhos brasileiros, observaram-se melhores correlações entre o boro solúvel em água quente e a disponibilidade do elemento às plantas, constatando-se também a superioridade deste método sobre outros métodos químicos existentes (BRASIL SOBRINHO, 1965; CASAGRANDE, 1978; SARABIA, 1982; CRUZ \& 
FERREIRA, 1984; VANDERLEY, 1984; RUY, 1986). Os teores de boro solúvel em água quente de diversos solos paulistas variaram de 0,06 a $0,32 \mu \mathrm{g} / \mathrm{g}$ para o horizonte A, 0,07 a $0,29 \mu \mathrm{g} / \mathrm{g}$ para o horizonte B e traços a $0,12 \mu \mathrm{g} / \mathrm{g}$ para o horizonte C (BRASIL SOBRINHO, 1965). Neste trabalho encontrou-se boa correlação tanto do boro total como do solúvel em água quente com o teor de matéria orgânica. HOROWITZ \& DANTAS (1973) encontraram teores compreendidos entre 0,58 e $4,34 \mu \mathrm{g} / \mathrm{g}$ de boro solúvel em água quente para solos de Pernambuco.

$\mathrm{O}$ boro extraído em água quente representa o boro presente na solução ou aquele fracamente adsorvido pelos componentes do solo (JIN et al., 1987). Embora o valor obtido seja, em muitos casos, correlacionado positivamente com a quantidade do elemento disponível para as culturas (WEAR \& PATTERSON, 1962; SINGH \& SINHA, 1976; CARTWRIGHT et al., 1983), melhores resultados têm sido obtidos com cloreto de cálcio diluído (de 0,01 a $0,02 \mathrm{~mol} / \mathrm{L}$ ), pois este sal minimiza problemas causados pela extração de matéria orgânica e dispersão de argila (PARKER \& GARDNER, 1981; BATAGLIA \& RAJJ, 1990; ADAMS et al., 1991).

\subsection{Interação boro-solo}

Uma grande variedade de atributos do solo afeta o comportamento do boro (EVANS \& SPARKS, 1983; KEREN \& BINGHAM, 1985). Quando o elemento é liberado pelos minerais do solo, pela matéria orgânica após sua mineralização, ou quando é adicionado ao solo por meio de fertilizantes, uma parte permanece na solução, e outra parte é adsorvida ou "fixada" pelas partículas do solo (GUPTA et al., 1985).

O teor de argila, o teor de carbono orgânico, a capacidade de troca 
de cátions, a superficie específica e a condutividade elétrica do extrato saturado parecem ser os fatores que apresentam correlações significativas com o boro adsorvido em diferentes tipos de solo (ELRASHIDI \& O'CONNOR, 1982). A adsorção do boro nos minerais de argila, nos óxidos e hidróxidos de ferro e de alumínio, e na matéria orgânica serão descritos a seguir com um pouco mais de detalhe, devido à importância que esses compostos têm no complexo coloidal dos solos tropicais.

\subsubsection{Adsorção de boro em minerais de argila}

O boro pode ser adsorvido por diversos minerais de argila, os quais apresentam diferentes capacidades de adsorção do elemento. Alguns autores citam que a ilita é o mais reativo dos minerais de argila, enquanto que a caulinita apresenta o mais baixo nível de adsorção de boro (HINGSTON, 1964; KEREN \& MEZUMAN, 1981). Entretanto, GOLDBERG \& GLAUBIG (1986b) obtiveram a seguinte ordem de reatividade: caulinita $>$ ilita $>$ montmorilonita. Resultados obtidos em estudos com ilita e montmorilonita sugerem que o boro é mais adsorvido nas bordas do que na superfície planar dos minerais de argila (EVANS $\&$ SPARKS, 1983).

- A adsorção de boro aumenta significativamente com o aumento da superfície exposta das partículas do mineral de argila (KEREN \& TALPAZ, 1984). Esse efeito marcante foi observado após quebra das lâminas de montmorilonita com vibrador ultrassônico, atribuindo-se o aumento da adsorção à maior área exposta pela borda do cristal, já que a superfície planar permaneceu constante. 


\subsubsection{Adsorção de boro em óxidos e hidróxidos de $\mathrm{Fe}$ e de $\mathrm{Al}$}

- Os óxidos e hidróxidos de ferro e de alumínio adsorvem grandes quantidades de boro (HATCHER et al., 1967; KEREN \& GAST, 1983; McPHAIl et al., 1972; GOLDBERG \& GLAUBIG, 1985, 1988). BINGHAM et al. (1971) encontraram correlação positiva entre o teor de $\mathrm{Al}_{2} \mathrm{O}_{3}$ e a adsorção de boro em quatro solos do México e seis solos do Havaí. Quanto menor o grau de cristalinidade do óxido, ou seja, quanto maior o teor de óxidos mal cristalizados (extraídos com oxalato de amônio), maior a capacidade de adsorção de boro (SIMS \& BINGHAM, 1968a; GOLDBERG \& GLAUBIG, 1985).

SIMS \& BINGHAM (1968a) e Mc PHAIL et al. (1972) sugeriram que a adsorção do boro é específica, ocorrendo por troca de ligantes, mecanismo pelo qual o composto de boro desloca uma hidroxila da superfície do hidróxido e forma compostos covalentes (Figura 1). Esse mecanismo ocorre tanto na superfície dos óxidos e hidróxidos, como nas arestas quebradas de minerais de argila (CAMARGO, 1991). A adsorção específica do boro, que ocorre independentemente do sinal da carga líquida da superfície dos hidróxidos, ocorre principalmente com as espécies $\mathrm{B}(\mathrm{OH})_{3}$ e $\mathrm{B}(\mathrm{OH})_{4}{ }^{-}$(KEREN \& BINGHAM, 1985).

- O hidróxido de alumínio retém maiores quantidades de boro do que o de ferro (SIMS \& BINGHAM, 1968a), devido à maior ocorrência de hidroxilas, comparado com o hidróxido de ferro, que se apresenta como óxido parcialmente hidratado $(\mathrm{FeOOH})$ ou como óxido hidratado $\left(\mathrm{Fe}_{2} \mathrm{O}_{3} \cdot \mathrm{nH}_{2} \mathrm{O}\right)$ (DANTAS, 1991).

Os materiais Al-hidróxi são os constituintes sólidos do solo que mais retêm boro (HATCHER et al., 1967). Por meio de dados de espectro infravermelho, verificou-se que o boro adsorvido retarda o crescimento de cristais de $\mathrm{Al}(\mathrm{OH})_{3}$, por do bloqueio de sítios de polimerização (BEYROUTY et al., 1984). 

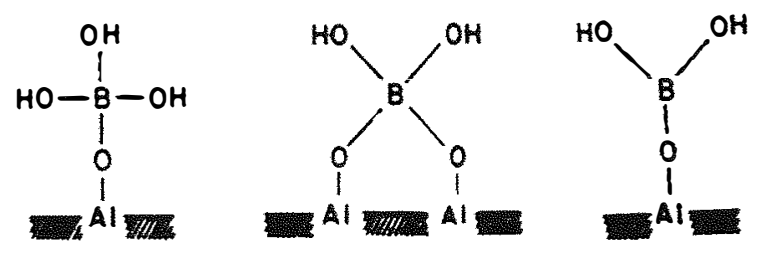

Figura 1. Algumas configurações do complexo boro com a superfície dos óxidos e hidróxidos de $\mathrm{Al}$, ou arestas de minerais de argila (KEREN \& BINGHAM, 1985).

$\mathrm{O}$ Fe e o $\mathrm{Al}$ presentes nas entrecamadas como recobrimento ou até como impureza aumentam bastante a quantidade de boro adsorvido em minerais de argila (SIMS \& BINGHAM, 1968b; GUPTA et al., 1985). Três mecanismos são considerados para explicar o fenômeno (EVANS \& SPARKS, 1983):

- ligação do $\mathrm{H}$ do $\mathrm{B}(\mathrm{OH})_{3}$ nas entrecamadas ricas em oxigênio na superficie planar da argila;

- ligação iônica do íon borato com materiais adsorvidos nas entrecamadas (por exemplo, hidróxido de alumínio);

- reação do íon borato com materiais que estão nas entrecamadas e que se movem para sítios externos ou para a solução.

\subsubsection{Adsorção de boro na matéria orgânica}

Os constituintes orgânicos do solo desempenham importante papel na adsorção de boro. O boro disponível encontra-se associado, principalmente, à matéria orgânica, o que explica seus teores mais altos nos horizontes superficiais (BERGER \& TRUOG, 1940; EVANS \& SPARKS, 1983). Há diversos trabalhos que mostram estreita correlação entre teores de boro solúvel em água quente e o 
teor de matéria orgânica dos solos (BRASIL SOBRINHO, 1965; GUPTA, 1968; HOROWITZ \& DANTAS, 1973; RUY, 1986).

O boro pode ligar-se a diversos compostos, como xilose, manose, glucose e galactose, que são formados à medida que ocorre decomposição da matéria orgânica (PARKS \& WHITE, 1952). Os autores postularam que a matéria orgânica concorre para a fixação do boro pela formação de complexos boratodiol, como mostra a seguinte reação:

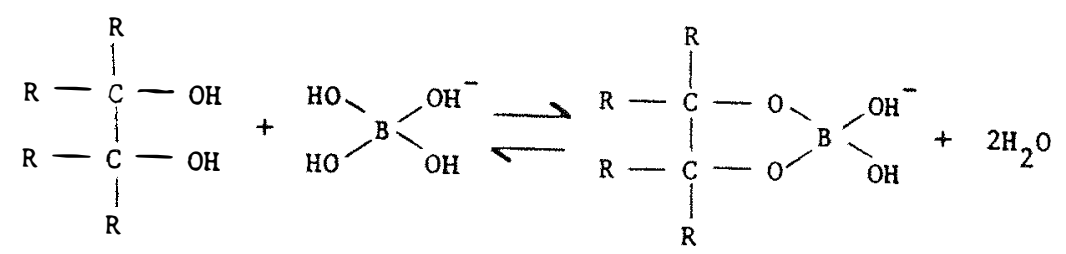

4. Estudo realizado há quase cinqüenta anos mostrou que a destruição da matéria orgânica por oxidação levou a uma significativa liberação de boro numa forma disponível às plantas e causou um decréscimo na fixação de boro (OLSON \& BERGER, 1946). Resultado semelhante foi obtido por MEZUMAN \& KEREN (1981). Entretanto, em outro experimento, houve aumento na adsorção de boro após a remoção da matéria orgânica, sendo atribuído ao incremento na superfície exposta de óxidos de $\mathrm{Fe}$ e de $\mathrm{Al}$ mal cristalizados, que teriam seus sítios de adsorção oclusos pelo recobrimento da matéria orgânica (MARZADORI et al., 1991).

Nos experimentos de OLSON \& BERGER (1946) e MEZUMAN \& KEREN (1981) foi usada água oxigenada, que não é considerada suficiente para remover totalmente a matéria orgânica. Procurando resolver esse problema, MARZADORI et al. (1991) utilizaram $\mathrm{NaClO}$, afirmando que a eliminação da 
matéria orgânica foi mais eficiente.

A matéria orgânica retarda ou até impede um possível comportamento histerético do boro nos solos, ou seja, uma dessorção mais lenta do boro, com base em simples processos de troca iônica (YERMIYAHU et al., 1988). Assim sendó, ela desempenharia um papel positivo na liberação de boro pelas superficies do solo, por permitir que haja reversibilidade no processo de adsorção do elemento (MARZADORI et al., 1991).

\subsubsection{Efeito do $\mathrm{pH}$ na adsorção de boro}

A adsorção de boro é altamente influenciada pelo $\mathrm{pH}$, aumentando à medida que o $\mathrm{pH}$ aumenta, atingindo um máximo na faixa alcalina e decrescendo abruptamente a partir daí (BINGHAM et al., 1971; KEREN et al., 1983; KEREN \& GAST, 1983; GOLDBERG \& GLAUBIG, 1986b; BARROW, 1989).

Os picos de adsorção para os óxidos ocorrem na faixa de $\mathrm{pH}$ entre 7 e 9 (GOLDBERG \& GLAUBIG, 1985). Para os minerais de argila, a faixa está entre 8 e 10 (GOLDBERG \& GLAUBIG, 1986b). A adsorção de boro em função do $\mathrm{pH}$ para dois solos alofânicos do México (BINGHAM et al., 1971), dois latossolos brasileiros (RIBEIRO \& BRAGA, 1974), quatro solos de Israel (MEZUMAN \& KEREN, 1981), quinze solos de regiões áridas (GOLDBERG \& GLAUBIG, 1986a) e para constituintes da matéria orgânica (EVANS, 1987; GU \& LOWE, 1990) foram similares às adsorções em óxidos e em minerais de argila, apresentando um máximo próximo do $\mathrm{pH} 9$.

O ácido bórico é a espécie que predomina em pHs abaixo de 7, e sua adsorção é baixa, devido à baixa afinidade que ele tem com os minerais de argila (EVANS \& SPARKS, 1983). Na faixa de reação ácida, a concentração da espécie $\mathrm{B}(\mathrm{OH})_{4}^{-}$é pequena, e assim sua contribuição na quantidade total de boro adsorvido é baixa, embora sua afinidade com a argila seja alta. À medida que o 
pH aumenta, a concentração de $\mathrm{B}(\mathrm{OH})_{4}{ }^{-}$também aumenta e, aproximadamente, ao pH 9 atinge a máxima adsorção, pois a quantidade de $(\mathrm{OH})^{-}$ainda é baixa a ponto de competir com o borato (HINGSTON, 1964).

Acréscimos adicionais do $\mathrm{pH}$ resultarão num aumento da concentração de hidroxila, em relação ao $\mathrm{B}(\mathrm{OH}) 4^{-}$, e a quantidade de boro adsorvido decresce rapidamente, devido à competição com o $(\mathrm{OH})^{-}$por sítios de adsorção (KEREN \& BINGHAM, 1985). O valor de $\mathrm{pH}$ no qual irá ocorrer máxima adsorção de $\mathrm{B}$ dependerá dos coeficientes de afinidade entre as espécies $\mathrm{B}(\mathrm{OH})_{3}, \mathrm{~B}(\mathrm{OH})_{4}^{-}$e $(\mathrm{OH})^{-}$e os sítios de adsorção da superfície de minerais de argila, óxidos, matéria orgânica etc. (KEREN \& GAST, 1983).

Segundo SCHALSCHA et al. (1973), uma possível explicação para a adsorção de boro ser dependente de $\mathrm{pH}$ é que o próton dissociado do ácido bórico reage com o grupo hidroxila da superfície para formar água, deixando um sítio carregado positivamente. $\mathrm{O}$ desenvolvimento máximo de sítios ocorre a um $\mathrm{pH}$ equivalente ao $\mathrm{pK}_{1}$ do ácido bórico (aproximadamente 9,1).

\subsubsection{Efeito da calagem na adsorção de boro}

A prática agrícola mais utilizada para se elevar o $\mathrm{pH}$ dos solos é a calagem. Em vista do que foi comentado até o momento, é de se esperar que após aplicação de calcário haja aumento na adsorção do boro por solos, principalmente aqueles com altos teores de óxidos de ferro e de alumínio.

Há muito tempo se tem registro do efeito da calagem no aumento da adsorção de boro pelo solo. Carbonatos de cálcio e de magnésio foram adicionados a solos com diferentes pHs e teores de C orgânico, observando-se aumento na porcentagem de $\mathrm{B}$ adsorvido pelos solos à medida que aumentava a dose de calcário (MIDGLEY \& DUNKLEE, 1939). Notou-se efeito do calcário na adsorção de boro num solo de textura média, onde o produto ocasionou um 
aumento no pH de 4,8 para 6,4 (BISHOP \& COOK, 1958). Os autores cogitaram uma possível formação de metaboratos insolúveis de cálcio e concluíram que, mesmo misturado ao adubo de fórmula 10-10-10, o calcário promoveu diminuição no teor de boro solúvel no solo. Um fato interessante observado nesse trabalho foi que o gesso agrícola $\left(\mathrm{CaSO}_{4} \cdot 2 \mathrm{H}_{2} \mathrm{O}\right)$ não influiu na adsorção de boro pelo solo. HATCHER et al. (1967) mostraram que a adsorção de boro aumentou de duas a cinco vezes após aplicação de calcário em diversos solos ácidos americanos, acompanhando um aumento de $\mathrm{pH}$. Quanto menor o teor de boro no solo, mais significativo é o efeito da calagem no aumento da adsorção do elemento (GUPTA \& MacLEOD, 1977).

No Brasil, aumentos no pH de 4,2 a 5,6, causados pela aplicação de doses crescentes de calcário num latossolo vermelho-escuro de textura média causaram aumento significativo na quantidade de boro adsorvido (CRUZ et al., 1987).

- Quando os solos recebem calcário, as diversas formas de alumínio trocável são substituídas pelo cálcio e magnésio, e precipitam-se na forma de $\mathrm{Al}(\mathrm{OH})_{3}$, como mostra a equação 1 :

$2 \mathrm{AlX}_{3}+3 \mathrm{CaCO}_{3}+3 \mathrm{H}_{2} \mathrm{O} \rightarrow 3 \mathrm{CaX}_{2}+2 \mathrm{Al}(\mathrm{OH})_{3}+3 \mathrm{CO}_{2}$

em que $\mathbf{X}$ representa o sítio de troca; segundo HATCHER et al. (1967), esse precipitado pode adsorver boro. Os autores consideraram que, enquanto o aumento do $\mathrm{pH}$ aumenta a adsorção de boro, o efeito dominante é o decréscimo em sua concentração na solução do solo, devido à adsorção do elemento no $\mathrm{Al}(\mathrm{OH})_{3}$ recém-precipitado.

A adsorção de boro no hidróxido de alumínio é alta logo após a aplicação de calcário devido à recém-precipitação do $\mathrm{Al}(\mathrm{OH})_{3}$ (EVANS \& SPARKS, 1983; BEYROUTH et al., 1984). Passado algum tempo, a adsorção do 
boro nesse composto toma-se menos intensa. A afinidade das espécies de boro pelos íons $\mathrm{OH}^{-}$é muito maior nos materiais Al-hidróxi do que nos minerais de argila, provavelmente devido à presença de grupos de sílica nas bordas dos minerais (KEREN \& BINGHAM, 1985).

Com o objetivo de estudar o efeito do $\mathrm{CaCO}_{3}$ com mais detalhe, GOLDBERG \& FORSTER (1991) avaliaram a adsorção de boro em dois solos cálcicos, em um solo não-cálcico e em dois minerais de calcita $\mathrm{A}$ adsorção do elemento na calcita exibiu um comportamento similar àquele observado nos solos, enquanto que a adsorção máxima decresceu aproximadamente $10 \%$ depois da remoção do mineral do solo.

\subsubsection{Energia livre}

De posse dos resultados obtidos em curvas de adsorção, pode-se calcular a energia livre molar do sistema. As mudanças na energia livre que ocorrem quando um elemento é adsorvido podem servir como uma medida da extensão ou da força que guia determinada reação (SINGH, 1971). A equação termodinâmica usada por SINGH (1971) foi:

$$
\Delta \mathrm{G}_{\mathrm{o}}=\mathrm{R} \mathrm{T}(\ln \text { Boro equilíbrio - } \ln \text { Boro adicionado) }
$$

em que $\Delta \mathrm{G}_{0}=$ energia livre $(\mathrm{mol} / \mathrm{L}), \mathrm{R}=8,30 \mathrm{Joule} / \mathrm{mol} .{ }^{\circ} \mathrm{K}$ e $\mathrm{T}=25^{\circ} \mathrm{C}=298^{\circ} \mathrm{K}$.

\subsection{Isotermas de adsorção}

As isotermas de adsorção são equações matemáticas usadas para descrever convenientemente a adsorção de solutos por sólidos em termos 
quantitativos, a temperaturas constantes. "Uma isoterma de adsorção mostra a quantidade de adsorvato (soluto) adsorvida por um adsorvente, em função da concentração de equilíbrio do adsorvato. A técnica usada para gerar os dados de adsorção é, a princípio, bastante simples, pois uma quantidade conhecida de adsorvato é adicionada ao sistema contendo uma quantidade conhecida de adsorvente. Admite-se que a diferença entre a quantidade adicionada e a remanescente na solução encontra-se adsorvida na superfície adsorvente (BOHN et al., 1979).

Duas equações de adsorção são comumente utilizadas para descrever a adsorção de ânions nos solos: a de Langmuir e a de Freundlich, que serão descritas, a seguir.

\subsubsection{Equação de Langmuir}

A equação de Langmuir foi inicialmente utilizada para descrever a adsorção de gases por sólidos. Ela baseia-se em três suposições:

- a superfície de adsorção é homogênea, isto é, a adsorção é constante e independente da extensão da cobertura da superfície;

- a adsorção ocorre em sítios específicos, sem interação com as moléculas do adsorvato;

- a adsorção torna-se máxima quando uma camada monomolecular cobre totalmente a superficie do adsorvente.

A forma mais comum da equação de Langmuir é:

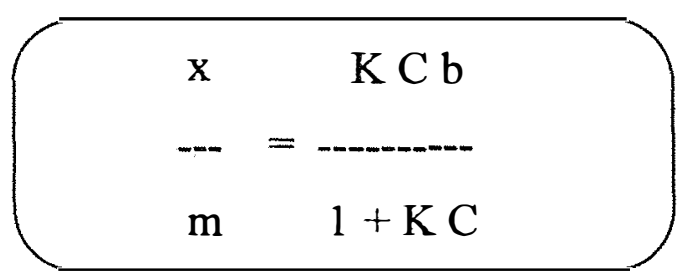


em que $\mathbf{C}$ é a concentração de equilíbrio do adsorvato, $\mathbf{x} / \mathbf{m}$ é a massa de adsorvato por unidade de massa do adsorvente, $\mathbf{K}$ é a constante relacionada à energia de ligação adsorvato-adsorvente, e b é a quantidade máxima de adsorvato que pode ser adsorvida, isto é, após a formação de uma camada monomolecular completa.

A equação 3 é freqüentemente rearranjada para a forma linear (equação 4), a fim de se verificar se os dados se ajustam ao modelo de Langmuir.

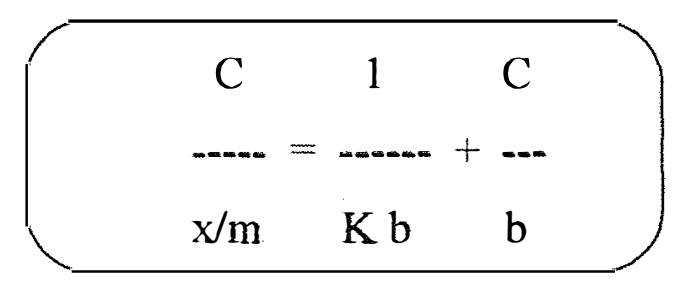

Se os resultados de adsorção seguirem o modelo de Langmuir, um gráfico de $C / \mathbf{x} / \mathbf{m}$ versus $C$ produz uma reta com uma inclinação igual a 1/b e intercepto $\mathbf{1 / K b}$. A constante de Langmuir é obtida dividindo-se a inclinação (1/b) pelo intercepto $(\mathbf{1} / \mathbf{K b})$.

LAVERDIÈRE \& KARAM (1984) sugerem o termo "capacidade tampão máxima" (CTM), definido como o produto das constantes de Langmuir $\mathbf{K}$ e b, para exprimir o aumento na quantidade adsorvida do elemento por unidade de aumento em sua concentração na solução em equilíbrio. Solos com altos valores de CTM apresentam alta capacidade de adsorção de determinado elemento, tornando-o, assim, pouco disponivel para as plantas.

Quando se relaciona a adsorção máxima de um elemento com relações entre os atributos do solo, tais como carbono/argila, Fe/argila e Al/argila, são obtidos melhores resultados do que quando se utilizam os atributos isoladamente (SHARPLEY, 1983). De acordo com este autor, a relação carbono/argila fornece um índice bastante confiável da superficie "ativa" de um 
solo, tanto que a adsorção e a dessorção de fósforo estavam correlacionadas positivamente com esta relação, enquanto que, tanto para carbono, como para teor de argila, individualmente, as correlações não foram estatisticamente significativas.

Embora a equação 4 tenha sido derivada supondo-se uma energia de adsorção constante, essa situação raramente ocorre na natureza, já que a energia de adsorção tende a decrescer com o aumento da superfície coberta pelo adsorvato (HARTER \& BAKER, 1977). Entretanto, como a interação com moléculas já adsorvidas tende a aumentar à medida que a superfície coberta aumenta (BOHN et al., 1979), o efeito resultante é que estes dois fenômenos tendem a se compensar, produzindo uma energia de ligação relativamente constante.

Apesar de o ajuste dos resultados experimentais de adsorção à equação de Langmuir não dar informações sobre o mecanismo químico da reação (SPOSITO, 1982), e o uso dessas equações constituir um procedimento de ajuste de curva, em que os parâmetros obtidos apenas são válidos para as condições nas quais o experimento foi desenvolvido (CASAGRANDE, 1993), ela tem sido utilizada por muitos pesquisadores para estimar a capacidade de adsorção de vários adsorvatos, principalmente dos menos estudados, como o boro.

\subsubsection{Equação de Freundlich}

Outra equação utilizada para descrever fenômenos de adsorção é a de Freundlich. Esse autor afirma que os dados de adsorção para soluções muito diluídas podem ser assim representados:

$$
\mathrm{x} / \mathrm{m}=\mathrm{K} \mathrm{C}^{\mathrm{b}}
$$


em que $\mathbf{K}$ e b são constantes empíricas, e os outros termos são os mesmos da equação de Langmuir. A equação de Freundlich foi desenvolvida empiricamente, sem um fundamento teórico (BOHN et al., 1979). Entretanto, sugere que a energia de adsorção decresce logaritmicamente, à medida que a superfície vai se tornando coberta pelo adsorvato, o que a diferencia da equação de Langmuir. $\mathrm{O}$ modelo de Freundlich pode ser derivado teoricamente ao se considerar que o decréscimo na energia de adsorção com o aumento da superfície coberta pelo adsorvato é devido à heterogeneidade da superfície (BOHN et al., 1979). Como o grau de heterogeneidade é desconhecido para muitos casos, tanto a equação de Freundlich como a de Langmuir são mais bem tratadas como descrições empíricas do processo real de adsorção (VEITH \& SPOSITO, 1977).

A forma linear da equação de Freundlich é:

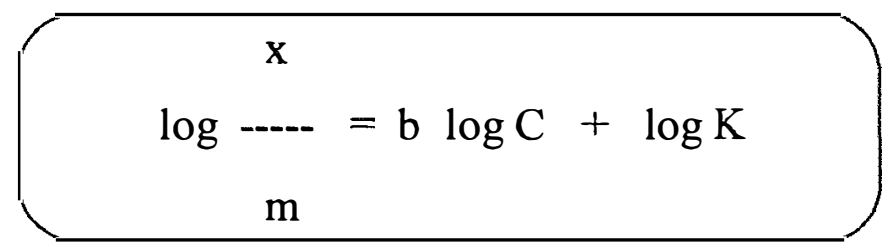

A equação de Freundlich tem a limitação de não prever a adsorção máxima do adsorvato, mas geralmente apresenta bom ajuste dos dados de adsorção devido à pouca sensibilidade dos gráficos log-log e pela grande flexibilidade ao ajuste das constantes $\mathbf{K}$ e b (BOHN et al., 1979). Estas constantes, apesar de empíricas, correlacionam-se, respectivamente, com a capacidade e com a intensidade de adsorção do adsorvato (BLADEL \& MOREALE, 1977).

Diversos autores têm utilizado as isotermas de Langmuir e de Freundlich para descrever a adsorção de boro em minerais e em solos. HINGSTON (1964) descreveu a adsorção do elemento usando a isoterma de Langmuir. As equações de Langmuir e a de Freundlich adequaram-se à adsorção 
de boro em caulinita e em montmorilonita, sendo melhor o ajuste do modelo de Freundlich (SINGH, 1971).

Uma limitação da isoterma de Langmuir é a impossibilidade de descrever o comportamento da adsorção em altas concentrações de boro e em condições variáveis de pH (KEREN \& MEZUMAN, 1981; EVANS \& SPARKS, 1983; GOLDBERG \& GLAUBIG, 1986b). Entretanto, HINGSTON (1964) encontrou desvios entre os valores obtidos em laboratório e os estimados pelo modelo, tanto em baixas, como em altas concentrações de boro. Um dos motivos desses desvios parece ser a presença de multisítios de adsorção do elemento (HATCHER \& BOWER, 1958; GRIFFIN \& BURAU, 1974).

CATANI et al. (1971), ELRASHIDI \& O'CONNOR (1982) e NICHOLAICHUK et al. (1988) obtiveram melhores ajustes dos dados de adsorção utilizando o modelo de Freundlich, principalmente pelo fato de terem adicionado quantidades bastante elevadas de boro $(100 \mu \mathrm{g} / \mathrm{mL})$, bem superiores às normalmente encontradas em solos. 


\section{MATERIAL E MÉTODOS}

\subsection{Solos}

Foram retiradas amostras superficiais $(0-0,20 \mathrm{~m})$ e subsuperficiais (na profundidade de maior expressão do horizonte B) de cinco solos representativos do Estado de São Paulo, geográfica e economicamente (Tabela 1). Nos latossolos, a profundidade de amostragem do horizonte $\mathrm{B}$ foi de 0,60 a 0,80m, e no podzólico vermelho-amarelo, de 0,80 a 1,00m. É importante que o horizonte subsuperficial tenha sido avaliado, pois uma parte representativa das raízes de determinadas culturas, como as perenes e semi-perenes, explora intensamente o horizonte $\mathrm{B}$, principalmente em períodos de estiagem prolongada. Além disso, é comum um teor mais baixo de boro na camada subsuperficial, onde os mecanismos de adsorção tomam-se importantes, devido aos teores baixos comumente encontrados na solução do solo $(0,5 \mu \mathrm{g} / \mathrm{mL}$ ou menos) (PARKER \& GARDNER, 1982).

\subsection{Caracterização química, física e mineralógica}

A caracterização química, física e mineralógica das amostras seguiu a metodologia descrita por CAMARGO et al. (1986). 
Tabela 1. Solos utilizados no presente estudo e locais de amostragem.

\begin{tabular}{lc}
\hline \multicolumn{1}{c}{ Solos } & Local \\
\hline Podzólico vermelho-amarelo eutrófico text. arenosa/média (PV are/md) & Pindorama \\
Latossolo vermelho-amarelo álico textura média (LV md) & Mogi-Guaçu \\
Latossolo vermelho-escuro álico textura média (LE arg) & Conchal \\
Latossolo vermelho-escuro álico textura muito argilosa (LE md) & Limeira \\
Latossolo roxo distrófico textura muito argilosa (LR arg) & Ribeirão Preto \\
\hline
\end{tabular}

\subsubsection{Análises químicas}

a) Carbono orgânico: obtido pela oxidação da matéria orgânica do solo com solução de dicromato de potássio, em presença de ácido sulfúrico, e titulação do excesso de dicromato com sulfato ferroso amoniacal.

b) Cátions trocáveis ( $\mathrm{Ca}, \mathrm{Mg}, \mathrm{K}$ e $\mathrm{Na}$ ): extração dos elementos trocáveis com solução normal de acetato de amônio pH 7,0, e determinação de seus teores no extrato.

c) $\mathrm{pH} \mathrm{em} \mathrm{CaCl}_{2}$ 0,01mol/L: relação terra-solução $1: 2,5$ e obtenção dos valores através da medida da variação do potencial em um eletrodo de vidro com a variação da atividade hidrogeniônica da solução em que ele está mergulhado, usando um eletrodo de referência.

d) Teores totais de óxidos $\left(\mathrm{SiO}_{2}, \mathrm{~F}_{2} \mathrm{O}_{3}, \mathrm{Al}_{2} \mathrm{O}_{3}\right.$ e $\left.\mathrm{TiO}_{2}\right)$ : obtidos após ataque sulfúrico.

e) Ferro e aluminio livres: em meio tamponado (bicarbonato $\mathrm{pH}$ 7,3), ferro e alumínio foram extraídos pelo ditionito de sódio e complexados pelo citrato de sódio, permanecendo em solução. 
f) Ferro e aluminio mal cristalizados: obtidos pela solubilização dos compostos mal cristalizados em ácido oxálico e seu sal de amônio.

\subsubsection{Determinação do boro solúvel em $\mathrm{CaCl}_{2} 0,01 \mathrm{~mol} / \mathrm{L}$ a quente}

Para a determinação do boro solúvel em solução de $\mathrm{CaCl}_{2}$ a quente, foi seguido o método descrito por BINGHAM (1982): 40mL de uma solução de $\mathrm{CaCl}_{2} 0,01 \mathrm{~mol} / \mathrm{L}$ e uma pitada de carvão ativado foram adicionados a $20 \mathrm{~g}$ de terra e colocados em refluxo, fervendo-se, em seguida, por exatamente cinco minutos. Após o resfriamento, filtrou-se a suspensão com funil de plástico e papel Whatman $\mathrm{n}^{\circ} 41$. Uma alíquota de $4 \mathrm{~mL}$ do extrato foi pipetada para tubo de leitura em espectrofotômetro, ajustado para 430nm de comprimento de onda, após adição de $1 \mathrm{~mL}$ de solução tampão (composta por acetato de amônio, EDTA e ácido acético glacial) e $1 \mathrm{~mL}$ de solução de azometina - H (0,9g de Azometina-H em $100 \mathrm{~mL}$ de água deionizada $+2 \mathrm{~g}$ de ácido ascórbico). Para cada conjunto de determinações de boro no solo, foi conduzido um ensaio em branco.

\subsubsection{Análises físicas}

a) Análise granulométrica: pelo método da pipeta.

b) Superficie especifica: empregou-se o método utilizado por CIHACEK \& BREMMER (1979), baseado na técnica de retenção de éter monoetílico do etileno glicol (EMEG), proposto por HEILMAN et al. (1965). Em lugar do pré-tratamento das amostras com pentóxido de fósforo $\left(\mathrm{P}_{2} \mathrm{O}_{5}\right)$, para retirada da água, foi feita secagem das amostras em estufa por $24 \mathrm{~h}$ a $110^{\circ} \mathrm{C}$, conforme RATNER-ZOMAR et al. (1983). 


\subsubsection{Análise mineralógica qualitativa}

Amostras de argila previamente ratadas, para eliminação da matéria orgânica e dos óxidos de ferro, foram analisadas com auxílio da difração de raios $\mathrm{X}$ no estado natural e após saturação com $\mathrm{Mg}^{2+}$, glicoladas, e saturadas com $\mathrm{K}^{+} \mathrm{e}$ submetidas às temperaturas de 25,350 e $550^{\circ} \mathrm{C}$.

\subsection{Adsorção de boro}

Antes de se procederem as determinações de boro adsorvido, uma amostra da camada superficial de cada solo recebeu uma quantidade de $\mathrm{CaCO}_{3}$, que, teoricamente, seria necessária para elevar a porcentagem de saturação por bases a $70 \%$, com objetivo de testar o efeito da calagem na adsorção do elemento. As amostras foram umedecidas e mantidas na "capacidade de campo" $(0,03 \mathrm{MPa})$ por um mês. Em seguida, foram secas ao ar e novamente passadas em peneira de $2 \mathrm{~mm}$ de malha. As quantidades de $\mathrm{CaCO}_{3}$ aplicadas, em gramas por $\mathrm{kg}$ de terra, para o PV, o LEmd, o LRarg, o LVmd e o LEarg foram, respectivamente: 0,11, $0,51,2,29,3,06$ e 4,31 .

No estudo de adsorção, utilizou-se o método preconizado por OSAZAKI \& CHAO (1968), com a modificação de que estes autores utilizaram concentrações de boro na faixa de 0 a $100 \mu \mathrm{g} / \mathrm{mL}$, sendo que aqui foi utilizada a faixa de 0 a $16 \mu \mathrm{g} / \mathrm{mL}$. Essa faixa foi também utilizada por CORREA et al. (1985) em latossolos do Paraná e parece ser mais adequada para representar os teores do elemento em solução de solos brasileiros.

Para determinação da quantidade de boro adsorvido, o equivalente a $4,000 \mathrm{~g}$ de terra fina seca em estufa foi mantido em agitação lenta, em tubos de

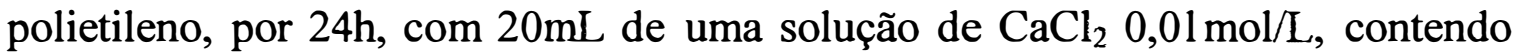


diferentes quantidades de boro $(0 ; 1 ; 2 ; 4 ; 8$ e $16 \mu \mathrm{g} / \mathrm{mL})$, usando-se ácido bórico como fonte. Soluções diluídas de cálcio são largamente utilizadas em estudos de adsorção, apesar de a solução de $\mathrm{CaCl}_{2}$,, $01 \mathrm{~mol} / \mathrm{L}$ ser constantemente mais concentrada do que a solução do solo. A agitação lenta é importante para o estudo das reações de adsorção, porque se evita abrasão intensa das partículas do solo, sendo então recomendado usualmente o agitador vertical, com poucas revoluções por minuto (BARROW, 1987).

A suspensão foi depois centrifugada por quinze minutos a 2000rpm (SHUMWAY \& JONES, 1972), filtrada, e uma alíquota de $10 \mathrm{~mL}$ do sobrenadante foi removida, sendo o boro posteriormente determinado por indução de plasma, na Seção de Fertilidade do Solo e Nutrição de Plantas, do Instituto Agronômico de Campinas. Esse método vem sendo utilizado com sucesso nos estudos em que se determinam o boro (GU \& LOWE, 1990) e apresenta algumas vantagens em relação à determinação colorimétrica com azometina- $\mathrm{H}$, tais como análise simples e rápida, supressão do uso do carvão ativado, pois não é exigida uma solução límpida, confecção de curva padrão com intervalos maiores (no presente estudo, não foi necessária diluição das amostras, mesmo nas concentrações próximas a $16 \mu \mathrm{g} / \mathrm{mL}$ ), impressão direta dos resultados em computador, tornando mais rápido o serviço de análise e interpretação dos resultados, e maior precisão, à medida que o aparelho realiza cinco medidas do extrato e imprime no relatório de saída a média das cinco leituras, incluindo o desvio-padrão (GESTRING \& SOLTANPOUR, 1981).

As análises foram feitas em duplicata. $\mathrm{O}$ teor de boro adsorvido no solo foi obtido subtraindo-se o boro em equilíbrio na solução, após a centrifugação e filtração, do boro adicionado nas diversas concentrações. Embora pequena, a quantidade de boro originalmente presente nas amostras foi também descontada, para efeito de cálculos do valor de boro adsorvido. Para a 
determinação do boro adsorvido nas amostras que receberam as soluções de boro menos concentradas $(0 ; 1$ e $2 \mu \mathrm{g} / \mathrm{mL})$, foi construída uma curva padrão obtida a partir das seguintes soluções: $0 ; 0,2 ; 0,4 ; 0,8 ; 1,0$ e $2,0 \mu \mathrm{g} / \mathrm{mL}$ de boro. Para as demais concentrações ( $4 ; 8$ e $16 \mu \mathrm{g} / \mathrm{mL}$ ), a curvão padrão foi obtida a partir de soluções com $0 ; 1 ; 2 ; 4 ; 8$ e $16 \mu \mathrm{g} / \mathrm{mL}$ de boro.

\subsection{Análises estatísticas}

Com os resultados obtidos na caracterização das amostras de terra, foram feitas correlações e análises de regressão múltipla, para se determinarem quais os atributos que mais se correlacionaram com o teor de $\mathrm{B}$ solúvel em $\mathrm{CaCl}_{2}$ a quente dos solos. Para obtenção dos coeficientes de correlação simples, foi utilizado o programa "Ajuste" (ZULLO JÚNIOR \& ARRUDA, 1986), e para a análise de regressão múltipla foi utilizado o programa SAS - Statistical Analysis System.

Para estudo da adequação dos modelos de Langmuir e de Freundlich, foi usado o programa "Fitfun.bas" (BARROW, 1987), que ajusta equações não lineares aos dados de adsorção, seguindo a metodologia dos "desvios mínimos" (MEAD, 1981; SHANI et al., 1992).

De maneira análoga ao estudo com os teores de boro solúvel em $\mathrm{CaCl}_{2}$ a quente, diversas correlações foram obtidas entre o boro adsorvido e os atributos químicos e físicos dos solos, além das constantes de Langmuir e de Freundlich. Para as correlações simples, optou-se pela quantidade de boro adsorvido após adição de $2 \mu \mathrm{g} / \mathrm{mL}$ de boro, seguindo metodologia proposta por HARADA \& TAMAI (1968) e MANDAL et al. (1993). 


\section{RESULTADOS}

\subsection{Análises químicas}

\subsubsection{Análises químicas de rotina}

De maneira geral, observou-se uma grande heterogeneidade na fertilidade dos solos (Tabela 2). Considerando-se a condição natural dos solos, ou seja, antes da aplicação do carbonato de cálcio, são feitas algumas considerações, segundo critérios propostos por RAJJ et al. (1985):

- o podzólico vermelho-amarelo (PV) é o solo mais fértil, visto que a saturação por bases, tanto em superficie como em subsuperficie, é média (62\%); a acidez é média nas duas camadas; o teor de magnésio é alto em superfície e médio em subsuperficie; e o teor de potássio é médio nas duas profundidades;

- o latossolo vermelho-escuro textura média (LEmd) vem a seguir com $\mathrm{V} \%=50$ que, apesar de baixa, confere ao solo um bom potencial em superfície, mas com uma saturação por bases muito baixa em subsuperfície (14\%). Essa característica reflete-se também no $\mathrm{pH}$, pois a acidez é alta em superficie e muito alta em subsuperficie; o teor de magnésio é alto no horizonte $\mathrm{A}$ e baixo no $\mathrm{B}$; o teor de $\mathrm{K}$ cai drasticamente em profundidade (alto $\mathrm{x}$ muito baixo). Vale ressaltar nesse solo o aumento expressivo na porcentagem de saturação por alumínio, que chegou a quase seis vezes mais no horizonte subsuperficial; 
Tabela 2. Resultados das análises químicas dos horizontes A e B dos solos estudados.

\begin{tabular}{|c|c|c|c|c|c|c|c|c|c|c|c|}
\hline \multirow[b]{2}{*}{ Amostra } & \multicolumn{4}{|c|}{$\mathrm{pH}$} & \multirow[b]{2}{*}{$\mathrm{Mg}$} & \multirow[b]{2}{*}{$\mathrm{K}$} & \multirow[b]{2}{*}{$\mathrm{Al}$} & \multirow[b]{2}{*}{$\mathrm{H}+\mathrm{Al}$} & \multirow[b]{2}{*}{$\mathrm{CTC}_{7}$} & \multirow[b]{2}{*}{$\mathrm{V}$} & \multirow[b]{2}{*}{$\mathrm{m}$} \\
\hline & Horizonte & $\mathrm{CaCl}_{2}$ & $\mathrm{C}$ & $\mathrm{Ca}$ & & & & & & & \\
\hline \multirow{4}{*}{ LR arg } & \multicolumn{3}{|c|}{$\mathrm{g} / \mathrm{dm}^{3}$} & \multicolumn{6}{|c|}{$\mathrm{mmol}_{\mathrm{c}(+)} / \mathrm{dm}^{3}$} & \multicolumn{2}{|c|}{--.- \% } \\
\hline & A & 4,4 & 9 & 9 & 7 & 4,8 & 8 & 88 & 108,8 & 19 & 28 \\
\hline & $A^{*}$ & 4,6 & 14 & 28 & 20 & 5,6 & 3 & 80 & 133,6 & 40 & 5 \\
\hline & B & 4,5 & 7 & 7 & 7 & 1,2 & 4 & 64 & 79,2 & 19 & 21 \\
\hline \multirow[t]{3}{*}{$\mathrm{PV}$ are/md } & A & 5,3 & 5 & 17 & 14 & 1,6 & 0 & 20 & 52,6 & 62 & 0 \\
\hline & $A^{*}$ & 5,2 & 5 & 19 & 14 & 1,4 & 0 & 15 & 49,4 & 70 & 0 \\
\hline & B & 4,7 & 4 & 33 & 8 & 2,9 & 0 & 34 & 77,9 & 56 & 4 \\
\hline \multirow[t]{3}{*}{ LVmd } & A & 3,2 & 10 & 22 & 16 & 0,5 & 25 & 121 & 159,5 & 24 & 38 \\
\hline & $A^{*}$ & 4,7 & 9 & 24 & 12 & 0,8 & 3 & 28 & 64,8 & 57 & 8 \\
\hline & $\mathrm{B}$ & 3,6 & 5 & 1 & 1 & 0,4 & 15 & 47 & 49,4 & 4 & 88 \\
\hline \multirow[t]{3}{*}{ LE arg } & A & 3,7 & 13 & 3 & 2 & 1,6 & 42 & 150 & 156,6 & 4 & 86 \\
\hline & $A^{*}$ & 4,7 & 12 & 38 & 26 & 0,6 & 3 & 64 & 128,6 & 50 & 4 \\
\hline & B & 3,5 & 9 & 4 & 4 & 0,6 & 14 & 109 & 117,6 & 8 & 61 \\
\hline \multirow[t]{3}{*}{ LE md } & $\mathrm{A}$ & 4,4 & 9 & 18 & 8 & 4,7 & 4 & 31 & 61,7 & 50 & 11 \\
\hline & $A^{*}$ & 4,8 & 9 & 55 & 33 & 4,4 & 1 & 28 & 120,4 & 77 & 1 \\
\hline & $\mathrm{B}$ & 3,5 & 5 & 7 & 4 & 0,6 & 22 & 72 & 83,6 & 14 & 63 \\
\hline
\end{tabular}

* horizonte A com calcário

- o latossolo roxo textura muito argilosa (LRarg) é o mais uniforme em termos de atributos químicos, pois nas duas camadas a porcentagem de saturação por bases é muito baixa, a acidez é alta, e o teor de magnésio é médio. 
O teor de potássio varia de alto em superfície para baixo em subsuperfície, e a $\mathrm{m} \%$ varia muito pouco. Trata-se, portanto, de um solo quimicamente pobre;

- os dois últimos solos (latossolo vermelho-amarelo textura média LVmd e latossolo vermelho-escuro textura muito argilosa - LEarg) podem ser descritos conjuntamente, pois apresentam atributos bastante semelhantes: a acidez é muito alta, a V\% é muito baixa, e a $\mathrm{m} \%$ aumenta bastante em subsuperfície. No LVmd, o teor de magnésio é alto no horizonte $\mathrm{A}$ e baixo no horizonte $\mathrm{B}$, enquanto que no LEarg ele é baixo nos dois horizontes. Ambos os solos possuem teor muito baixo de potássio em subsuperfície; já na camada superficial, o teor é muito baixo no LVmd e médio no LEarg.

Apesar de a recomendação de adubação em uso no Estado de São Paulo não contemplar a avaliação do teor de cálcio trocável do solo, uma vez que, pela prática regular de calagens, o elemento não deveria apresentar problemas de deficiência (RAIJ et al., 1985), torna-se interessante comentar a variação de seu teor nos solos, devido às diversas relações que existem entre o cálcio e o boro (PARKS \& SHAW, 1941; HARADA \& TAMAI, 1968; KEREN \& O'CONNOR, 1982; GÁRATE et al., 1984; GU \& LOWE, 1990), e que serão analisadas nos ítens seguintes. Além disso, pode-se considerar os limites de cálcio trocável propostos recentemente pelo Instituto Agronômico de Campinas (RAIJ, 1995), a fim de auxiliar a interpretação dos resultados.

$\mathrm{Na}$ camada superficial, todos os solos apresentam valores altos de cálcio ( $>7 \mathrm{mmol}_{\mathrm{d}} \mathrm{dm}^{3}$ ), com exceção do horizonte A do LEarg, onde o teor é baixo. No horizonte $\mathrm{B}$, os teores são médios ou baixos, exceto o $\mathrm{PV}$, que tem um teor alto do elemento. As maiores variações nos teores após a aplicação de carbonato de cálcio ocorreram no LEarg, no LRarg e no LEmd, com aumentos de 12,6 , 3,1 e 3,0 vezes, respectivamente. Nos solos de textura mais grosseira (LVmd e PV) os aumentos no teor de Ca trocável foram bem menores. 
Ainda como resposta à aplicação de $\mathrm{CaCO}_{3}$, o LVmd e o LEarg tiveram os aumentos mais pronunciados de $\mathrm{pH}$ mas, mesmo assim, a acidez continuou alta. Os teores de $\mathrm{C}$ orgânico permaneceram praticamente constantes, com exceção do LRarg, onde o aumento foi de mais de $50 \%$ (de 9 para $14 \mathrm{~g} / \mathrm{dm}^{3}$ ). A adição do carbonato proporcionou aumento nos teores de $\mathrm{Mg}$ de quase todos os solos, exceção feita ao LVmd, onde houve pequena queda no teor do elemento (de 16 para $12 \mathrm{mmol}_{d} / \mathrm{dm}^{3}$ ) e ao $\mathrm{PV}$, onde o teor não se alterou. Em relação ao potássio, houve diminuição no teor em três amostras (PV, LEarg e LEmd) e aumento nas outras duas (LRarg e LVmd). O maior efeito da calagem foi observado nos teores de alumínio, que caíram drasticamente nos solos onde ele se encontrava presente na forma trocável. Esse efeito marcante pode ser visto também na acentuada queda na porcentagem de saturação por alumínio nas camadas superficiais dos solos (Tabela 2).

\subsubsection{Análises químicas complementares}

Na tabela 3 encontram-se os teores totais de óxidos, ferro e alumínio livres $\left(\mathrm{Fe}_{\mathrm{d}}\right.$ e $\left.\mathrm{Al}_{\mathrm{d}}\right)$ e mal cristalizados $\left(\mathrm{Fe}_{\mathrm{o}}\right.$ e $\left.\mathrm{Al}_{0}\right)$, índices ki e kr, e teor de boro solúvel em $\mathrm{CaCl}_{2}$ 0,01 mol/L a quente (Bs). A classificação dos latossolos, de acordo com RESENDE \& SANTANA (1988), baseada nos valores de ki $\left(\mathrm{SiO}_{2} / \mathrm{Al}_{2} \mathrm{O}_{3}\right)$ e de $\mathrm{kr}\left(\mathrm{SiO}_{2} / \mathrm{Al}_{2} \mathrm{O}_{3}+\mathrm{Fe}_{2} \mathrm{O}_{3}\right)$, foi a seguinte:

LRarg: caulinítico sesquioxídico $(\mathrm{ki}>0,75$ e $\mathrm{kr}<0,75)$.

LVmd, LEarg e LEmd: caulinítico não sesquioxídico (ki > 0,75 e kr $>0,75)$.

Como os valores de ki estiveram próximos de 2, os solos foram classificados como cauliníticos. Em relação ao $\mathbf{k r}$, somente o LRarg foi considerado sesquioxídico, o que parece bem coerente, já que os teores de $\mathrm{Fe}$ total dos dois horizontes foram os maiores entre as amostras. 
Tabela 3. Teores de óxidos de ferro e alumínio totais, livres $\left(\mathrm{Fe}_{\mathrm{d}}\right.$ e $\left.\mathrm{Al} \mathrm{l}_{\mathrm{d}}\right)$ e mal cristalizados $\left(\mathrm{Fe}_{\mathrm{o}}\right.$ e $\mathrm{Al}_{\mathrm{o}}$ ), índices ki e $\mathrm{kr}$, e teor de boro solúvel em $\mathrm{CaCl}_{2} 0,01 \mathrm{~mol} / \mathrm{L}$ a quente (Bs) da terra fina seca ao ar dos horizontes A e B dos solos estudados.

\begin{tabular}{|c|c|c|c|c|c|c|c|c|c|c|c|c|}
\hline Amostra & Horiz. & $\mathrm{SiO}_{2}$ & $\mathrm{Fe}_{2} \mathrm{O}_{3}$ & $\mathrm{Al}_{2} \mathrm{O}_{3}$ & $\mathrm{TiO}_{2}$ & $\mathrm{Fe}_{\mathrm{d}}$ & $\mathrm{Al}_{d}$ & $\mathrm{Fe}_{0}$ & $\mathrm{Al}_{0}$ & ki & $\mathrm{kr}$ & Bs \\
\hline & & & & & $\mathrm{g} / \mathrm{kg}$ & & & & & & & $\mathrm{mg} / \mathrm{dm}$ \\
\hline \multirow[t]{2}{*}{ LR arg } & A & 110 & 326 & 189 & 139 & 208 & 36 & 3,4 & 0,7 & 1,0 & 0,5 & 0,38 \\
\hline & B & 110 & 341 & 189 & 142 & 208 & 29 & 4,5 & 0,7 & 1,0 & 0,5 & 0,28 \\
\hline \multirow[t]{2}{*}{$\mathrm{PV}$ are/md } & A & 29 & 23 & 29 & 15 & 10 & 5 & 0,7 & 0,2 & 1,7 & 1,1 & 0,07 \\
\hline & B & 121 & 47 & 114 & 27 & 27 & 6 & 1,0 & 0,3 & 1,8 & 1,4 & 0,37 \\
\hline \multirow[t]{2}{*}{ LVmd } & A & 47 & 18 & 43 & 4 & 17 & 8 & 1,0 & 0,4 & 1,2 & 1,5 & 0,24 \\
\hline & B & 62 & 21 & 43 & 5 & 20 & 13 & 0,7 & 0,5 & 2,4 & 1,9 & 0,17 \\
\hline \multirow[t]{2}{*}{ LE arg } & A & 189 & 167 & 179 & 67 & 120 & 18 & 2,4 & 0,6 & 1,8 & 1,1 & 0,61 \\
\hline & B & 197 & 174 & 179 & 58 & 144 & 21 & 2,1 & 1,3 & 1,9 & 1,2 & 0,25 \\
\hline \multirow[t]{2}{*}{ LE md } & A & 63 & 24 & 60 & 14 & 20 & 13 & 1,0 & 0,3 & 1,9 & 1,4 & 0,17 \\
\hline & B & 91 & 29 & 80 & 16 & 23 & 12 & 1,0 & 0,3 & 1,8 & 1,6 & 0,21 \\
\hline
\end{tabular}

No tocante ao ferro, deve-se fazer uma análise separada dos latossolos e do PV. Para os latossolos, mais de $60 \%$ do total de ferro estavam na forma livre, enquanto que as formas mal cristalizdas responderam, em média, por $1 \%$ nos solos argilosos e $4 \%$ nos de textura média. No caso do PV, as formas livres responderam por 43 e $57 \%$ do total, respectivamente, para os horizontes A e $\mathrm{B}$, enquanto as formas mal cristalizadas representaram cerca de $4 \%$, de maneira similar aos latossolos de textura média. 
Para o alumínio, independentemente do tipo de solo, as formas livres responderam por, aproximadamente, $16 \%$ do total, e as formas mal cristalizdas não chegaram a representar $1 \%$ do total (média de $0,6 \%$ ).

Excetuando-se o horizonte A do LEarg, onde o teor de boro solúvel em $\mathrm{CaCl}_{2}$ a quente $(\mathrm{Bs})$ foi alto, todas as demais amostras apresentaram teores baixos ou próximos do limite entre baixo e médio $\left(0,20 \mathrm{mg} / \mathrm{dm}^{3}\right)$, o que indica, segundo RAIJ (1995), um baixo potencial dos solos em fornecer esse elemento. Em três solos (LRarg, LVmd e LEarg), os teores nos horizontes A foram superiores aos verificados no horizonte $\mathrm{B}$, possivelmente devido ao maior teor de carbono orgânico na camada superficial (Tabela 2). A tendência não se confirmou no LEmd, onde o teor de boro solúvel aumentou um pouco no horizonte $\mathrm{B}$, apesar da diminuição no teor de carbono.

No PV, o boro solúvel aumentou consideravelmente no horizonte $\mathrm{B}$, provavelmente devido à presença do gradiente textural abrupto, já que o horizonte $\mathrm{B}$, mesmo possuindo um teor baixo de carbono $\left(4 \mathrm{~g} / \mathrm{dm}^{3}\right)$, tem um teor de argila somente menor que os dos horizontes B dos latossolos argilosos. Por isso, nesse solo o teor de boro solúvel aumentou cinco vezes em profundidade, mostrando que o efeito da granulometria foi mais decisivo do que o da matéria orgânica.

\subsection{Análises físicas}

Os resultados das análises físicas dos solos aparecem na tabela 4. A variação dos atributos físicos foi grande, assim como ocorreu para os atributos químicos. Como era de se esperar, os latossolos apresentaram grande homogeneidade textural nas duas profundidades. Utilizando-se critérios da Sociedade Brasileira de Ciência do Solo (LEMOS \& SANTOS, 1984), o LRarg e o LEarg foram classificados como muito argilosos, o LVmd como franco-arenoso, e o LEmd franco-arenoso em superfície e franco-argilo-arenoso em subsuperfície. 
Tabela 4. Resultados das análises físicas dos horizontes A e B dos solos estudados.

\begin{tabular}{|c|c|c|c|c|c|c|}
\hline Amostra & Horiz. & Areia grossa & Areia fina & Silte & Argila & S.E. \\
\hline & & . & $g /$ & 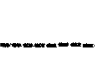 & - & $\mathrm{m}^{2} / \mathrm{g}$ \\
\hline \multirow[t]{2}{*}{ LR arg } & $A$ & 40 & 120 & 230 & 610 & 69,7 \\
\hline & B & 50 & 70 & 210 & 670 & 60,6 \\
\hline \multirow[t]{2}{*}{$\mathrm{PV}$ are/md } & A & 170 & 670 & 100 & 60 & 20,7 \\
\hline & B & 120 & 420 & 120 & 340 & 33,2 \\
\hline \multirow[t]{2}{*}{ LVmd } & A & 180 & 620 & 60 & 140 & 7,3 \\
\hline & B & 140 & 600 & 60 & 200 & 8,2 \\
\hline \multirow[t]{2}{*}{ LE arg } & A & 50 & 90 & 140 & 720 & 76,9 \\
\hline & B & 40 & 80 & 130 & 750 & 69,9 \\
\hline \multirow[t]{2}{*}{ LE md } & A & 180 & 570 & 80 & 170 & 34,8 \\
\hline & B & 190 & 510 & 80 & 220 & 23,8 \\
\hline
\end{tabular}

No PV ocorreu o maior gradiente textural, pois o teor de argila aumentou quase seis vezes em profundidade; assim, no horizonte A o solo é franco-arenoso, e no $\mathrm{B}$, franco-argilo-arenoso.

Em todas as amostras, o teor de areia total e de areia fina diminuíram em profundidade, enquanto que para a areia grossa o teor aumentou no LRarg e no LEmd. O teor de areia fina foi maior do que o de areia grossa em todos os solos, sendo que, na média, ela representou $73 \%$ do teor total de areia.

Os latossolos de textura argilosa tiveram os maiores valores de superficie específica (em torno de $70 \mathrm{~m}^{2} / \mathrm{g}$ ), enquanto que no PV e no LEmd ela 
variou de 20 a $35 \mathrm{~m}^{2} / \mathrm{g}$, chegando até aos baixíssimos valores do LVmd (em torno de $8 \mathrm{~m}^{2} / \mathrm{g}$ ). A superfície específica apresentou correlação significativa e positiva com o teor de argila $\left(r=0,93^{* *}\right)$. A correlação da S.E. com o teor de carbono orgânico não foi estatisticamente significativa, embora fosse observada tendência de aumento da S.E. com o teor de carbono, já que em três dos quatro latossolos a superfície específica da camada superficial foi mais alta do que na camada subsuperficial.

No PV, o gradiente textural foi, possivelmente, a principal causa do aumento da S.E. em profundidade. No LVmd, os valores estiveram muito próximos, devido aos teores semelhantes de $\mathrm{C}$ e de argila nas duas profundidades analisadas.

\subsection{Análises mineralógicas}

Nas figuras 2, 3, 4, 5 e 6 são apresentados os difratogramas de raios $\mathrm{X}$ da fração argila deferrificada dos horizontes subsuperficiais dos solos. A caulinita, com picos a $0,72 \mathrm{~nm}$ e $0,36 \mathrm{~nm}$, foi o mineral dominante, aparecendo em todas as amostras. A gibbsita, com difrações a $0,48 \mathrm{~nm}$ e $0,44 \mathrm{~nm}$, somente não esteve presente no PV, que foi o único solo a apresentar um pico de mica, com difrações na faixa de $1,00 \mathrm{~nm}$.

Picos de vermiculita com hidroxila entrecamadas (VHE) somente não apareceram no PV. Este mineral é identificado em picos na faixa de $1,47 \mathrm{~nm}$ quando a amostra é saturada com magnésio e posteriormente glicolada. Quando ela é saturada com potássio, há redução gradual do espaçamento basal para valores em torno de 1,00nm (FONTES, 1990). Nos difratogramas de raios X do PV foram notados picos de anatásio, óxido de titânio que não sofre ataque do ditionito e é extremamente resistente a tratamentos térmicos, permanecendo sem 


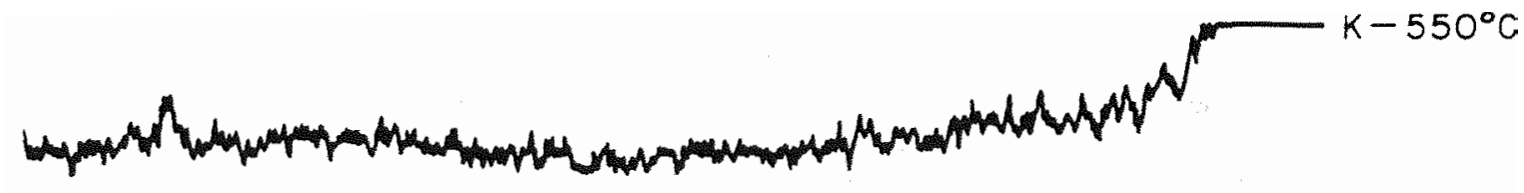

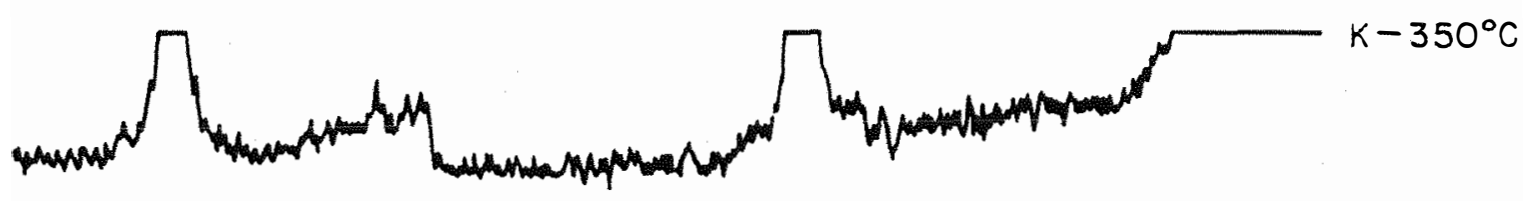

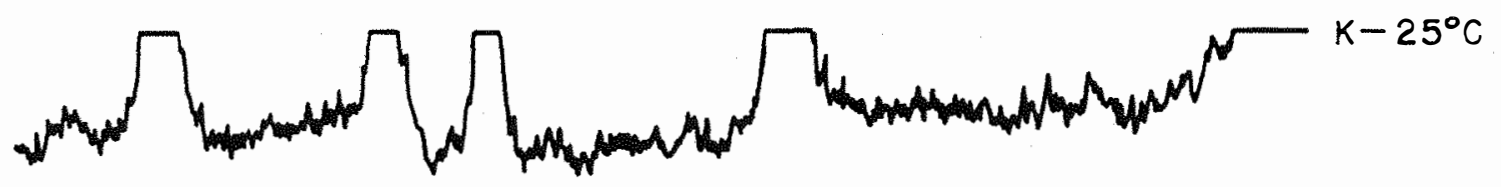

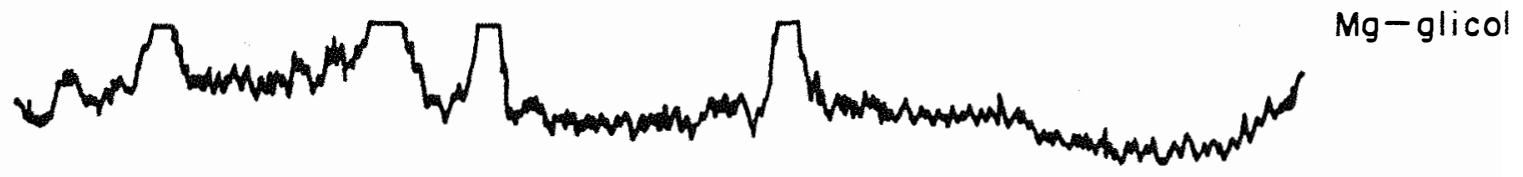

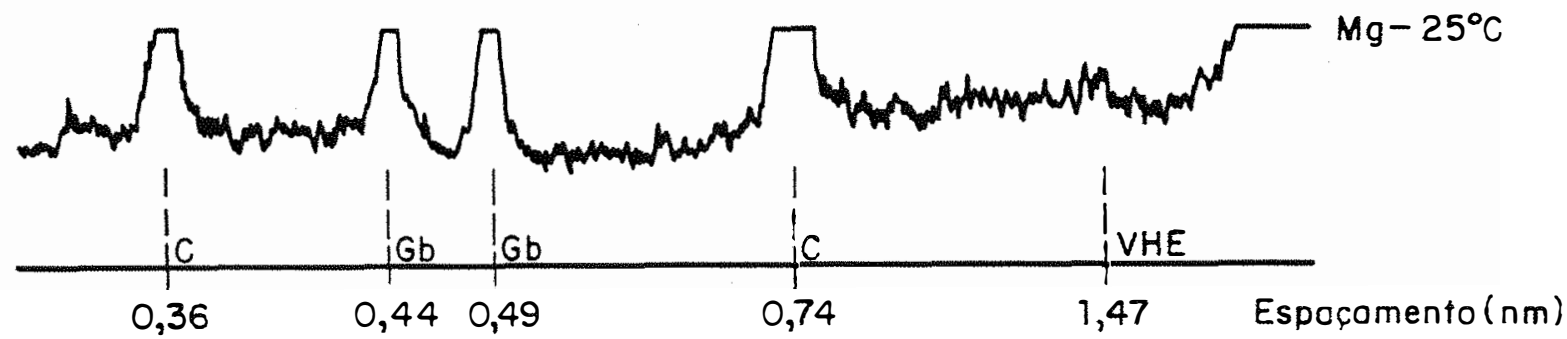

Figura 2. Difratogramas de raios $\mathrm{X}$ da fração argila deferrificada do horizonte $\mathrm{B}$ do LRarg $(\mathrm{C}=$ caulinita; $\mathrm{Gb}=$ gibbsita; $\mathrm{VHE}=$ vermiculita com hidroxila entrecamadas). 

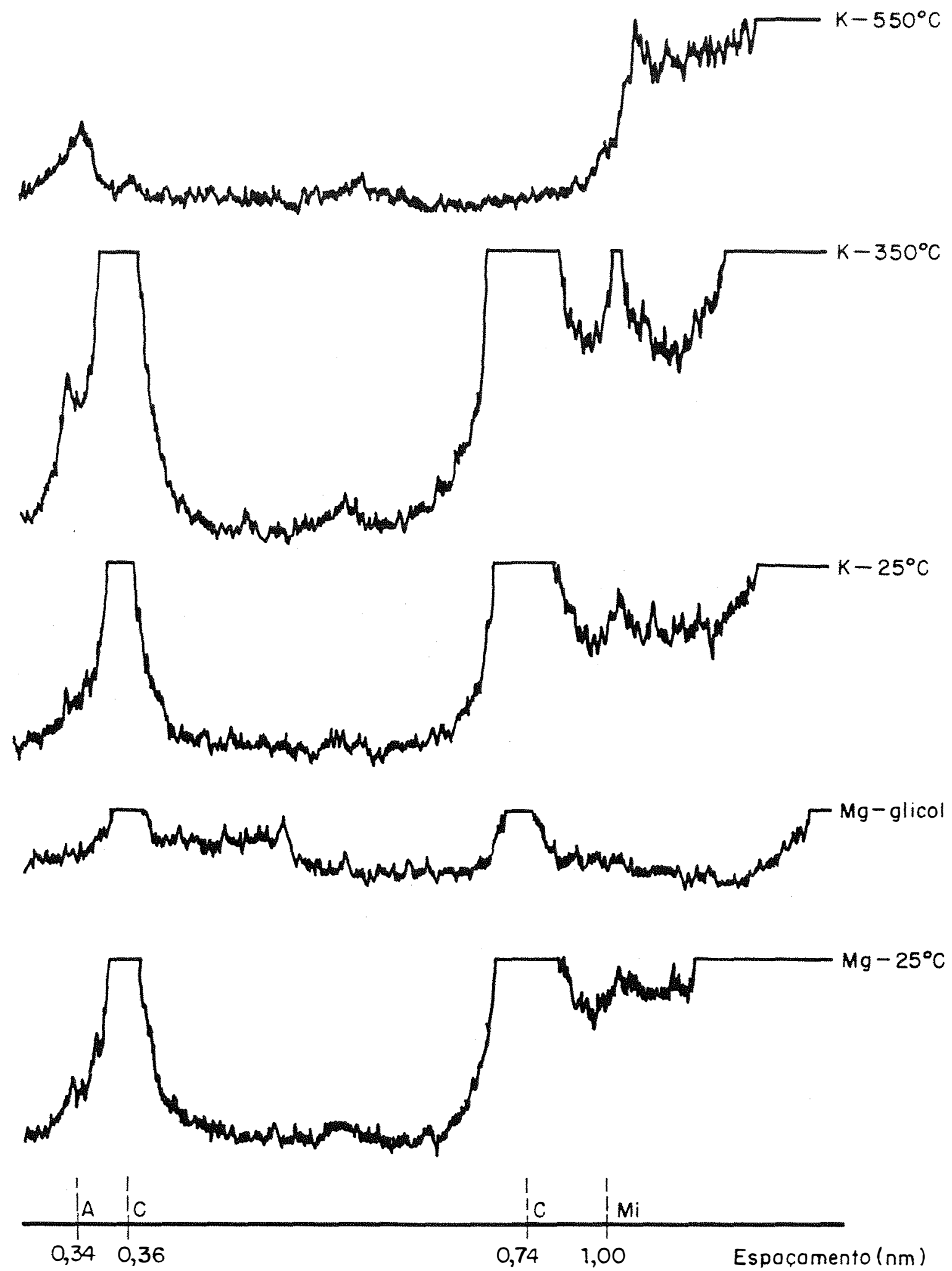

Figura 3. Difratogramas de raios $X$ da fração argila deferrificada do horizonte $B$ do PV (A = anatásio; $\mathrm{C}=$ caulinita; $\mathrm{Mi}=$ mica $)$. 


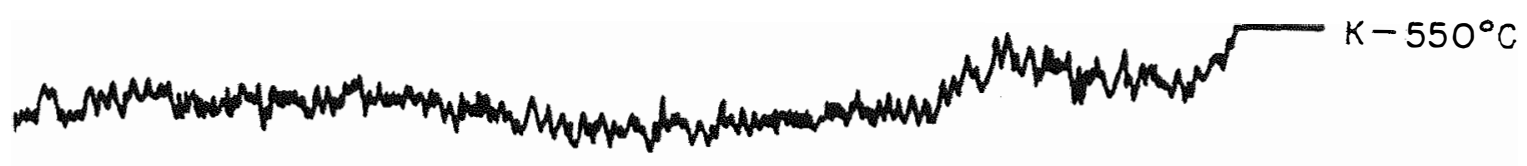
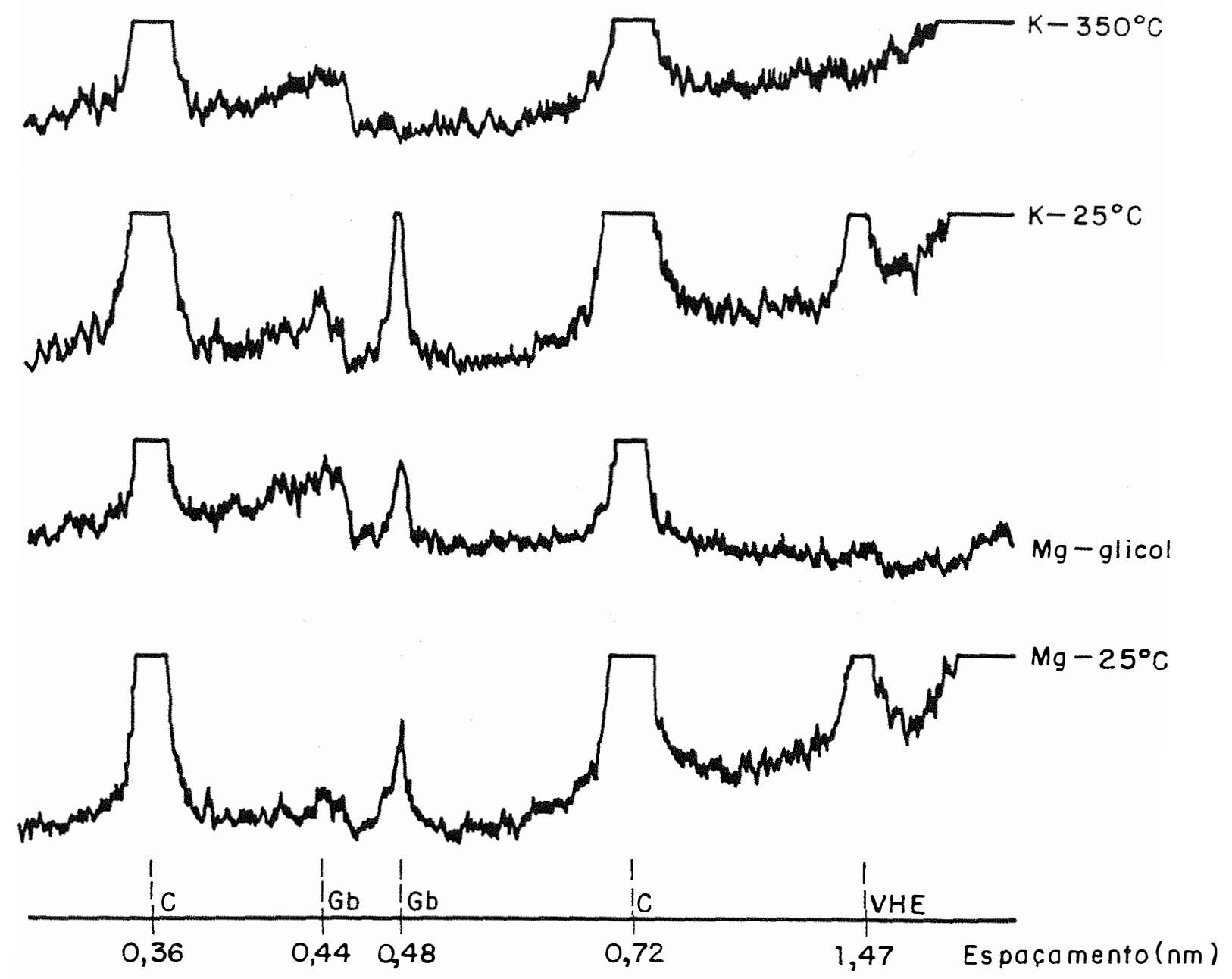

Figura 4. Difratogramas de raios $X$ da fração argila deferrificada do horizonte $B$ do LVmd (C = caulinita; $\mathrm{Gb}=$ gibbsita; VHE = vermiculita com hidroxila entrecamadas). 


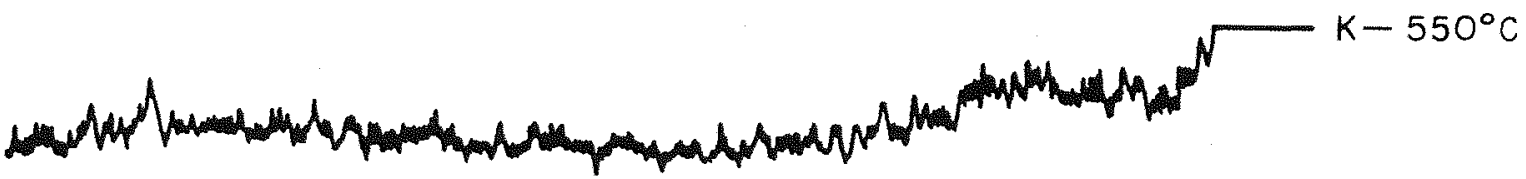

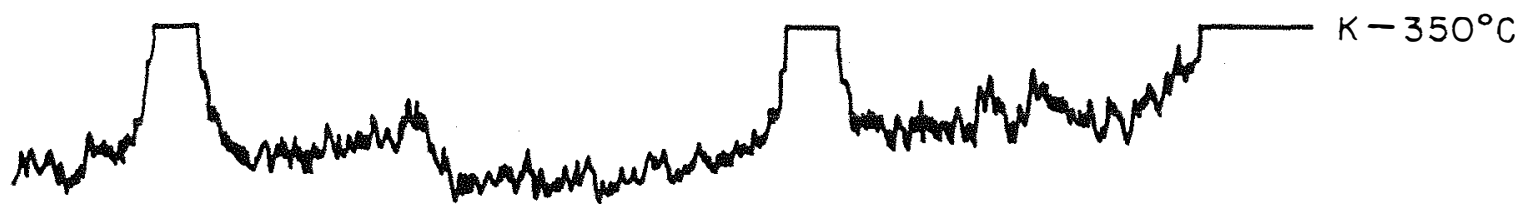

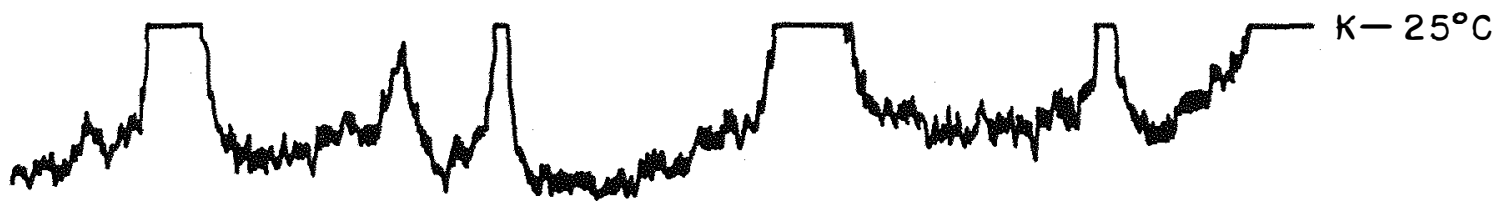
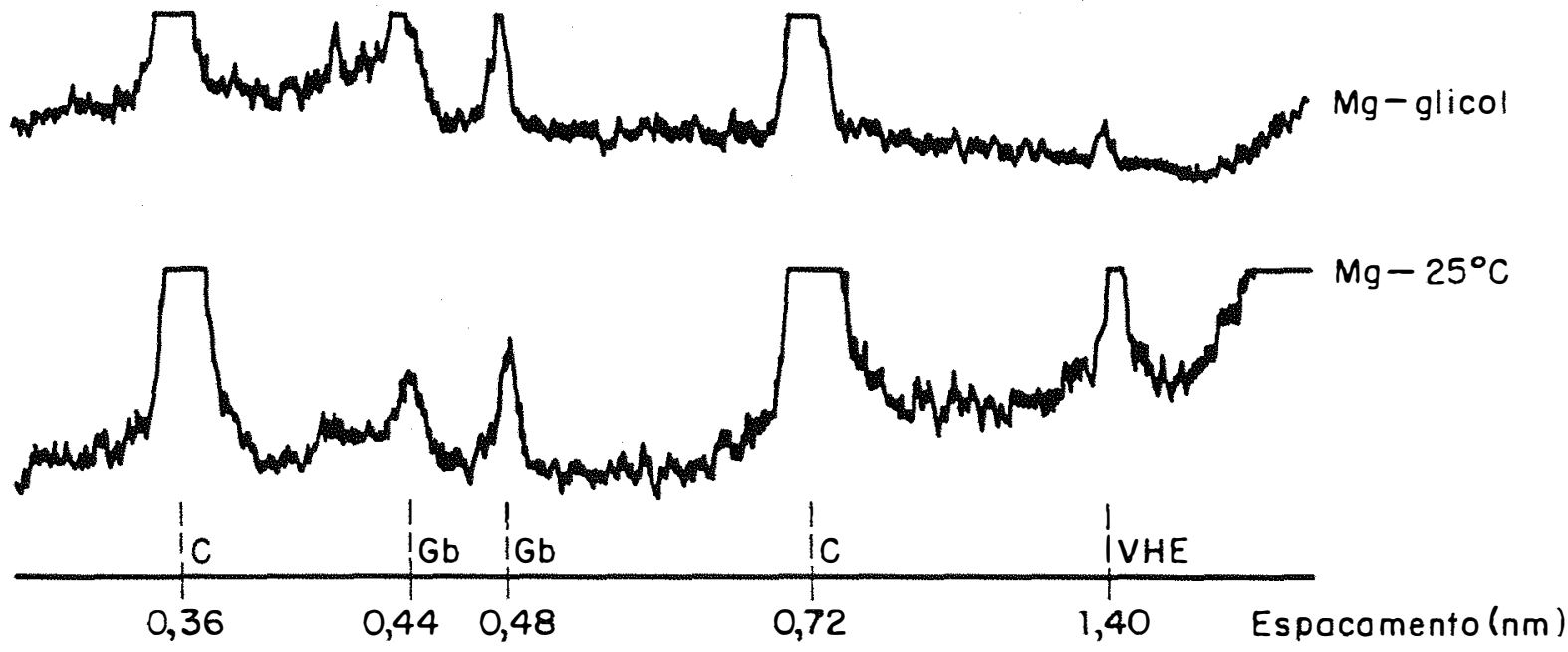

Figura 5. Difratogramas de raios $\mathrm{X}$ da fração argila deferrificada do horizonte $\mathrm{B}$ do LEarg $(\mathrm{C}=$ caulinita; $\mathrm{GB}=$ gibbsita; $\mathrm{VHE}=$ vermiculita com hidroxila entrecamadas). 


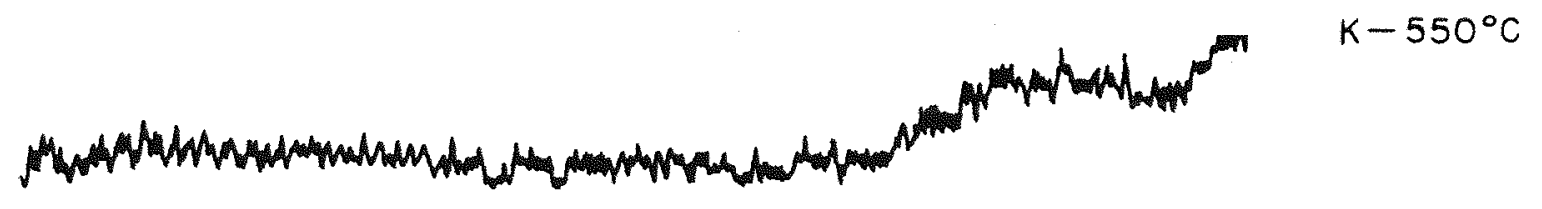
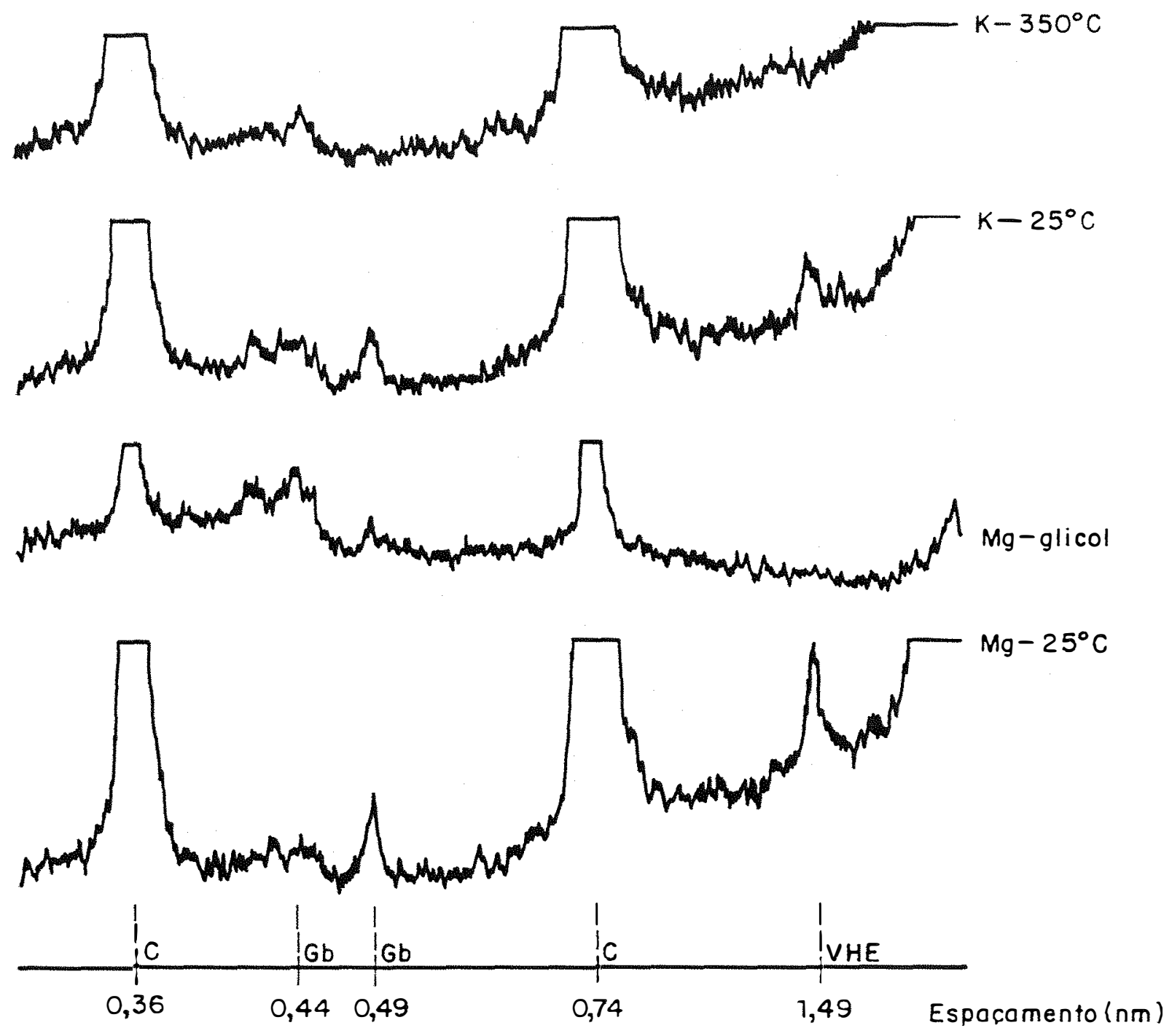

Figura 6. Difratogramas de raios $X$ da fração argila deferrificada do horizonte $B$ do LEmd (C = caulinita; GB = gibbsita; VHE = vermiculita com hidroxila entrecamadas). 
colapsar mesmo a temperaturas elevadas como 350 e $550^{\circ} \mathrm{C}$, ao contrário da maioria dos minerais de argila.

4.4. Correlações simples entre as quantidades de boro solúvel (Bs) em solução de $\mathrm{CaCl}_{2}$ 0,01 mol/L a quente e alguns atributos dos solos

São analisadas, inicialmente, as correlações simples entre as quantidades de boro solúvel em $\mathrm{CaCl}_{2} 0,01 \mathrm{~mol} / \mathrm{L}$ a quente $(\mathrm{Bs})$ e cada um dos atributos do solo. Em seguida, é apresentada a regressão múltipla, em que estão contempladas, conjuntamente, todas as variáveis que possam ter interferido no teor de boro dos solos.

As correlações simples entre as quantidades de boro solúvel em $\mathrm{CaCl}_{2}$ a quente e $\mathrm{pH}$ não foram significativas, apresentando uma dispersão muito grande dos resultados (Tabela 5). Por exemplo, no LEarg, os valores de $\mathrm{pH}$ foram praticamente os mesmos nas duas profundidades (3,7 e 3,5 - respectivamente), enquanto que o teor de Bs diminuiu de $0,61 \mathrm{mg} / \mathrm{dm}^{3}$ no horizonte A para $0,25 \mathrm{mg} / \mathrm{dm}^{3}$ no B. Analogamente, um mesmo teor de Bs $\left(0,17 \mathrm{mg} / \mathrm{dm}^{3}\right)$ foi encontrado no horizonte $\mathrm{B}$ do LVmd $(\mathrm{pH}=3,6)$ e no horizonte $\mathrm{A}$ do LEmd $(\mathrm{pH}=$ $4,4)$.

A correlação entre Bs e teor de carbono orgânico foi feita para todos os solos e, depois, somente para os latossolos, devido ao gradiente textural do PV. A correlação do boro solúvel com o teor de carbono orgânico dos latossolos foi estatisticamente significativa a 5\% (Tabela 5). Quando se considerou também o PV, a correlação entre Bs e carbono não foi significativa. Como citado no ítem 4.1.2., o teor de carbono orgânico praticamente não variou, mas o teor de Bs aumentou, possivelmente devido ao fato de o teor de argila ter aumentado quase seis vezes. Dentre os demais atributos químicos de fertilidade, somente a CTC total apresentou correlação positiva com o boro solúvel, a 5\% de probabilidade, 
sendo que para os outros o coeficiente de correlação foi muito baixo e não significativo.

Em relação aos teores de óxidos, a única correlação significativa foi com alumínio total (Tabela 5). Para ferro total, ferro e alumínio livres e mal cristalizados, elas apresentaram coeficientes de correlação baixos e não significativos.

A correlação entre os teores de boro solúvel e os teores de silte não foi significativa. Tanto a correlação com areia total, como com areia grossa e areia fina, foram negativas e estatisticamente significativas a $5 \%$ de probabilidade (Tabela 5).

No PV, houve aumento considerável na quantidade de boro solúvel do horizonte A para o $\mathrm{B}$, o que pode ser atribuído ao maior teor de argila deste último, uma vez que o teor de carbono foi o mesmo nas duas profundidades. A correlação entre Bs e teor de argila foi positiva e estatisticamente significativa a $5 \%$ (Tabela 5).

Outro atributo que se correlacionou positivamente com Bs foi a superficie específica (S.E.). Tal resultado era previsto, porque a S.E. é um parâmetro de superfície e, por isso, altamente relacionada ao teores de matéria orgânica e argila.

Como as correlações simples medem apenas as associações entre as variáveis individualmente, foi feita regressão múltipla entre o boro solúvel e os seguintes atributos: $\mathrm{pH}$, carbono orgânico, cátions trocáveis, $\mathrm{V} \%, \mathrm{~m} \%$, óxidos de ferro e de alumínio, nas diversas formas, teor de argila e superfície específica. A equação obtida foi:

$\mathrm{Bs}=-0,09+6,63 \cdot 10^{-3} \mathrm{Ca}$ trocável $+7,45 \cdot 10^{-3} \mathrm{Al}$ trocável $+1,69 \cdot 10^{-3}$ Al total 
Tabela 5. Coeficientes de correlação simples entre os teores de boro solúvel em $\mathrm{CaCl}_{2}$ $0,01 \mathrm{~mol} / \mathrm{L}$ a quente e alguns atributos dos solos.

\begin{tabular}{|c|c|}
\hline Atributo & Coeficiente de correlação \\
\hline $\mathrm{pH}$ & $-0,29(\mathrm{~ns})$ \\
\hline Carbono orgânico ${ }^{1}$ & $0,60(\mathrm{~ns})$ \\
\hline Carbono orgânico ${ }^{2}$ & $0,75^{*}$ \\
\hline Cálcio & $-0,12(\mathrm{~ns})$ \\
\hline Magnésio & $0,51(\mathrm{~ns})$ \\
\hline Potássio & $0,03(\mathrm{~ns})$ \\
\hline Alumínio & $0,22(\mathrm{~ns})$ \\
\hline $\mathrm{H}+\mathrm{Al}$ & $0,32(\mathrm{~ns})$ \\
\hline CTC efetiva & $0,29(\mathrm{~ns})$ \\
\hline CTC total & $0,63^{*}$ \\
\hline V\% & $-0,39(\mathrm{~ns})$ \\
\hline $\mathrm{m} \%$ & $0,34(\mathrm{~ns})$ \\
\hline Ferro total & $0,46(\mathrm{~ns})$ \\
\hline Alumínio total & $0,70^{*}$ \\
\hline Ferro livre & $0,48(\mathrm{~ns})$ \\
\hline Alumínio livre & $0,39(\mathrm{~ns})$ \\
\hline Ferro mal cristalizado & $0,46(\mathrm{~ns})$ \\
\hline Alumínio mal cristalizado & $0,26(\mathrm{~ns})$ \\
\hline Areia fina & $-0,68^{*}$ \\
\hline Areia grossa & $-0,64^{*}$ \\
\hline Areia total & $-0,67^{*}$ \\
\hline Silte & $0,47(\mathrm{~ns})$ \\
\hline Argila & $0,69^{*}$ \\
\hline Superfīcie específica & $0,68^{*}$ \\
\hline
\end{tabular}

$\begin{array}{ll}{ }^{7} \text { Todos os solos } & { }^{*} \text { Significativo a } 5 \% \text { de probabilidade } \\ { }^{2} \text { Somente os latossolos } & * * \text { Significativo a } 1 \% \text { de probabilidade }\end{array}$


No Apêndice 1 é apresentado o resumo do procedimento estatístico adotado na regressão múltipla, assim como os valores parciais dos coeficientes de determinação e também o $\mathrm{r}^{2}$ acumulado no modelo. Observa-se que o teor total de óxido de alumínio (Alt) respondeu por $49 \%$ da variação dos valores de boro solúvel. Com a adição dos teores trocáveis de cálcio $(\mathrm{Ca})$ e de alumínio $(\mathrm{Al})$, o modelo representou $85 \%$ da variação no teor de Bs. Todas as demais variáveis não entraram no modelo, já que não atingiram os $15 \%$ de probabilidade exigidos pelo programa SAS, em regressões múltiplas aplicadas a fenômenos biológicos.

\subsection{Adsorção de boro}

Como o número de resultados encontrados na literatura envolvendo a determinação de boro por indução de plasma é bastante restrito, serão apresentadas as curvas-padrões obtidas (Figuras 7 e 8), considerando-se as duas situações citadas no ítem 3.3., ou seja, uma curva para as menores concentrações de boro adicionado aos solos $(0 ; 1$ e $2 \mu \mathrm{g} / \mathrm{mL})$ e outra para as soluções mais concentradas $(4 ; 8$ e $16 \mu \mathrm{g} / \mathrm{mL})$.

Observa-se o ótimo ajuste das curvas aos dados, mesmo nas maiores concentrações de boro (Figura 8). A grande vantagem que pode ser atribuída a esse fato foi a possibilidade da leitura direta do boro remanescente na solução em equilíbrio, após agitação por $24 \mathrm{~h}$, sem a necessidade de diluição do extrato, o que tornou a operação de determinação do elemento mais rápida e precisa.

A adsorção de boro nos cinco solos estudados após adição de doses

crescentes do elemento encontra-se na tabela 6. Os teores de boro adsorvido aumentaram à medida que as quantidades adicionadas do elemento foram maiores. Entretanto, o aumento foi cada vez menos acentuado à medida que as 


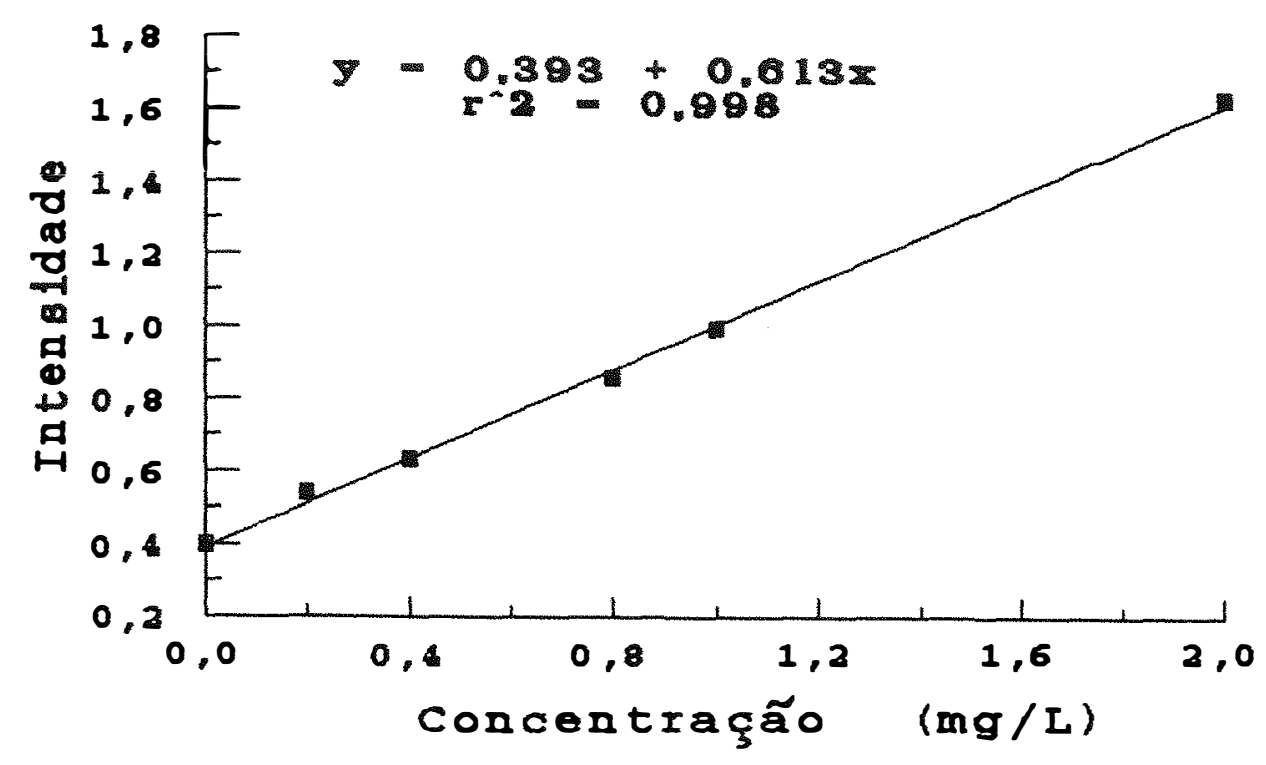

Figura 7. Curva-padrão utilizada para determinação do boro por indução de plasma após adição das soluções menos concentradas de boro $(0 ; 1 \mathrm{e}$ $2 \mu \mathrm{g} / \mathrm{mL})$.

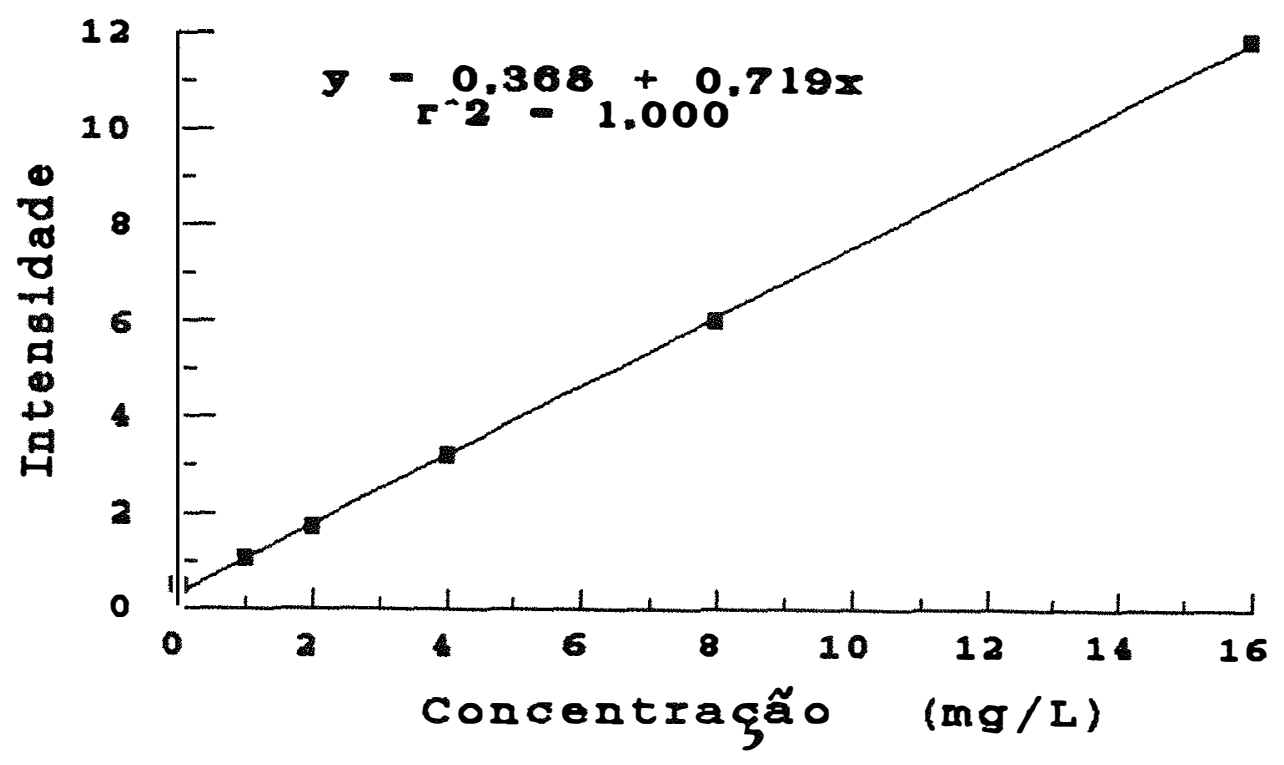

Figura 8. Curva-padrão utilizada para determinação do boro por indução de plasma após adição das soluções mais concentradas de boro $(4 ; 8 \mathrm{e}$ $16 \mu \mathrm{g} / \mathrm{mL})$. 
Tabela 6. Quantidades de boro em equilíbrio na solução $(\mu \mathrm{g} / \mathrm{mL})$ e adsorvido $(\mu \mathrm{g} / \mathrm{g})$ por grama de terra dos solos estudados e porcentagem do boro adsorvido em função das quantidades de boro adicionadas, em $\mu \mathrm{g} / \mathrm{mL}$ ( $\mathrm{A}$ = horizonte $\mathrm{A}, \mathrm{B}=$ horizonte $\mathrm{B} \mathrm{e} \mathrm{A}^{*}=$ horizonte $\mathrm{A}$ com calcário).

\begin{tabular}{|c|c|c|c|c|c|c|c|c|c|c|}
\hline \multirow{2}{*}{ Solo } & \multirow{2}{*}{$\begin{array}{c}\text { Boro } \\
\text { adicionado }\end{array}$} & \multicolumn{3}{|c|}{ Boro em equilíbrio } & \multicolumn{6}{|c|}{ Boro adsorvido } \\
\hline & & A & $\mathrm{A}^{*}$ & B & A & $\mathrm{A}^{*}$ & B & A & $\mathrm{A}^{*}$ & B \\
\hline \multirow{5}{*}{$\begin{array}{l}\text { LR } \\
\text { arg }\end{array}$} & 1 & 0,77 & 0,76 & 0,71 & 1,15 & 1,18 & 1,45 & 23 & 24 & 29 \\
\hline & 2 & 1,63 & 1,58 & 1,53 & 1,85 & 2,10 & 2,33 & 18 & 21 & 23 \\
\hline & 4 & 3,46 & 3,33 & 3,23 & 2,71 & 3,35 & 3,84 & 13 & 17 & 19 \\
\hline & 8 & 7,05 & 6,86 & 6,75 & 4,75 & 5,69 & 6,26 & 12 & 14 & 16 \\
\hline & 16 & 14,46 & 14,35 & 14,16 & 7,69 & 8,27 & 9,21 & 10 & 10 & 11 \\
\hline \multirow{5}{*}{$\begin{array}{l}\text { PV } \\
\text { are/ } \\
\text { md }\end{array}$} & 1 & 0,81 & 0,78 & 0,63 & 0,95 & 1,11 & 1,84 & 19 & 22 & 37 \\
\hline & 2 & 1,67 & 1,60 & 1,42 & 1,63 & 1,98 & 2,89 & 16 & 20 & 29 \\
\hline & 4 & 3,58 & 3,49 & 3,16 & 2,09 & 2,53 & 4,20 & 10 & 13 & 21 \\
\hline & 8 & 7,45 & 7,23 & 6,95 & 2,76 & 3,85 & 5,25 & 7 & 10 & 13 \\
\hline & 16 & 15,30 & 15,06 & 14,74 & 3,51 & 4,71 & 6,29 & 4 & 6 & 8 \\
\hline \multirow{5}{*}{$\begin{array}{l}\text { LV } \\
\text { md }\end{array}$} & 1 & 0,87 & 0,84 & 0,85 & 0,65 & 0,78 & 0,73 & 13 & 16 & 15 \\
\hline & 2 & 1,82 & 1,74 & 1,78 & 0,91 & 1,29 & 1,09 & 9 & 13 & 11 \\
\hline & 4 & 3,72 & 3,64 & 3,70 & 1,40 & 1,79 & 1,49 & 7 & 9 & 7 \\
\hline & 8 & 7,64 & 7,58 & 7,61 & 1,78 & 2,32 & 1,96 & 4 & 5 & 5 \\
\hline & 16 & 15,56 & 15,40 & 15,46 & 2,19 & 2,98 & 2,72 & 3 & 4 & 4 \\
\hline \multirow{5}{*}{$\begin{array}{l}\mathrm{LE} \\
\mathrm{arg}\end{array}$} & 1 & 0,59 & 0,45 & 0,39 & 2,07 & 2,74 & 3,05 & 41 & 55 & 61 \\
\hline & 2 & 1,30 & 1,16 & 1,01 & 3,52 & 4,19 & 4,93 & 35 & 42 & 49 \\
\hline & 4 & 3,10 & 2,91 & 2,69 & 4,50 & 5,44 & 6,57 & 22 & 27 & 33 \\
\hline & 8 & 6,74 & 6,51 & 6,16 & 6,31 & 7,43 & 9,22 & 16 & 19 & 23 \\
\hline & 16 & 14,39 & 14,27 & 13,78 & 8,05 & 8,65 & 11,12 & 10 & 11 & 14 \\
\hline \multirow{5}{*}{$\begin{array}{l}\text { LE } \\
\mathrm{md}\end{array}$} & 1 & 0,87 & 0,80 & 0,85 & 0,65 & 1,01 & 0,75 & 13 & 20 & 15 \\
\hline & 2 & 1,79 & 1,64 & 1,74 & 1,05 & 1,80 & 1,32 & 10 & 18 & 13 \\
\hline & 4 & 3,74 & 3,55 & 3,63 & 1,30 & 2,26 & 1,84 & 6 & 11 & 9 \\
\hline & 8 & 7,67 & 7,38 & 7,46 & 1,65 & 3,12 & 2,70 & 4 & 8 & 7 \\
\hline & 16 & 15,56 & 15,24 & 15,38 & 2,20 & 3,81 & 3,12 & 3 & 5 & 4 \\
\hline
\end{tabular}


soluções ficaram mais concentradas, o que pode ser observado nas últimas três colunas da tabela 6 .

A porcentagem de boro adsorvido foi maior na menor dose de boro adicionado $(1 \mu \mathrm{g} / \mathrm{mL})$, com média geral de $27 \%$ para todos os solos, quando considerados os horizontes A, B e A com calcário. A partir daí, houve decréscimo na porcentagem de boro adsorvido, até a média de 7\% quando foram adicionados $16 \mu \mathrm{g} / \mathrm{mL}$ de boro.

Considerando-se o conjunto dos solos, a porcentagem de boro adsorvido diminuiu 3,9 vezes entre a menor e a maior dose, sendo que para o PV, o LVmd, o LEarg e o LEmd os decréscimos foram semelhantes, respectivamente de 4,3 , 4,4, 4,5 e 4,0 vezes, enquanto que no LRarg houve diminuição de 2,4 vezes.

Os maiores valores de porcentagem de boro adsorvido em relação ao adicionado ocorreram no LEarg, principalmente nas soluções menos concentradas. Por exemplo, na menor dose $(1 \mu \mathrm{g} / \mathrm{mL}$ de boro), a média desse solo foi $52 \%$, enquanto que, nas mesmas condições, o LRarg adsorveu $25 \%$, e o LVmd adsorveu apenas $15 \%$ do boro adicionado. O maior valor percentual foi do LEarg, horizonte $\mathrm{B}$, na dose $1 \mu \mathrm{g} / \mathrm{mL}$, com $61 \%$ de adsorção; o menor valor foi do $\mathrm{LVmd}$, no horizonte A sem calcário, na maior dose de boro adicionado $(2,19 \mu \mathrm{g} / \mathrm{g}$ de boro adsorvidos após adição de $16 \mu \mathrm{g} / \mathrm{mL}$ do elemento, correspondendo a $3 \%$ de adsorção).

Em termos de adsorção por unidade de massa de terra, o maior valor foi do LEarg, em que $11,12 \mu \mathrm{g} / \mathrm{g}$ de boro foram adsorvidos após adição de $16 \mu \mathrm{g} / \mathrm{mL}$ do elemento. As menores adsorções ocorreram no horizonte A sem calcário dos latossolos de textura média (LVmd e LEmd), correspondendo a $0,65 \mu \mathrm{g} / \mathrm{g}$ de boro após adição de $1 \mu \mathrm{g} / \mathrm{mL}$. 
- A adsorção de boro no horizonte B foi maior do que no horizonte A em todas as amostras, acompanhando um aumento no teor de argila em profundidade, que ocorreu para todos os solos, em menor ou maior intensidade (Tabela 4). O maior aumento do horizonte A para o $\mathrm{B}$ foi registrado no $\mathrm{PV}$, onde a quantidade de boro adsorvido aumentou $89 \%$, em média, considerando-se todas as concentrações de boro adicionado, enquanto que a média de aumento para os latossolos foi de $29 \%$.

\subsubsection{Efeito da adição de carbonato de cálcio}

Em todos os solos, a quantidade de boro adsorvido aumentou após a aplicação de $\mathrm{CaCO}_{3}$ no horizonte superficial (Tabela 6). A magnitude do aumento na adsorção de boro devido à calagem aparece na tabela 7 .

$\mathrm{Na}$ média geral de todas as amostras, o aumento médio no boro adsorvido devido à calagem foi de $32,6 \%$. O aumento mais representativo ocorreu no LEmd (72,6\%), sendo que os demais solos de textura arenosa ou média (LVmd e PV) tiveram aumentos da ordem de $30 \%$, e para os solos de textura argilosa os aumentos foram menores do que $20 \%$.

Nos latossolos de textura média, a adsorção de boro no horizonte $\mathrm{A}$ após a aplicação de calcário foi superior à adsorção no horizonte $\mathrm{B}$, fato que não ocorreu nem nos outros dois latossolos argilosos, nem no PV. Nesse último, o teor de argila no horizonte subsuperficial pareceu ser o fator determinante na definição do valor de boro adsorvido.

\subsubsection{Representação gráfica da adsorção de boro nos solos}

As figuras 9, 10, 11, 12 e 13 mostram a relação entre boro adicionado e sua adsorção nos solos. 
Tabela 7. Porcentagem de aumento na adsorção de boro nas amostras do horizonte A devido à aplicação de calcário.

\begin{tabular}{cccccc}
\hline Boro adicionado & LRarg & PV & LVmd & LEarg & LEmd \\
\hline$\mu \mathrm{g} / \mathrm{mL}$ & & & & & \\
\cline { 2 - 6 } & 2,6 & 16,8 & 20,2 & 32,4 & 55,4 \\
2 & 13,5 & 21,5 & 41,8 & 19,0 & 71,4 \\
4 & 23,6 & 21,0 & 27,9 & 20,9 & 73,8 \\
8 & 19,8 & 39,5 & 30,3 & 17,7 & 89,1 \\
16 & 7,5 & 34,2 & 36,1 & 7,4 & 73,2 \\
\hline Módia & 13,4 & 26,6 & 31,2 & 19,5 & 72,6 \\
\hline
\end{tabular}

Em quase todos os solos, houve duas fases de adsorção: na primeira, representada pelas adições de soluções menos concentradas de boro ( 1 e $2 \mu \mathrm{g} / \mathrm{mL})$, a inclinação das curvas foi bem mais acentuada do que na segunda fase,representada pelas soluções mais concentradas $(4,8$ e $16 \mu \mathrm{g} / \mathrm{mL})$, mostrando um umento cada vez menor no teor de boro adsorvido em relação ao adicionado (Figuras 10,11, 12 e 13). No LRarg a curvatura não foi tão acentuada como nos outros solos, ou seja, o aumento na quantidade de boro adsorvido em relação ao adicionado foi praticamente constante, com alguma inclinação entre 8 e $16 \mu \mathrm{g} / \mathrm{mL}$ no horizonte A com calcário (Figura 9).

A partir da dose $4 \mu \mathrm{g} / \mathrm{mL}$, até a dose máxima $(16 \mu \mathrm{g} / \mathrm{mL})$, o segmento de curva dos horizontes superficiais sem calcário de todas as amostras passou a ser praticamente linear. Nas amostras com calcário, a tendência de linearidade das curvas entre 4 e $16 \mu \mathrm{g} / \mathrm{mL}$ de $\mathrm{B}$ adicionado se manteve somente nas amostras de textura mais grosseira - PV, LVmd e LEmd (Figuras 10, 11 e 13). Para o horizonte B, o fenômeno ocorreu no LRarg e no LVmd (Figuras 9 e 11). 


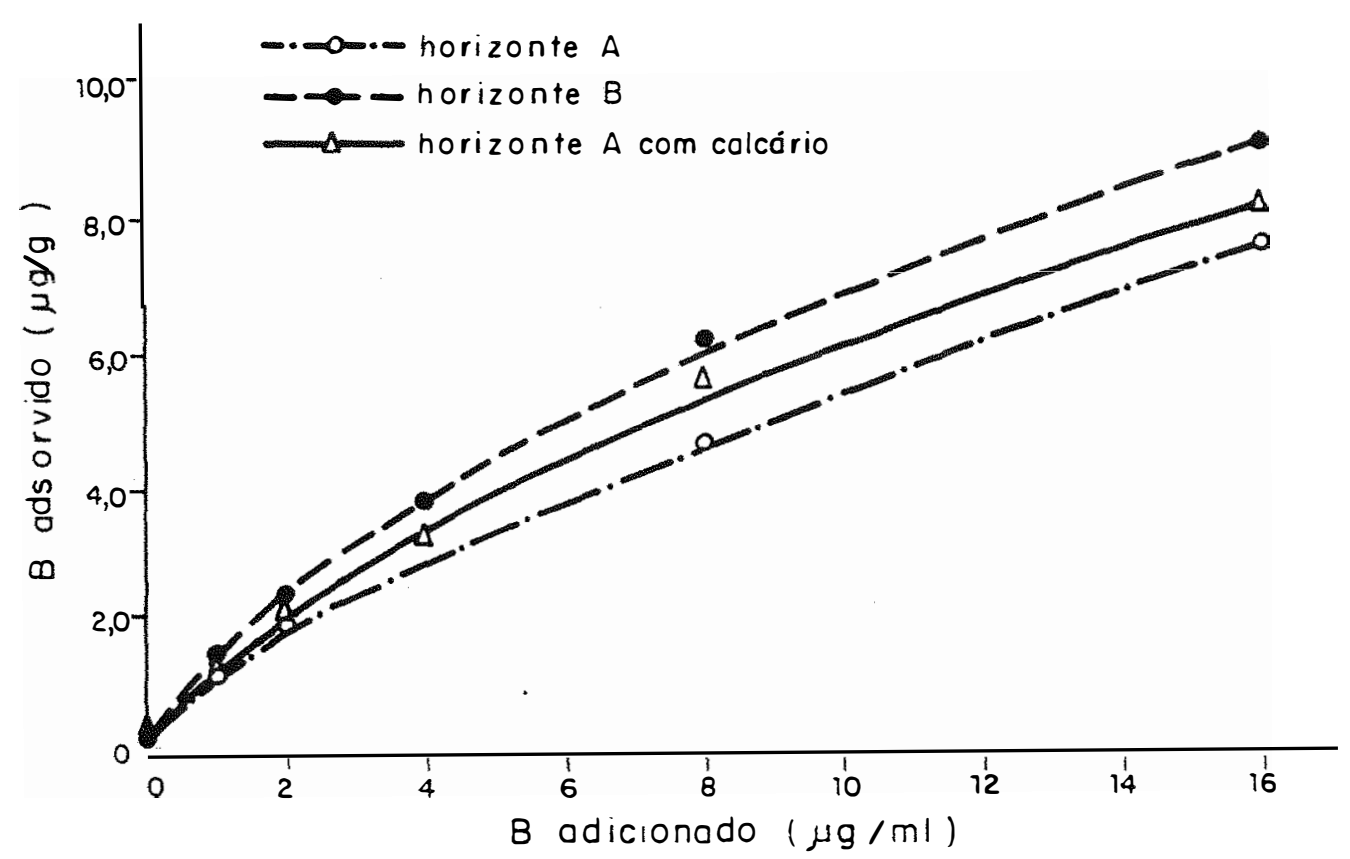

Figura 9. Adsorção de boro no latossolo roxo argiloso (LRarg), após adição de soluções de $\mathrm{CaCl}_{2}$ 0,01mol/L com $1 ; 2 ; 4 ; 8$ e $16 \mu \mathrm{g} / \mathrm{mL}$ de boro.

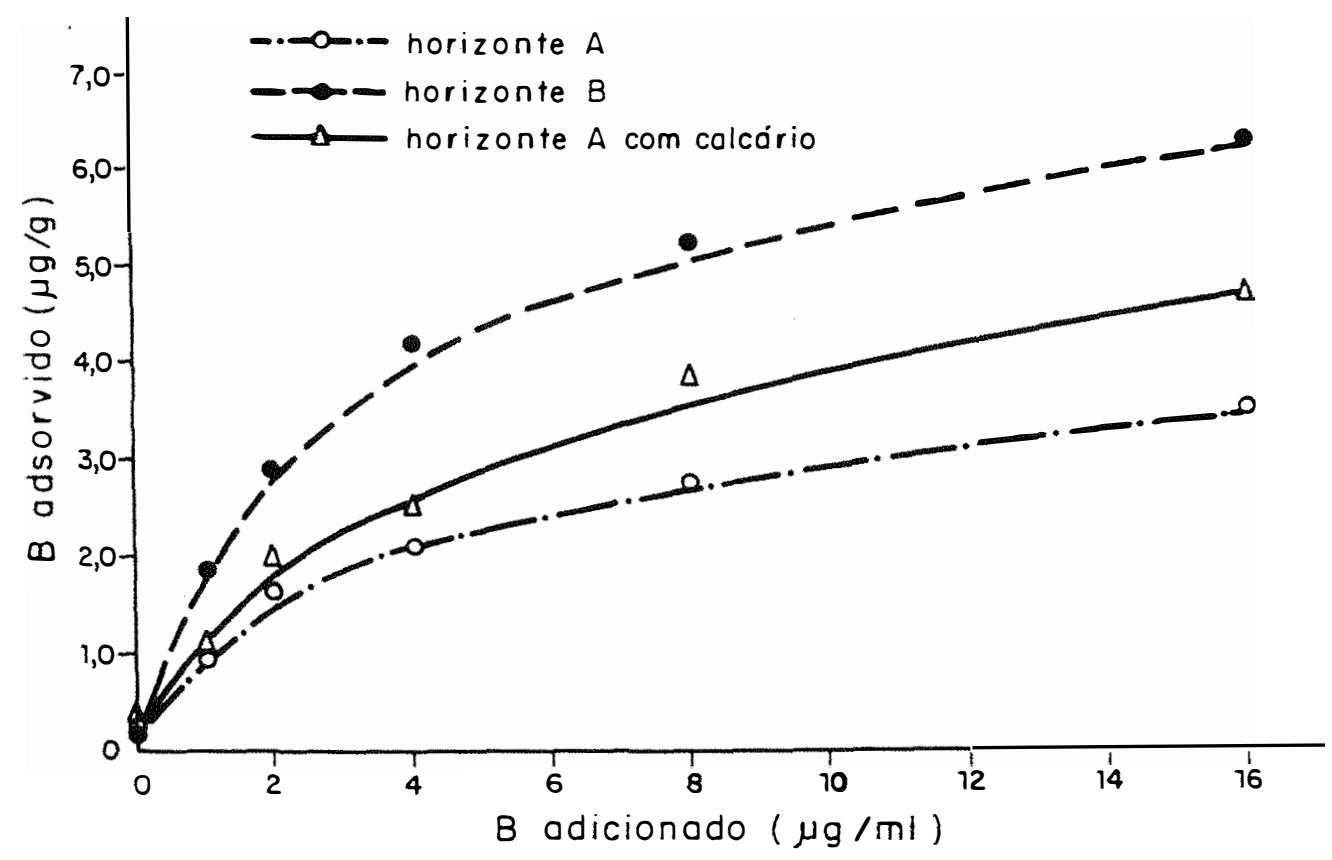

Figura 10. Adsorção de boro no podzólico vermelho-amarelo (PV), após adição de soluções de $\mathrm{CaCl}_{2}$ 0,01 mol/L com 1;2;4;8 e $16 \mu \mathrm{g} / \mathrm{mL}$ de boro. 


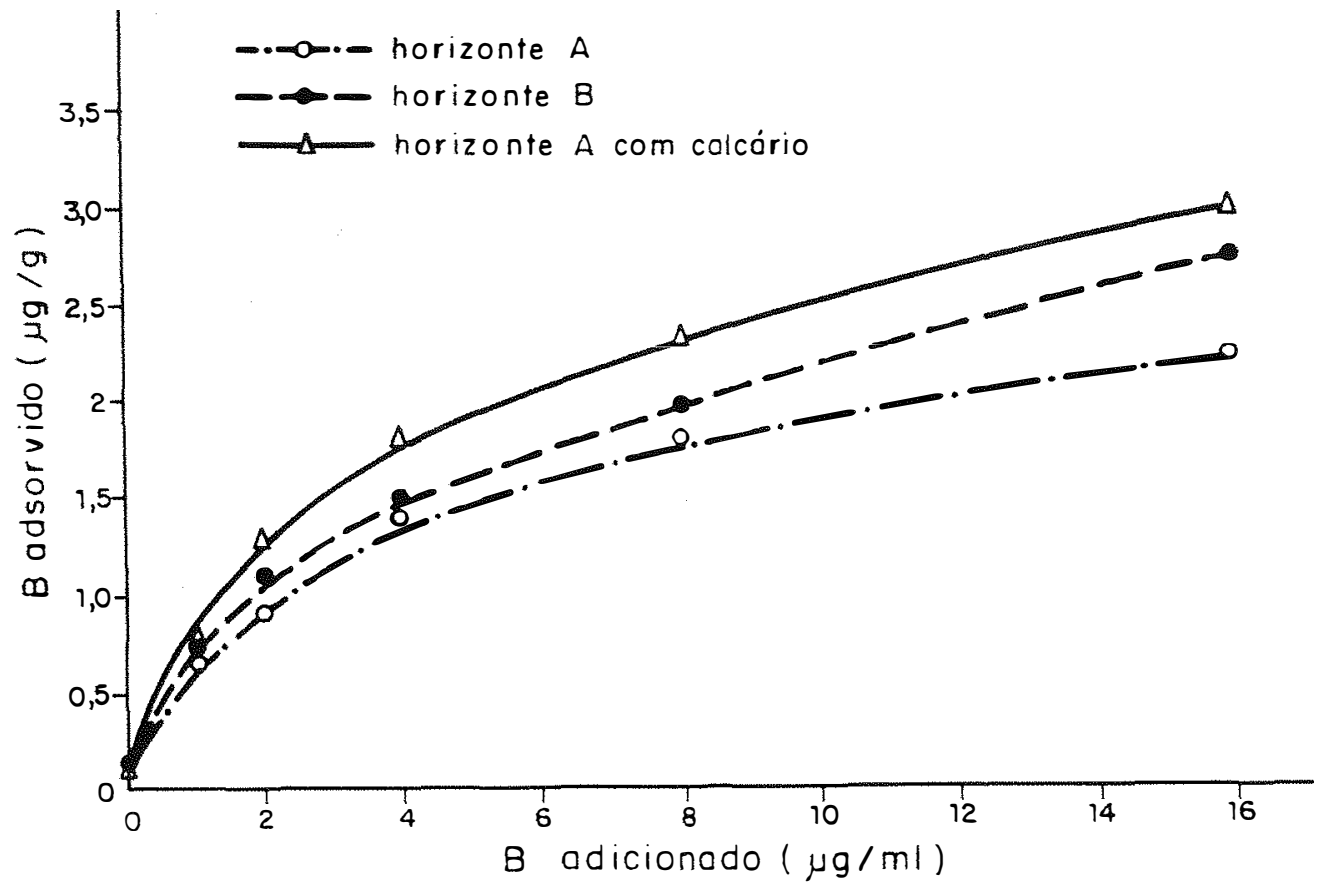

Figura 11. Adsorção de boro no latossolo vermelho-amarelo textura média (LVmd), após adição de soluções de $\mathrm{CaCl}_{2} 0,01 \mathrm{~mol} / \mathrm{L}$ com $1 ; 2 ; 4 ; 8$ e $16 \mu \mathrm{g} / \mathrm{mL}$ de boro.

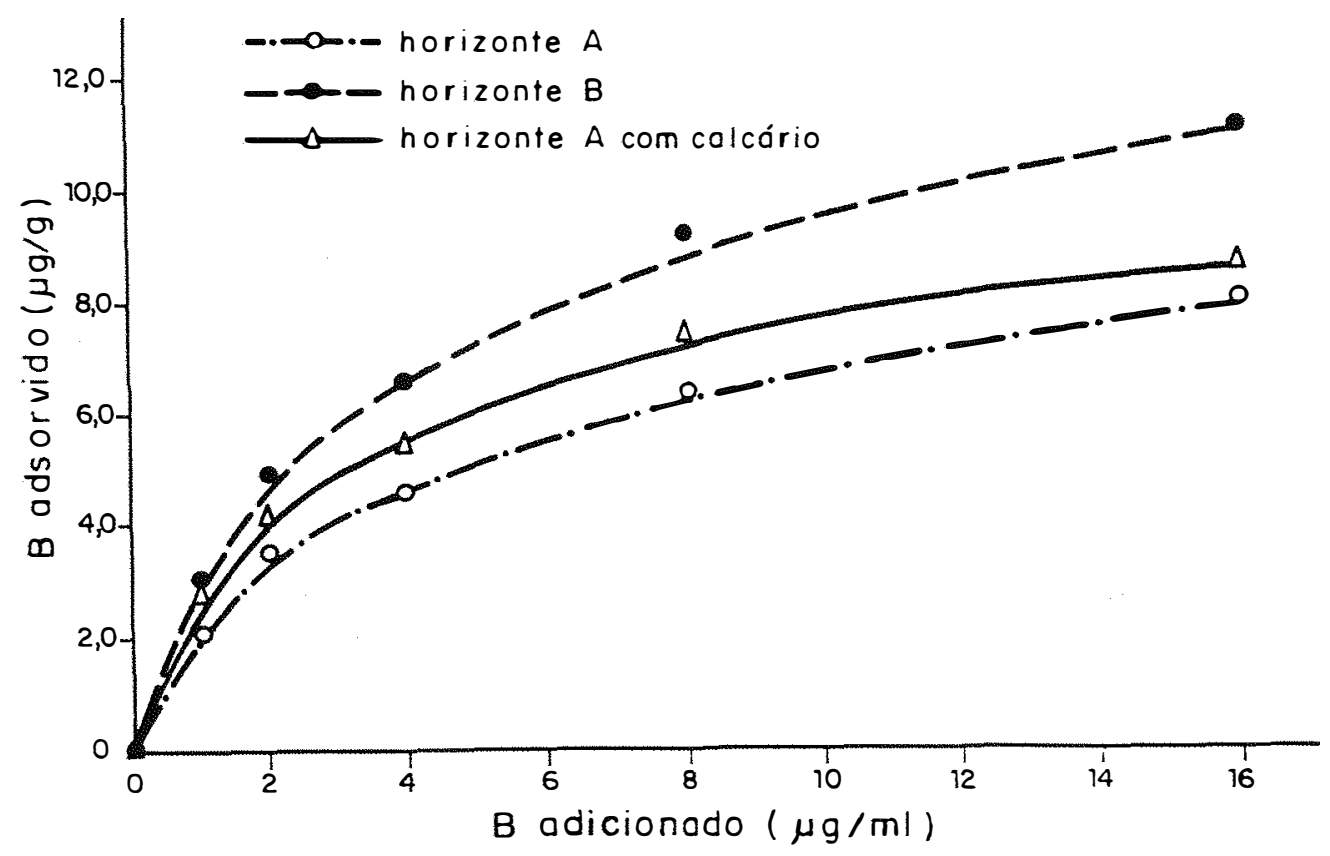

Figura 12. Adsorção de boro no latossolo vermelho-escuro argiloso (LEarg), após adição de soluções de $\mathrm{CaCl}_{2}$ 0,01 mol/L com $1 ; 2 ; 4 ; 8$ e $16 \mu \mathrm{g} / \mathrm{mL}$ de boro. 


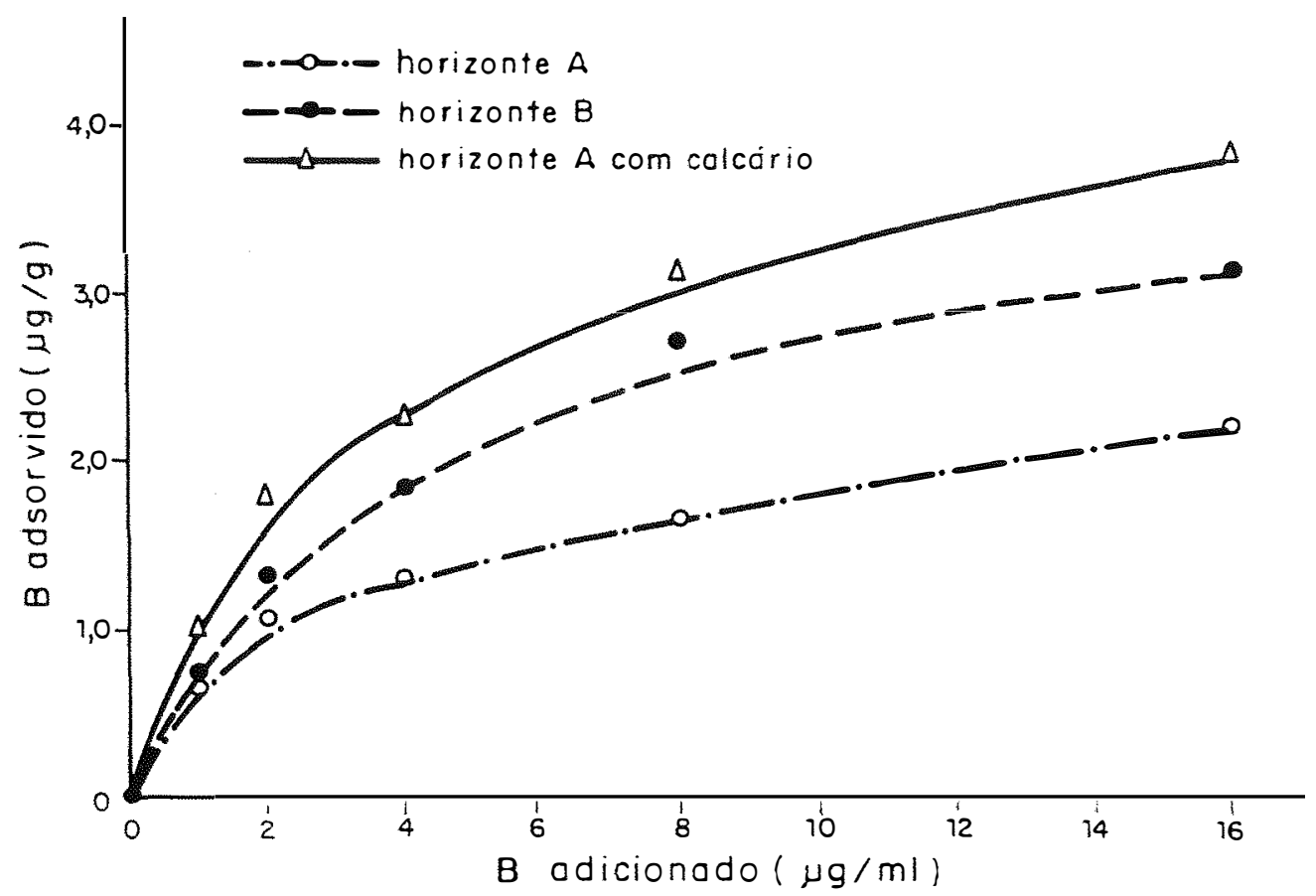

Figura 13. Adsorção de boro no latossolo vermelho-escuro textura média (LEmd), após adição de soluções de $\mathrm{CaCl}_{2} \quad 0,01 \mathrm{~mol} / \mathrm{L}$ com $1 ; 2 ; 4 ; 8$ e $16 \mu \mathrm{g} / \mathrm{mL}$ de boro.

4.5.3. Correlações entre boro adsorvido e atributos dos solos

Analogamente ao feito para boro solúvel, são apresentadas as correlações simples entre boro adsorvido após adição de $2 \mu \mathrm{g} / \mathrm{mL}$ do elemento e cada um dos atributos dos solos (Tabela 8), para depois ser apresentada a regressão múltipla.

Os valores de boro adsorvido não apresentaram correlações estatisticamente significativas com nenhum dos atributos químicos dos solos $(\mathrm{pH}$, carbono orgânico, cálcio, magnésio, potássio, alumínio, H + Al, CTC total, CTC efetiva, V\% e m\%), e os valores dos coeficientes de correlação aparecem na tabela 1 A do Apêndice 2. 
Tabela 8. Correlações entre boro adsorvido após adição de $2 \mu \mathrm{g} / \mathrm{mL}$ de boro e diversos atributos dos solos.

\begin{tabular}{ll}
\hline Atributo & Boro adsorvido \\
\hline Fe total & $0,40(\mathrm{~ns})$ \\
Al total & $0,71^{*}$ \\
Fe livre & $0,49(\mathrm{~ns})$ \\
Al livre & $0,27(\mathrm{~ns})$ \\
Fe mal cristalizado & $0,35(\mathrm{~ns})$ \\
Al mal cristalizado & $0,76^{* *}$ \\
Areia fina & $-0,73^{*}$ \\
Areia grossa & $-0,74^{*}$ \\
Areia total & $-0,73^{*}$ \\
Silte & $0,38(\mathrm{~ns})$ \\
Argila & $0,79^{* *}$ \\
Superficie específica & $0,73^{*}$ \\
\hline
\end{tabular}

* Significativo a $5 \%$ de probabilidade; ${ }^{* *}$ Significativo a $1 \%$ de probabilidade.

A correlação entre boro adsorvido e carbono orgânico não foi significativa. Embora se esperasse um aumento na adsorção de boro à medida que o teor de carbono fosse mais alto, ocorreu, na verdade, uma variação muito grande nos resultados. Assim sendo, para um teor de $\mathrm{C}=9,0 \mathrm{~g} / \mathrm{dm}^{3}$ (Tabela 2), a

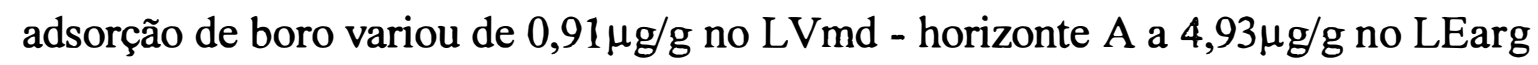
- horizonte B (Tabela 6). Da mesma forma, o PV - horizonte A e o LEmd horizonte A com calcário adsorveram quantidades semelhantes $(1,63 \mathrm{e} 1,80 \mu \mathrm{g} / \mathrm{g}$ de boro, respectivamente), apesar de o teor de carbono do segundo solo ser quase 
duas vezes maior do que o do primeiro $\left(9,0\right.$ versus $5,0 \mathrm{~g} / \mathrm{dm}^{3}$ de carbono orgânico, respectivamente).

A correlação entre boro adsorvido e óxido de alumínio mal cristalizado foi positiva e altamente significativa a $1 \%$ de probabilidade (Tabela 8). Para alumínio total, a correlação foi também positiva e significativa, variando somente o nível de significância (5\%). Em relação ao ferro total, livre e mal cristalizado, todas as correlações foram positivas, mas não significativas. Um dos motivos da não significância das correlações podem ter sido os maiores valores de boro adsorvido do LEarg (Tabela 6), em detrimento dos teores de ferro inferiores aos do LRarg (Tabela 3). Com isso, a distribuição dos resultados seguiu uma curva quadrática, com valores crescentes de boro adsorvido nos solos até aproximadamente $200 \mathrm{~g} / \mathrm{kg}$ de ferro total, $120 \mathrm{~g} / \mathrm{kg}$ de ferro livre e $2,5 \mathrm{~g} / \mathrm{kg}$ de ferro mal cristalizado.

As correlações entre boro adsorvido e teores de areia fina, areia grossa, areia total, argila e superfície específica foram altamente significativas, com coeficientes de correlação que variaram de $0,73^{*}$ a $0,79^{* *}$ (Tabela 8). A correlação com teor de silte foi positiva, mas não significativa, $\operatorname{com} r=0,38$.

$\mathrm{Na}$ análise de regressão múltipla, o boro adsorvido foi colocado no modelo em função de $\mathrm{pH}$, carbono orgânico, cátions trocáveis, $\mathrm{V} \%, \mathrm{~m} \%$, boro solúvel em $\mathrm{CaCl}_{2}$ a quente, óxidos de ferro e de alumínio nas diversas formas, teor de argila e superfície específica. A equação obtida foi:

$$
\text { Bads }=1,65-0,11 \mathrm{Al} \text { livre }-3,03 \mathrm{Bs}+8,23 \cdot 10^{-2} \text { argila }
$$

O resumo do procedimento estatístico adotado na regressão múltipla, assim como os valores parciais dos coeficientes de determinação e também o $\mathrm{r}^{2}$ acumulado no modelo aparecem no Apêndice 1. O teor de argila respondeu por $62 \%$ da variação dos valores de boro adsorvido. A inclusão do teor 
de alumínio livre no modelo fez o coeficiente de determinação aumentar para aproximadamente $88 \%$, enquanto que após ser adicionado o teor de boro solúvel o $r^{2}$ atingiu $93 \%$, ou seja, a variação nos teores de boro adsorvido pelos solos foi quase que totalmente explicada pelos teores de argila, alumínio livre e boro solúvel (equação 8). Como no caso da análise de regressão múltipla para boro solúvel, todas as demais variáveis não entraram no modelo, pois não atingiram os $15 \%$ de probabilidade exigidos pelo programa SAS.

\subsection{Energia livre do sistema $\left(\Delta \mathrm{G}_{\mathrm{o}}\right)$}

$\mathrm{Na}$ tabela 9 estão apresentados os valores de energia livre do sistema, obtidos a partir dos resultados da tabela 6 e da equação 2 .

Todos os valores de $\Delta \mathbf{G}_{\mathbf{0}}$ foram negativos, mostrando que a quantidade de boro em equilíbrio na solução após adição de boro e agitação por $24 \mathrm{~h}$ foi sempre inferior ao valor adicionado, ou seja, a reação de adsorção de boro foi termodinamicamente espontânea. Os maiores valores médios, em módulo, foram encontrados nos solos argilosos $(973,9 \mathrm{~J} / \mathrm{mol}$ para o LEarg e 480,3J/mol para o LRarg), como já era esperado, seguindo tendência observada na tabela 7.

O podzólico vermelho-amarelo, devido ao acréscimo no teor de argila em profundidade, teve uma $\Delta \mathbf{G}_{\mathbf{0}}$ média dos três horizontes de $423 \mathrm{~J} / \mathrm{mol}$, bastante próxima da média do LRarg. Nesses solos, o horizonte B é de extrema importância para estudos de reações entre íons e a superfície dos colóides, principalmente quando o gradiente textural ocorre a menos de $1,0 \mathrm{~m}$ de profundidade, que é uma região de intenso desenvolvimento das raízes de várias culturas de interesse econômico. Os latossolos de textura média tiveram os menores valores médios de energia livre (256J/mol para o LEmd e $218 \mathrm{~J} / \mathrm{mol}$ para 
Tabela 9. Valores de energia livre $\left(\Delta \mathrm{G}_{\mathrm{o}}\right)$ para adsorção de boro, em diferentes concentrações de equilíbrio do elemento.

\begin{tabular}{|c|c|c|c|c|c|c|}
\hline \multirow{2}{*}{\multicolumn{2}{|c|}{$\begin{array}{l}\text { Solo / } \\
\text { camada }\end{array}$}} & \multicolumn{5}{|c|}{ Boro adicionado $(\mu \mathrm{g} / \mathrm{mL})$} \\
\hline & & 1 & 2 & 4 & 8 & 16 \\
\hline \multirow[t]{3}{*}{ LRarg } & A & -647 & -506 & -359 & -313 & -250 \\
\hline & $\mathrm{A}^{*}$ & -679 & -583 & -453 & -380 & -269 \\
\hline & B & -847 & -662 & -529 & -420 & -302 \\
\hline \multirow[t]{3}{*}{$\mathrm{PV}$ are $/ \mathrm{md}$} & A & -521 & -446 & -274 & -176 & -111 \\
\hline & $\mathrm{A}^{*}$ & -614 & -552 & -337 & -250 & -150 \\
\hline & B & -1143 & -847 & -583 & -348 & -203 \\
\hline \multirow[t]{3}{*}{ LV md } & A & -344 & -233 & -179 & -114 & -69 \\
\hline & $\mathrm{A}^{*}$ & -431 & -344 & -233 & -133 & -94 \\
\hline & B & -402 & -288 & -193 & -124 & -85 \\
\hline \multirow[t]{3}{*}{ LE arg } & A & -1305 & -1065 & -630 & -424 & -262 \\
\hline & $A^{*}$ & -1975 & -1348 & -787 & -510 & -283 \\
\hline & B & -2329 & -1690 & -981 & -647 & -369 \\
\hline \multirow[t]{3}{*}{ LE md } & A & -344 & -274 & -166 & -104 & -69 \\
\hline & $\mathrm{A}^{*}$ & -552 & -487 & -295 & -199 & -120 \\
\hline & B & -402 & -344 & -240 & -173 & -98 \\
\hline
\end{tabular}

* = horizonte A com calcário 
o LVmd), um pouco menores do que a média do horizonte superficial do PV $(343 \mathrm{~J} / \mathrm{mol})$.

Em todos os casos, $\Delta \mathbf{G}_{\mathbf{0}}$ decresceu com o aumento na concentração de boro adicionado, indicando que quanto mais concentrada a solução, menos firmemente o elemento foi adsorvido, de maneira semelhante ao observado na tabela 7.

4.7. Modelos de Langmuir e de Freundlich

As constantes $\mathbf{K}$ e $\mathbf{b}$ de Langmuir e de Freundlich, obtidas a partir das equações 3 e 5 , e a capacidade tampão máxima (CTM), resultado do produto das constantes $\mathbf{K}$ e $\mathbf{b}$ de Langmuir, aparecem na tabela 10.

As maiores adsorções máximas estimadas, de acordo com o modelo de Langmuir (Admáx), foram dos solos de textura fina (LRarg e LEarg), variando de 9,3 a $15,8 \mu \mathrm{g} / \mathrm{g}$ de boro. Em seguida, ficou o horizonte B do podzólico, em torno de $7 \mu \mathrm{g} / \mathrm{g}$, e os latossolos de textura média e o horizonte superficial do PV, com menos de $6 \mu \mathrm{g} / \mathrm{g}$ de boro adsorvido (Tabela 10 ).

As adsorções máximas estimadas para o LRarg foram as mais altas (maiores de $13,7 \mu \mathrm{g} / \mathrm{g}$ ), confirmando a tendência observada na figura 9, de linearidade no aumento na adsorção de boro em função da adição de doses crescentes do elemento. Os menores valores foram do LVmd, com média de $2,6 \mu \mathrm{g} / \mathrm{g}$ de boro adsorvido.

Embora a adição de carbonato de cálcio tenha provocado aumentos nos teores de boro adsorvido em todos os solos (Tabela 7), as estimativas do modelo de Langmuir para adsorção máxima, após a aplicação do corretivo, somente foram maiores para o LEmd e para o PV, com $79 \%$ e $44 \%$ de aumento, respectivamente. No LEarg e no LVmd, os valores de Admáx foram praticamente 
Tabela 10. Constantes de Langmuir e de Freundlich, e capacidade tampão máxima (CTM) obtidas a partir dos resultados de adsorção de boro.

\begin{tabular}{|c|c|c|c|c|c|c|}
\hline \multirow{2}{*}{\multicolumn{2}{|c|}{$\begin{array}{c}\text { Solo / } \\
\text { camada }\end{array}$}} & \multicolumn{3}{|c|}{ Langmuir } & \multicolumn{2}{|c|}{ Freundlich } \\
\hline & & $\mathrm{K}$ & $\mathrm{b}$ & CTM** & $\mathrm{K}$ & $b$ \\
\hline & & $\mathrm{ml} / \mu \mathrm{g}$ & $\mu \mathrm{g} / \mathrm{g}$ & $\mathrm{ml} / \mathrm{g}$ & & \\
\hline \multirow[t]{3}{*}{ LR arg } & A & 0,0646 & 15,7854 & 1,0197 & 1,2418 & 0,6818 \\
\hline & $A^{*}$ & 0,1038 & 13,7535 & 1,4276 & 1,6494 & 0,6107 \\
\hline & B & 0,1115 & 14,9141 & 1,6629 & 1,9280 & 0,5941 \\
\hline \multirow[t]{3}{*}{$\mathrm{PV}$ are/md } & A & 0,3564 & 3,9946 & 1,4237 & 1,2519 & 0,3814 \\
\hline & $A^{*}$ & 0,2740 & 5,7617 & 1,5787 & 1,5400 & 0,4228 \\
\hline & B & 0,4815 & 7,0330 & 3,3864 & 2,6423 & 0,3342 \\
\hline \multirow[t]{3}{*}{ LV md } & A & 0,3177 & 2,5758 & 0,8183 & 0,4023 & 0,6656 \\
\hline & $A^{*}$ & 1,1653 & 2,4805 & 2,8905 & 0,9835 & 0,4066 \\
\hline & B & 0,3812 & 2,8293 & 1,0785 & 0,8433 & 0,4232 \\
\hline \multirow[t]{3}{*}{ LE arg } & A & 0,3634 & 9,2882 & 3,3753 & 2,9701 & 0,3789 \\
\hline & $A^{*}$ & 0,6116 & 9,3979 & 5,7478 & 3,9787 & 0,3026 \\
\hline & B & 0,5220 & 12,3454 & 6,4443 & 4,8401 & 0,3247 \\
\hline \multirow[t]{3}{*}{ LE md } & A & 0,3466 & 2,4691 & 0,8558 & 0,7745 & 0,3803 \\
\hline & $A^{*}$ & 0,3456 & 4,4140 & 1,5255 & 1,3786 & 0,3814 \\
\hline & B & 0,2775 & 3,8681 & 1,0734 & 1,0474 & 0,4158 \\
\hline
\end{tabular}

* Horizonte A com calcário; ** Capacidade tampão máxima = K (Langmuir) x b (Langmuir) 
iguais na camada superficial com e sem calcário, e no LRarg houve diminuição de aproximadamente $15 \%$ após a calagem. Nesse último solo, observou-se uma inclinação na curva de adsorção de boro no horizonte A com calcário, entre a adição de 8 e de $16 \mu \mathrm{g} / \mathrm{mL}$ (Figura 9), enquanto que na amostra sem calcário tal inclinação não apareceu, justificando assim um maior valor de Admáx.

A capacidade tampão máxima (CTM) do LEarg foi a mais alta dentre os solos. Como esse parâmetro envolve o efeito da constante $\mathbf{K}$ de afinidade, nota-se que a tendência dos resultados foi diferente da observada para a constante b (adsorção máxima). O LRarg, por exemplo, que teve os maiores valores de Admáx, apresentou valores relativamente baixos de CTM, enquanto que o LEarg, cujos valores de Admáx foram somente inferiores aos do LRarg, mostrou altos valores da constante $\mathbf{K}$ de Langmuir, resultando assim numa maior capacidade tampão máxima. Tendência semelhante foi encontrada para a constante $\mathbf{K}$ de Freundlich, já que os maiores valores foram do LEarg, seguido do LRarg e do PV, com valores semelhantes, tendo finalmente os latossolos de textura média, com resultados mais baixos.

4.7.1. Correlações entre constantes de Langmuir e de Freundlich e atributos dos solos

Os coeficientes de correlação simples entre atributos dos solos e as constantes de Langmuir e de Freundlich, assim como a CTM (capacidade tampão máxima) são apresentados na tabela 11. As correlações com os atributos da análise química de rotina não foram estatisticamente significativas e são apresentadas em separado na tabela $2 \mathrm{~A}$ do Apêndice 2.

A constante b de Freundlich não se correlacionou significativamente com nenhum dos atributos testados, e por isso os coeficientes dessas correlações 
Tabela 11. Coeficientes de correlação entre constantes dos modelos de Langmuir e de Freundlich e alguns atributos dos solos.

\begin{tabular}{|c|c|c|c|c|}
\hline \multirow[t]{2}{*}{ Atributo } & \multicolumn{3}{|c|}{ Langmuir } & \multirow{2}{*}{$\frac{\text { Freundlich }}{\mathrm{K}}$} \\
\hline & $\mathrm{K}$ & $\mathrm{b}$ & CTM*** & \\
\hline & \multicolumn{4}{|c|}{ Coeficiente de correlação } \\
\hline Areia fina & 0,27 & $-0,92 * *$ & $-0,56$ & $-0,68^{*}$ \\
\hline Areia grossa & 0,21 & $-0,92 * *$ & $-0,57$ & $-0,68^{*}$ \\
\hline Areia total & 0,17 & $-0,93 * *$ & $-0,56$ & $-0,68^{*}$ \\
\hline Silte & $-0,62$ & $0,95 * *$ & 0,16 & 0,31 \\
\hline Argila & $-0,16$ & $0,89 * *$ & $0,63 *$ & $0,74^{*}$ \\
\hline Superficie especifica & $-0,21$ & $0,86^{* *}$ & 0,55 & $0,68^{*}$ \\
\hline Ferro total & $-0,64^{*}$ & $0,96 * *$ & 0,19 & 0,34 \\
\hline Alumínio total & $-0,30$ & $0,94 * *$ & 0,52 & $0,65^{*}$ \\
\hline Ferro livre & $-0,55$ & $0,97 * *$ & 0,29 & 0,43 \\
\hline Alumínio livre & $-0,68^{*}$ & $0,88 * *$ & 0,08 & 0,21 \\
\hline Ferro mal cristalizado & $-0,66^{*}$ & $0,91 * *$ & 0,13 & 0,29 \\
\hline Alumínio mal cristalizado & 0,08 & $0,69 *$ & $0,73 *$ & $-0,35$ \\
\hline Carbono / argila & 0,21 & $-0,66 * *$ & $-0,41$ & $-0,54^{*}$ \\
\hline Fe total / argila & $-0,71^{*}$ & $0,78 * *$ & $-0,07$ & $0,83^{* *}$ \\
\hline Fe livre / argila & $-0,75^{*}$ & $0,87 * *$ & $-0,01$ & 0,14 \\
\hline Al livre / argila & $-0,30$ & $-0,46$ & $-0,71^{*}$ & $-0,74^{*}$ \\
\hline
\end{tabular}

* Significativo a $5 \%$ de probabilidade; ${ }^{* *}$ Significativo a $1 \%$ de probabilidade; ${ }^{* * *}$ Capacidade tampão máxima $=\mathrm{K}$ (Langmuir) $\mathrm{x} \mathrm{b}$ (Langmuir)

não serão citados. Fato semelhante ocorreu com os parâmetros $\mathrm{Al}_{\mathfrak{t}} /$ argila, $\mathrm{Al}_{\mathrm{d}} /$ argila, $\mathrm{Al}_{\mathrm{o}}$ /argila, $\mathrm{Fe}_{\mathrm{o}}$ /argila (valores das relações entre carbono e óxidos de ferro e de alumínio com o teor de argila são encontrados no Apêndice 2 - Tabela 
3A). Para esses parâmetros, que relacionam carbono e óxidos com a argila, serão citadas na tabela 11 apenas as correlações estatisticamente significativas, uma vez que a intenção é somente testar a hipótese de LAVERDIÈRE \& KARAM (1984), que consideram melhores as correlações entre as constantes dos modelos com as razões entre os atributos, do que com eles isoladamente.

Devido ao fato de a constante $\mathbf{b}$ de Langmuir, correspondente à estimativa da adsorção máxima (Admáx), ter o maior número de correlações significativas com os atributos do solo (Tabela 11), e também considerando-se a importância prática de seu estudo, será feita uma análise mais detalhada desse atributo em relação às outras constantes.

Valores bastante próximos de $\mathrm{pH}$ em $\mathrm{CaCl}_{2}$ 0,01M, como, por exemplo, do PV no horizonte A com e sem calcário (Tabela 2), tiveram adsorções máximas estimadas bem diferentes (Tabela 10). Além disso, esse solo, que teve os pHs mais altos de todas as amostras, apresentou valores de Admáx bem menores do que os do LRarg, cujos pHs eram quase uma unidade mais baixos.

Outros atributos que não tiveram correlação significativa com a adsorção máxima foram os teores de carbono e de cálcio. No LEmd, o teor de carbono não se alterou após a aplicação de calcário (Tabela 2); entretanto, a adsorção máxima aumentou de 2,5 para $4,4 \mu \mathrm{g} / \mathrm{g}$ (Tabela 10). Já no PV, o teor de carbono passou de 9 para $14 \mathrm{~g} / \mathrm{dm}^{3}$ após a aplicação de $\mathrm{CaCO}_{3}$, e a adsorção máxima caiu de 15,8 para $13,7 \mu \mathrm{g} / \mathrm{g}$. Para o cálcio, as variações foram maiores: no LVmd, o teor variou de 22 para $1 \mathrm{mmol}_{\mathcal{C}} \mathrm{kg}$ entre o horizonte A sem calcário e o

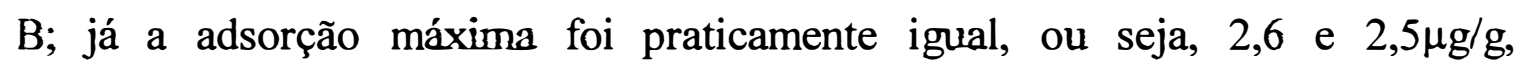
respectivamente.

As correlações simples entre a adsorção máxima e os atributos físicos dos solos foram estatisticamente significativas a $1 \%$ de probabilidade (Tabela 11), de maneira semelhante ao que ocorreu com esses atributos físicos e o 
boro adsorvido, diferindo apenas na correlação com teor de silte que, para adsorção máxima de boro, foi altamente significativa.

Os teores totais e livres de óxidos de ferro e de alumínio tiveram alta correlação positiva com Admáx, sendo maiores os valores para ferro. No caso dos óxidos mal cristalizados, o coeficiente de correlação manteve-se alto para ferro, mas foi menor para o alumínio, e significativo somente a $5 \%$.

A adsorção máxima correlacionou-se negativamente com o parâmetro carbono/argila. Os maiores valores de Admáx apareceram nos solos com teor alto de argila, que tiveram uma relação carbono/argila entre 0,01 e 0,02 (Tabelas 10 e 2A - Apêndice 2). Quando a relação foi maior do que 0,02, resultado dos teores mais baixos de argila, a adsorção máxima foi mais baixa. Tal resultado é coerente, uma vez que a adsorção máxima teve alta correlação positiva com argila, enquanto que com o teor de carbono não foi observada correlação.

As únicas correlações significativas entre Admáx e as relações entre óxidos/argila foram observadas para ferro total e ferro livre. Mesmo assim, os coeficientes foram mais baixos do que quando esses atributos foram correlacionados isoladamente com a adsorção máxima (Tabela 11).

Regressões múltiplas para adsorção máxima de boro e para a capacidade tampão máxima foram feitas em função de $\mathrm{pH}$, carbono orgânico, cátions trocáveis, $\mathrm{V} \%, \mathrm{~m} \%$, boro solúvel em $\mathrm{CaCl}_{2}$ a quente, óxidos de ferro e de alumínio, nas diversas formas, teor de argila e superfície específica. A equação obtida para adsorção máxima foi:

$$
\text { Admáx }=1,28+0,08 \text { Ca trocável }+0,07 \text { Fe livre }
$$

Para a capacidade tampão máxima, a regressão múltipla foi a seguinte: 
O resumo da análise de regressão múltipla, assim como os valores parciais dos coeficientes de determinação e também o $r^{2}$ acumulado no modelo aparecem no Apêndice 1. No caso da estimativa de adsorção máxima pelo modelo de Langmuir, o teor de óxido de ferro livre foi praticamente o único responsável pela variação nos valores da constante, uma vez que, na análise conjunta, apresentou um coeficiente de determinação igual a 94\%. O teor de cálcio trocável, que não teve correlação simples significativa com a adsorção máxima, entrou no modelo de regressão múltipla (equação 9), fazendo o $r^{2}$ subir para $96 \%$.

Para o parâmetro CTM (capacidade tampão máxima), foram cinco as variáveis aceitas na análise conjunta (equação 10). Entretanto, no resumo do procedimento estatístico (Apêndice 2) observa-se que as diversas formas de óxidos de alumínio explicaram $95 \%$ da variação nos valores de CTM. O modelo chegou a um coeficiente de determinação altíssimo $(0,998)$ com a inclusão do pH e do teor de óxido de ferro mal cristalizado.

4.7.2. Representação gráfica dos modelos de Langmuir e de Freundlich, e sua comparação com os valores obtidos em laboratório

As figuras 14, 15, 16, 17 e 18 mostram os valores de boro adsorvido aos solos, obtidos em laboratório, e as curvas obtidas a partir dos valores estimados pelos modelos de Langmuir e de Freundlich.

De maneira geral, os modelos descreveram bem a adsorção de boro nas amostras estudadas. Na menor dose de boro adicionado $(1 \mu \mathrm{g} / \mathrm{mL})$, o modelo de Freundlich estimou maiores valores de boro adsorvido que o de Langmuir em treze das quinze amostras, sendo inferiores somente no horizonte A (com e sem calcário) do Lvmd (Figura 16). 

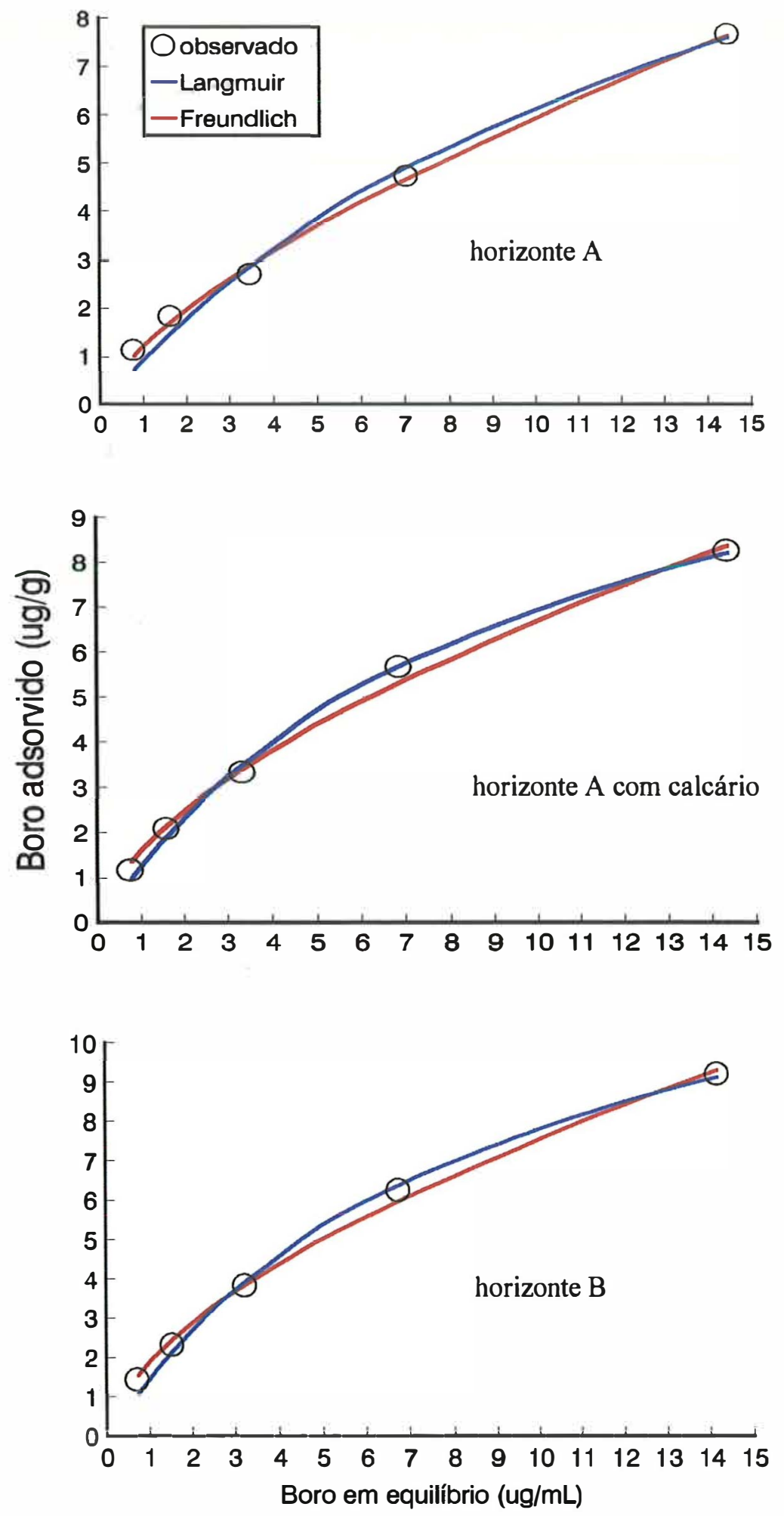

Figura 14. Adsorção de boro no LRarg e curvas obtidas a partir de valores estimados pelos modelos de Langmuir e de Freundlich. 

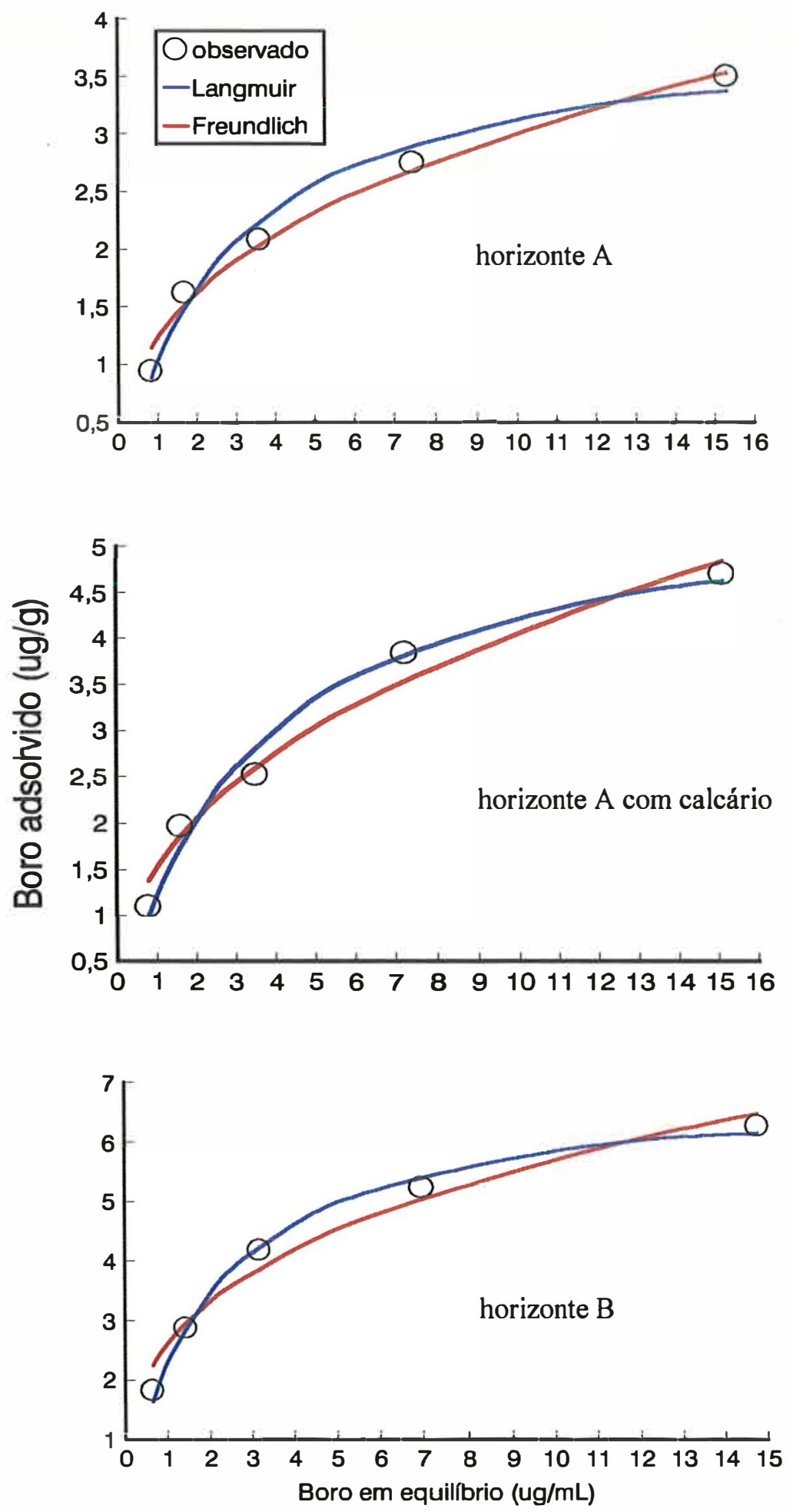

Figura 15. Adsorção de boro no PV e curvas obtidas a partir de valores estimados pelos modelos de Langmuir e de Freundlich. 

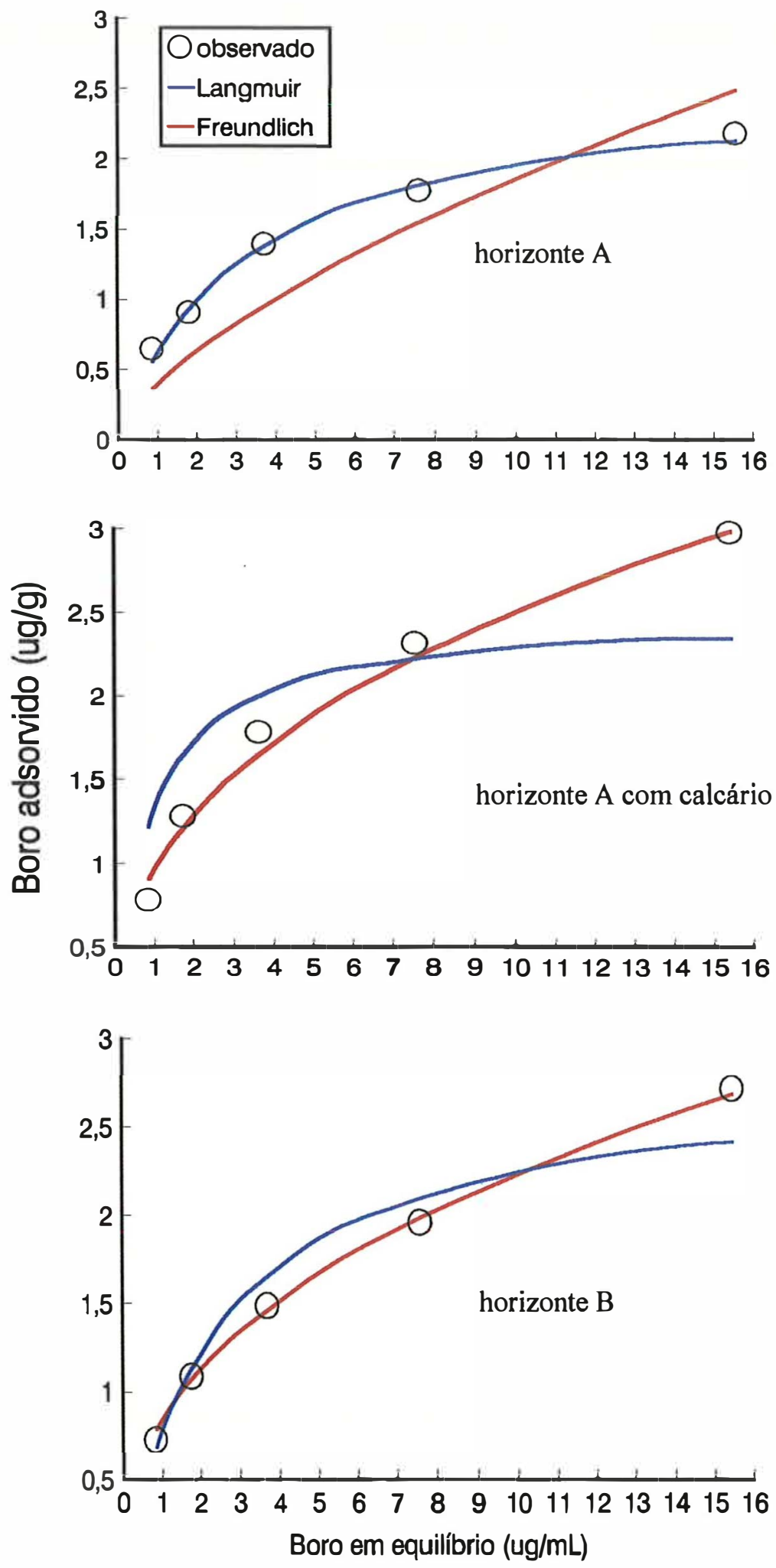

Figura 16. Adsorção de boro no LVmd e curvas obtidas a partir de valores estimados pelos modelos de Langmuir e de Freundlich. 

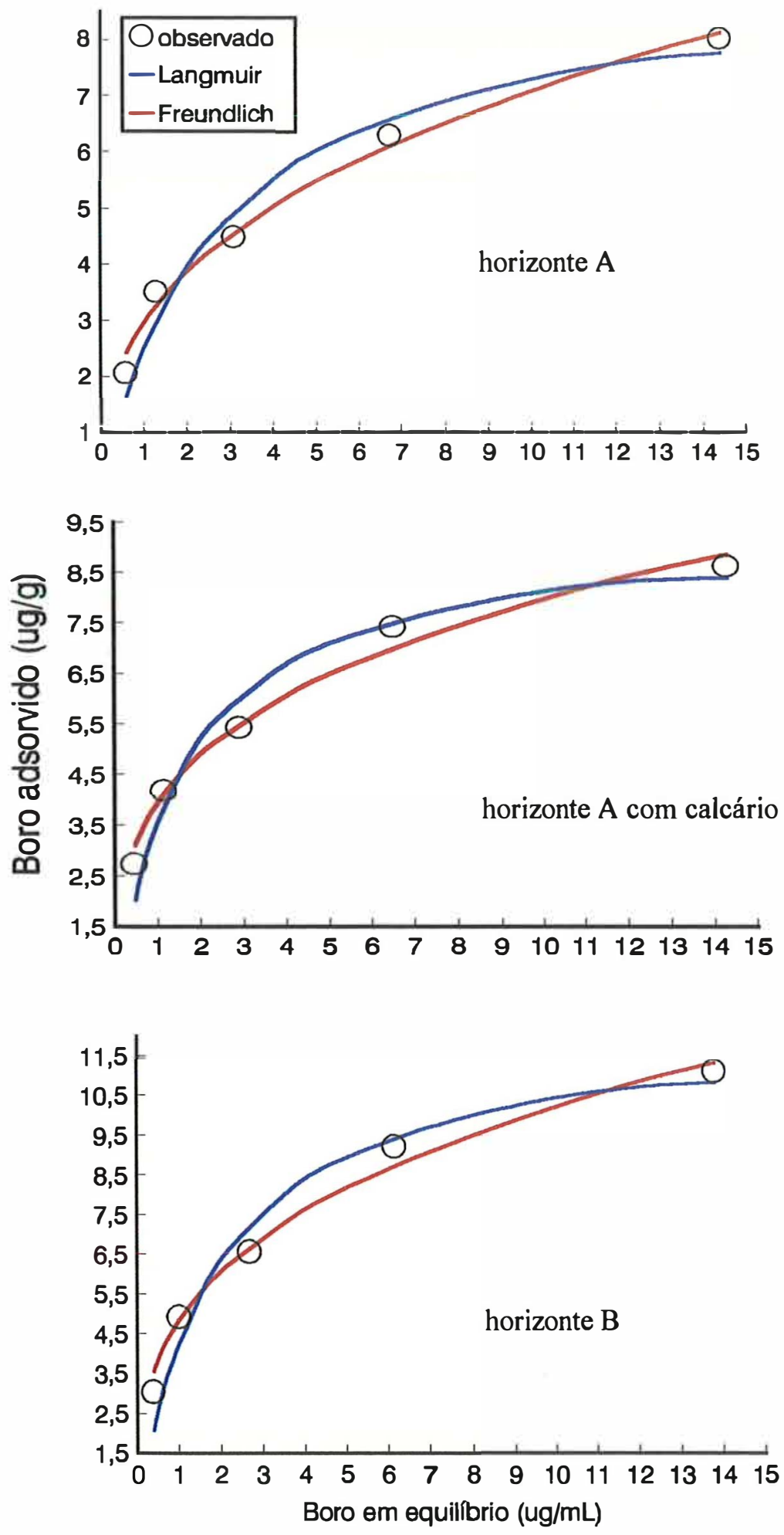

Figura 17. Adsorção de boro no LEarg e curvas obtidas a partir de valores estimados pelos modelos de Langmuir e de Freundlich. 

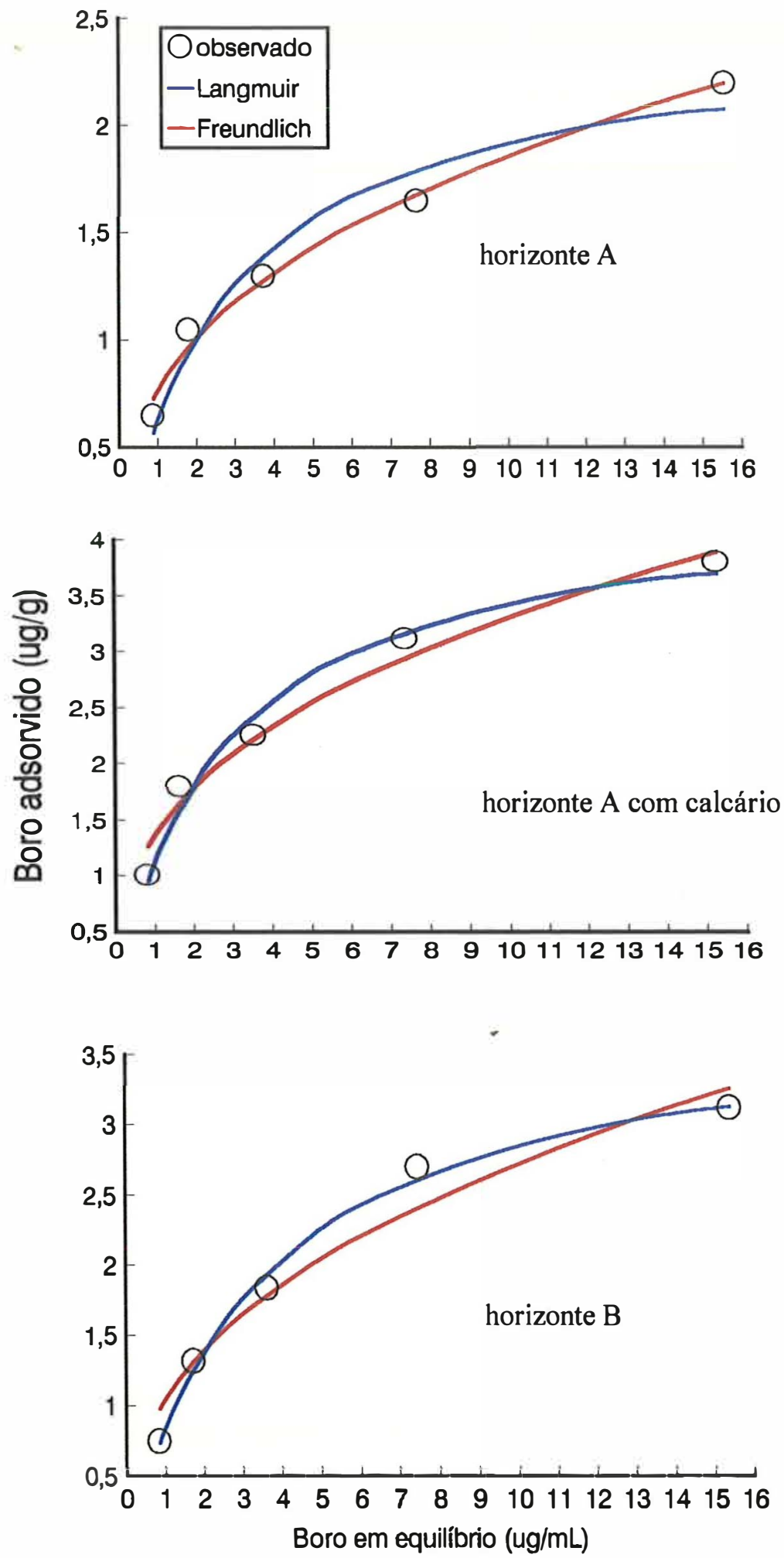

Figura 18. Adsorção de boro no LEmd e curvas obtidas a partir de valores estimados pelos modelos de Langmuir e de Freundlich. 
Nas doses intermediárias $(2,4$ e $8 \mu \mathrm{g} / \mathrm{mL})$ ocorreu o inverso, ou seja, o modelo de Langmuir estimou maiores quantidades de boro adsorvido do que o de Freundlich (a única exceção foi o horizonte A com calcário do LRarg) (Figura 14). Na maior dose de boro $(16 \mu \mathrm{g} / \mathrm{mL})$, o modelo de Freundlich voltou a estimar valores maiores de boro adsorvido.

$\mathrm{Na}$ tabela 12 aparecem as somas dos quadrados dos desvios (SQD) para cada horizonte dos cinco solos, nas cinco concentrações estudadas.

Tabela 12. Soma dos quadrados dos desvios entre os valores de adsorção de boro nos horizontes $\mathrm{A}, \mathrm{A}^{*}=\mathrm{A}$ com calcário e $\mathrm{B}$, obtidos após adição de cinco soluções com diferentes concentrações de boro $(\mathrm{L}=$ Langmuir e $\mathrm{F}=$ Freundlich).

\begin{tabular}{|c|c|c|c|c|c|c|c|c|c|c|c|c|c|}
\hline \multirow{2}{*}{\multicolumn{2}{|c|}{$\begin{array}{l}\text { Solo / } \\
\text { camada }\end{array}$}} & \multicolumn{2}{|c|}{$1 \mu \mathrm{g} / \mathrm{mL}$} & \multicolumn{2}{|c|}{$2 \mu \mathrm{g} / \mathrm{mL}$} & \multicolumn{2}{|c|}{$4 \mu \mathrm{g} / \mathrm{mL}$} & \multicolumn{2}{|c|}{$8 \mu \mathrm{g} / \mathrm{mL}$} & \multicolumn{2}{|c|}{$16 \mu \mathrm{g} / \mathrm{mL}$} & \multicolumn{2}{|c|}{$\Sigma$} \\
\hline & & $\mathrm{L}$ & $\mathrm{F}$ & $\mathrm{L}$ & $\mathrm{F}$ & $\mathrm{L}$ & $\mathrm{F}$ & $\mathrm{L}$ & $\mathrm{F}$ & $\mathrm{L}$ & $\mathrm{F}$ & $\mathrm{L}$ & $\mathrm{F}$ \\
\hline \multirow[t]{3}{*}{ LR arg } & A & 0,0361 & 0,0081 & 0,0016 & 0,0196 & 0,2809 & 0,2304 & 0,4096 & 0,1369 & 0,1225 & 0,2809 & 0,8507 & 0,6759 \\
\hline & $\mathrm{A}^{*}$ & 0,0121 & 0,2209 & 0,0676 & 0,1764 & 0,4624 & 0,2401 & 0,2916 & 0,0324 & 0,0841 & 0,4624 & 0,9178 & 1,1322 \\
\hline & B & 0,0016 & 0,2304 & 0,1521 & 0,3249 & 0,5776 & 0,2809 & 0,5929 & 0,1024 & 0,1225 & 0,4900 & 1,4467 & 1,4286 \\
\hline \multirow[t]{3}{*}{$\mathrm{PV}$ a/m } & A & 0,0100 & 0,0900 & 0,0009 & - & 0,0676 & 0,0004 & 0,0400 & 0,0001 & 0,0121 & 0,0049 & 0,1306 & 0,9540 \\
\hline & $\mathrm{A}^{*}$ & 0,0169 & 0,1849 & 0,0036 & 0,0064 & 0,2401 & 0,0529 & 0,0144 & 0,0256 & 0,0001 & 0,0484 & 0,2751 & 0,3182 \\
\hline & B & 0,2025 & 0,6400 & 0,3136 & 0,1849 & 0,1849 & 0,0009 & 0,1156 & 0,0001 & 0,0036 & 0,0900 & 0,8202 & 0,9159 \\
\hline \multirow[t]{3}{*}{ LV md } & A & 0,0009 & 0,0625 & 0,0081 & 0,0729 & 0,0016 & 0,1521 & 0,0049 & 0,0289 & 0,0016 & 0,1369 & 0,0171 & 0,4533 \\
\hline & $\mathrm{A}^{*}$ & 0,3025 & 0,0400 & 0,2025 & 0,0001 & 0,0625 & 0,0036 & 0,0064 & 0,0004 & 0,3969 & 0,0049 & 0,9708 & 0,0490 \\
\hline & B & 0,0025 & 0,0121 & 0,0169 & 0,0009 & 0,0484 & 0,0001 & 0,0289 & 0,0025 & 0,0841 & 0,0009 & 0,1808 & 0,0165 \\
\hline \multirow[t]{3}{*}{ LE arg } & A & 0,1600 & 0,8100 & 0,1521 & 0,1156 & 0,9801 & 0,2809 & 0,3481 & 0,0529 & 0,0225 & 0,2209 & 1,6628 & 1,4803 \\
\hline & $\mathrm{A}^{*}$ & 0,6889 & 1,5376 & 0,9801 & 0,5041 & 1,5625 & 0,3481 & 0,1600 & - & 0,0100 & 0,2401 & 3,4015 & 2,6299 \\
\hline & B & 1,3924 & 3,2041 & 1,9044 & 1,2321 & 3,1648 & 0,9409 & 0,5476 & 0,0361 & 0,0081 & 0,3969 & 7,0173 & 5,8101 \\
\hline \multirow[t]{3}{*}{ LE md } & A & 0,0004 & 0,0144 & 0,0016 & 0,0025 & 0,0169 & 0,0004 & 0,0256 & 0,0025 & 0,0121 & 0,0001 & 0,0566 & 0,0199 \\
\hline & $\mathrm{A}^{*}$ & 0,0144 & 0,1369 & - & - & 0,0900 & 0,0064 & 0,0169 & 0,0064 & 0,0049 & 0,0225 & 0,1262 & 0,1722 \\
\hline & B & 0,0036 & 0,0900 & 0,0044 & 0,0064 & 0,0225 & 0,0016 & 0,0049 & 0,0361 & 0,0001 & 0,0576 & 0,0355 & 0,1917 \\
\hline
\end{tabular}


Nos latossolos argilosos e no podzólico vermelho-amarelo, quase sempre a SQD do horizonte A sem calcário foi inferior à do mesmo horizonte com calcário, e este foi inferior ao valor do horizonte $\mathrm{B}$, tanto no modelo de Langmuir, como no de Freundlich. Nos latossolos de textura média, a tendência não se manteve, como pode ser observado na tabela 12.

Considerando-se o somatório dos valores de SQD (últimas colunas da tabela 12), os modelos apresentaram valores mais discrepantes de SQD no LVmd, enquanto que as menores diferenças ocorreram no LRarg. Os maiores valores absolutos (em torno de 3,2) apareceram no LEarg, no modelo de Freundlich, nas menores concentrações de boro adicionado (Tabela 12 e figura 17). No LEmd, para a concentração de $2 \mu \mathrm{g} / \mathrm{mL}$ de boro, os valores estimados pelos dois modelos foram iguais ao obtido em laboratório. Na tabela 13 estão resumidas as somas dos quadrados dos desvios por tipo de solo (considerando a soma das três camadas), em cada uma das concentrações de boro adicionado.

Tabela 13. Soma dos quadrados dos desvios por tipo de solo (considerando a soma das três camadas) após adição de cinco soluções com diferentes concentrações de boro $(\mathrm{L}=$ Langmuir e $\mathrm{F}=$ Freundlich $)$.

\begin{tabular}{cccccccccccccc}
\hline [B] & \multicolumn{2}{c}{ LR arg } & \multicolumn{2}{c}{ PV are/md } & \multicolumn{2}{c}{ LV md } & \multicolumn{2}{c}{ LE arg } & \multicolumn{2}{c}{ LE md } & \multicolumn{2}{c}{$\Sigma$} \\
$(\mu \mathrm{g} / \mathrm{mL})$ & $\mathrm{L}$ & $\mathrm{F}$ & $\mathrm{L}$ & $\mathrm{F}$ & $\mathrm{L}$ & $\mathrm{F}$ & $\mathrm{L}$ & $\mathrm{F}$ & $\mathrm{L}$ & $\mathrm{F}$ & $\mathrm{L}$ & $\mathrm{F}$ \\
\hline & & & & & & & & & & & & \\
1 & 0,0498 & 0,4594 & 0,2294 & 0,9149 & 0,3059 & 0,1146 & 2,2413 & 5,5517 & 0,0184 & 0,2413 & 2,8448 & 7,2819 \\
2 & 0,2213 & 0,5209 & 0,3181 & 0,1913 & 0,2275 & 0,0739 & 3,0366 & 1,8518 & 0,0020 & 0,0089 & 3,8055 & 2,6468 \\
4 & 1,3209 & 0,7514 & 0,4926 & 0,0542 & 0,1125 & 0,1558 & 5,7110 & 1,5699 & 0,1294 & 0,0084 & 7,7664 & 2,5397 \\
8 & 1,2941 & 0,2717 & 0,1700 & 0,0258 & 0,0402 & 0,0318 & 1,0557 & 0,0890 & 0,0474 & 0,0450 & 2,6074 & 0,4633 \\
16 & 0,3291 & 1,2333 & 0,0158 & 0,1433 & 0,4826 & 0,1427 & 0,0406 & 0,8579 & 0,0171 & 0,0802 & 0,8852 & 2,4574 \\
\hline$\Sigma$ & 3,2152 & 3,2367 & 1,2259 & 1,3295 & 1,1687 & 0,5188 & 12,0852 & 9,9203 & 0,2143 & 0,3838 & 17,9093 & 15,3891 \\
\hline
\end{tabular}


Analisando-se a última linha da tabela 13, em que estão os somatórios das SQDs de todos as camadas dos solos, nas cinco concentrações de boro, notam-se os maiores desvios nos latossolos argilosos. A seqüência observada foi LEarg > LRarg $>$ PV $>$ LVmd $>$ LEmd, seguindo de perto os decréscimos nos teores de argila.

O LEarg apresentou um somatório de desvios bem maior do que o dos demais solos, tanto no modelo de Langmuir, como no de Freundlich. Assim sendo, no caso dos valores estimados pelo modelo de Langmuir, o somatório foi igual a 12,0852, enquanto que a média dos demais solos foi 1,1648. Para o modelo de Freundlich, a diferença foi menor, apesar de ainda muito acentuada: 9,9203 para o LEarg, e 3,0778 na média dos outros quatro solos.

Embora a tendência de descrição do fenômeno de adsorção de boro pelos modelos fosse semelhante, algumas diferenças foram detectadas entre eles. O somatório das SQDs do LVmd e do LEarg foram maiores no modelo de Langmuir, enquanto que, para os demais solos, o somatório foi maior para os valores estimados pelo modelo de Freundlich (Tabela 13).

Diferentemente do que foi observado para os valores absolutos de $\mathrm{SQD}$, quando os maiores desvios foram obtidos nos solos de textura mais argilosa, as maiores diferenças dos somatórios de SQDs entre os modelos foram encontradas nos latossolos de textura média. No LVmd, a diferença foi de $125 \%$ (1,1687 para Langmuir e 0,5188 para Freundlich), e no LEmd ela foi 79\% maior para Freundlich $(0,3838 \times 0,2143)$. Estes contrastes acentuados entre os modelos podem também ser visualizados nas figuras 16 e 18. Nos demais solos, a diferença foi inferior a $25 \%$ entre os modelos.

A adequação dos modelos de Langmuir e de Freundlich aos valores obtidos em laboratório foi maior nas soluções mais concentradas em boro. Nas duas últimas colunas da tabela 13, observa-se que para Langmuir o menor somatório de SQD ocorreu com $16 \mu \mathrm{g} / \mathrm{mL}$ de boro adicionado. Para Freundlich, o 
menor somatório apareceu na concentração de $8 \mu \mathrm{g} / \mathrm{mL}$. O maior desvio no modelo de Langmuir $(7,7664)$ foi encontrado na concentração de $4 \mu \mathrm{g} / \mathrm{mL}$; nessa condição, o modelo superestimou os valores de boro adsorvido em todos os casos, com exceção do horizonte superficial sem calcário do LVmd. O maior desvio para Freundlich $(7,2819)$ apareceu na menor concentração de boro adicionado $(1 \mu \mathrm{g} / \mathrm{mL})$; analogamente ao modelo de Langmuir, os valores foram todos superestimados nessa concentração, exceção feita ao LVmd, horizonte A sem calcário (Figura 16). 


\section{DISCUSSÃO}

5.1. Boro solúvel em $\mathrm{CaCl}_{2} 0,01 \mathrm{~mol} / \mathrm{L}$ a quente

\subsubsection{Teores}

As médias dos teores de boro solúvel em $\mathrm{CaCl}_{2} \quad 0,01 \mathrm{~mol} / \mathrm{L}$ a quente dos horizontes superficiais e subsuperficiais dos solos foram semelhantes $(0,29 \mathrm{e}$ $0,26 \mathrm{mg} / \mathrm{dm}^{3}$, respectivamente). Entretanto, a amplitude de variação no horizonte A foi maior (de 0,07 a $0,61 \mathrm{mg} / \mathrm{dm}^{3}$ ) do que no horizonte $\mathrm{B}$, onde os teores variaram de 0,17 a $0,37 \mathrm{mg} / \mathrm{dm}^{3}$ (Tabela 3 ).

Seguindo critério de RUY (1986), para extração de boro com água quente e produção de matéria seca de girassol, os teores de boro solúvel encontrados neste trabalho foram médios para o horizonte $\mathrm{B}$ do $\mathrm{PV}$ e para o LRarg, nas duas profundidades. O teor foi alto no horizonte A do LEarg e baixo para todas as outras amostras.

Apesar de não serem utilizados os mesmos extratores para obtenção do boro solúvel, pode-se considerar que os valores deste trabalho estão dentro da faixa citada na literatura (SINGH \& SINHA, 1976; ELRASHIDI \& O'CONNOR, 1982; PARKER \& GARDNER, 1982; HADDAD \& KOLDOR, 1984; CORREA et al., 1985; JIN et al., 1987; JIN et al., 1988), e apresentam-se dentro dos limites encontrados em solos paulistas (BRASIL SOBRINHO, 1965).

Dentre as amostras estudadas, o menor valor foi do PV no horizonte A, possivelmente devido ao baixo teor de argila do solo (Tabela 4). Pequenas 
quantidades de boro extraído, principalmente na camada superficial de solos de textura arenosa, podem ser atribuídas, em parte, às maiores perdas do elemento por lixiviação (WILSON et al., 1951; CASAGRANDE, 1978). Depreende-se, daí, que a quantidade de boro que é lixiviada do horizonte A para o horizonte B textural dos solos podzolizados deve ser linearmente correlacionada com os índices pluviométricos do local onde se encontram os solos ou com a quantidade de água aplicada via irrigação, como observado por PINYERD et al. (1984) num estudo realizado em colunas.

Diversos trabalhos apresentam resultados semelhantes aos desse trabalho: em solos de textura média, SHUMWAY \& JONES (1972) constataram teores de boro solúvel em água quente inferiores a $1,0 \mathrm{mg} / \mathrm{dm}^{3}$. Solos arenosos da Índia, com teores de argila que variaram de 36 a $71 \mathrm{~g} / \mathrm{kg}$, apresentaram apenas traços de boro solúvel em água quente (SINGH \& SINHA, 1976), enquanto que valores de boro solúvel abaixo de $0,14 \mathrm{mg} / \mathrm{dm}^{3}$ foram encontrados em quatro ultissolos e um entissolo do leste americano (JIN et al., 1988).

Em relação ao maior valor observado $\left(0,61 \mathrm{mg} / \mathrm{dm}^{3}\right.$, para o horizonte superficial do LEarg), é importante salientar que essa amostra contém $720 \mathrm{~g} / \mathrm{kg}$ de argila (Tabela 4) e possui o maior teor de carbono ( $13 \mathrm{~g} / \mathrm{kg}$ ). Como conseqüência, a quantidade de boro extraído com $\mathrm{CaCl}_{2}$ a quente foi bem superior às das demais amostras, já que essas últimas apresentavam ou alto teor de carbono, ou alto teor de argila, mas sem a combinação de valores elevados para ambas as propriedades, como foi encontrado no horizonte A do LEarg. Esse teor de boro solúvel está próximo ao obtido por CORREA et al. (1985), que também estudaram um latossolo vermelho-escuro argiloso do Paraná. Tem-se observado, com freqüência, valores bem mais altos de boro solúvel em solos argilosos, tais como do nordeste brasileiro (HOROWITZ \& DANTAS, 1973), e dos Estados Unidos (PARKER \& GARDNER, 1982; JIN et al., 1987). 
A variação encontrada nos teores de boro solúvel nos solos utilizados nesse trabalho pareceu estar ligada ao material de origem. Houve uma distinção entre solos arenosos, ricos em sedimentos finos de quartzo originados da Formação Bauru e deficientes em boro, e solos derivados de basalto, não deficientes. Assim, os maiores valores foram dos horizontes superficiais do LRarg e do LEarg. Essas amostras, e mais a do horizonte subsuperficial do PV, apresentaram teores de boro solúvel em $\mathrm{CaCl}_{2}$ a quente superiores a $0,34 \mathrm{mg} / \mathrm{dm}^{3}$, limite considerado crítico por HADDAD \& KALDOR (1982), para dividir os solos em deficientes e não deficientes em boro. Seguindo este critério, as amostras dos três solos de textura arenosa ou média (PV, LVmd e LEmd) seriam consideradas deficientes no elemento.

\subsubsection{Boro solúvel $\mathrm{x}$ atributos químicos dos solos}

\subsubsection{Boro solúvel x pH}

Embora uma primeira análise das tabelas 2 e 3 mostre teores mais altos de boro solúvel em pHs mais altos, as amostras superficiais do PV e do LEarg apresentaram tendência discrepante, uma vez que os teores do elemento foram altos, em relação aos demais, e os pHs foram baixos. Devido a isso, e também à dispersão dos resultados apontada no ítem 4.4., as correlações simples entre boro solúvel e $\mathrm{pH}$ não foram estatisticamente significativas. Os valores de $\mathrm{pH}$ em $\mathrm{CaCl}_{2}$ 0,01mol/L variaram de 3,2 a 5,3, e nessa faixa de reação ácida o pH exerce pouco influência no teor de boro solúvel (CASAGRANDE, 1978; ELRASHIDI \& O'CONNOR, 1982). Numa faixa mais ampla de $\mathrm{pH}$ de solos paulistas, também não foi obtida correlação significativa entre essas propriedades (BRASIL SOBRINHO (1965). 
Os baixos coeficientes de correlação encontrados neste trabalho (de $-0,20$ a $-0,30$ ) confirmam os resultados de GUPTA (1968), que observou um $\mathbf{r}$ igual a 0,10 , estudando solos com pHs com reação levemente alcalina. Segundo hipótese do autor, mesmo num $\mathrm{pH}$ relativamente alto, uma parcela do boro retido deve permanecer numa forma disponível e, assim, não se correlacionar com o pH do solo. Raciocínio semelhante é válido para o trabalho de ELSEEWI \& ELMALKY (1979), que não observaram correlação significativa entre o teor de boro solúvel em água quente e $\mathrm{pH}$ de vinte e seis solos egípcios alcalinos $(\mathrm{pH}$ variando de 7,5 a 8,1$)$.

Uma das dúvidas que poderia haver com relação ao resultado deste trabalho seria a baixa quantidade de dados (10 amostras), que poderia tornar o estudo pouco abrangente, dificultando a possibilidade de significância entre boro solúvel e pH. Entretanto, em duzentas amostras de terra, oriundas de diversos solos indianos, também não se observou significância na correlação entre elas (SINGH \& SINHA, 1976).

Uma das possíveis causas da correlação não significativa pode ter sido o agrupamento de resultados advindos de camadas de solo de diferentes profundidades, fazendo com que a variação nos teores de carbono e de argila preponderassem sobre o pH (BRASIL SOBRINHO, 1965). Entretanto, tal argumento parece não ser válido, já que GUPTA (1978) estudou apenas amostras superficiais (até $0,15 \mathrm{~m}$ ) de quinze solos canadenses cultivados, e não obteve coeficiente de correlação significativo, corroborando a discussão até aqui apresentada.

\subsubsection{Boro solúvel $x$ carbono orgânico}

A correlação entre boro solúvel e carbono orgânico será discutida somente para os latossolos, uma vez que o gradiente textural do PV (Tabela 4) 
mascarou o resultado, tornando a correlação não significativa, quando considerados todos os solos.

O coeficiente de correlação para os latossolos foi 0,75 - significativo a 5\% de probabilidade (Tabela 5) - indicando maiores teores de boro solúvel em solos com teores mais altos de carbono orgânico. BRASIL SOBRINHO (1965) obteve um coeficiente um pouco menor $\left(0,51^{* *}\right)$ para vinte e nove amostras de solos paulistas. Outros autores obtiveram coeficientes de correlação positivos mais altos, tais como CASAGRANDE (1978), com $r=0,83^{* *}$, GUPTA (1978), $\mathrm{r}=0,93^{* *}$, ELRASHIDI \& O' CONNOR (1982) - $\mathrm{r}=0,80^{* *}$ e ADAMS et al. (1991) $-\mathrm{r}=0,94^{* *}$.

Um solo com alto teor de carbono orgânico pode suprir as plantas em boro durante um período de tempo relativamente longo, enquanto que outro solo, com baixo teor de carbono deverá ter aportes constantes de boro para ser considerado bem manejado. PARKER \& GARDNER (1982) confirmaram essa hipótese, uma vez que observaram, em solos com alto teor de carbono orgânico, uma baixa taxa de recuperação de boro adicionado em colunas, enquanto que solos arenosos, com baixo teor de carbono, apresentaram alta taxa de recuperação do elemento. Isso comprova que grande parte do boro do solo encontra-se intimamente ligada à matéria orgânica, o que justifica a correlação positiva encontrada nesse trabalho.

* Diante do que foi exposto, pode-se supor que a aplicação de estercos, compostos ou a adoção de práticas de manejo que visem o aumento no teor de matéria orgânica devam diminuir a quantidade de boro disponível às plantas. Entretanto, produtos oriundos da decomposição da matéria orgânica podem cobrir superficies ativas de óxidos de ferro, alumínio e manganês, e assim reduzir a capacidade adsortiva destes compostos, resultando numa maior disponibilidade do boro (MANDAL et al., 1993). 


\subsubsection{Boro solúvel $\mathrm{x}$ cátions trocáveis}

As correlações simples não significativas entre boro solúvel e cátions trocáveis eram esperadas e estão de acordo com os resultados encontrados na literatura. SINGH \& SINHA (1976) obtiveram os seguintes coeficientes de correlação para potássio, cálcio e magnésio: 0,04; 0,05 e 0,04 - respectivamente e explicaram que a possível causa foi a falta de significância por eles observada nas correlações entre boro e pH, carbono orgânico e textura.

A correlação entre os teores de boro e a CTC total obtida neste trabalho foi positiva, e confirma resultados de ELRASHIDI \& O'CONNOR (1982). Como a CTC total engloba também o hidrogênio ligado de forma covalente à superfície dos colóides, cujas cargas estão intimamente ligadas ao teor de argila, e a correlação não foi significativa para CTC efetiva, que corresponde à soma dos cátions trocáveis ao $\mathrm{pH}$ do solo, é de se supor que a significância foi mais devida a fenômenos de superfície do que à presença dos cátions que compõem a CTC. Esta hipótese parece viável, uma vez que os valores referentes à diferença entre CTC total e CTC efetiva foram positivamente correlacionados com boro solúvel em $\mathrm{CaCl}_{2}$, com coeficiente de correlação igual a 0,64 , significativo a $5 \%$ de probabilidade.

\subsubsection{Boro solúvel $\mathrm{x}$ óxidos}

A tabela 5 mostrou que os teores de boro solúvel foram positivamente correlacionados com o teor total de óxido de alumínio. A literatura é bastante escassa na quantidade de trabalhos relacionados a estas duas propriedades, já que a maioria deles baseia-se em estudos do efeito dos óxidos na adsorção do elemento aos solos. 
$\mathrm{O}$ coeficiente de correlação entre boro solúvel e $\mathrm{Al}_{2} \mathrm{O}_{3}$ foi mais alto do que o coeficiente entre boro solúvel e $\mathrm{Fe}_{2} \mathrm{O}_{3}$. SIMS \& BINGHAM (1968) também notaram maior afinidade entre o boro e compostos recobertos por hidróxidos de alumínio do que por hidróxidos de ferro. Em vista das similaridades químicas e estruturais entre as bordas das partículas de argila e hidróxidos de $\mathrm{Al}$, a adsorção de boro nestas duas superfícies foram comparadas, notando-se marcante superioridade na afinidade dos hidróxidos de alumínio por boro, o que talvez explique a maior correlação entre teores de boro e de óxido de $\mathrm{Al}$ (KEREN \& GAST, 1983). Em relação às demais correlações, PARKER \& GARDNER (1982) também não obtiveram correlação significativa com óxido de ferro mal cristalizado, embora ela fosse significativa para os óxidos livres.

\subsubsection{Boro solúvel $\mathrm{x}$ atributos físicos dos solos}

* Os teores de areia e de argila dos solos correlacionaram-se significativamente com seus teores de boro solúvel, conseqüência dos teores mais baixos de boro em solos de textura arenosa do que em solos de textura mais argilosa (BRASIL SOBRINHO, 1965; GUPTA, 1968; PINYERD et al., 1984), reforçando a sugestão de WEAR \& PETERSON (1962), de se utilizar a análise granulométrica para avaliar a disponibilidade de boro às plantas. Num trabalho que envolveu grande número de solos, essa hipótese foi validada, pois verificouse uma média de $1,05 \mathrm{mg} / \mathrm{dm}^{3}$ de boro solúvel em solos arenosos e $2,75 \mathrm{mg} / \mathrm{dm}^{3}$ nos argilosos (GUPTA, 1968).

Para solos brasileiros, CASAGRANDE (1978) encontrou correlação positiva entre o teor de argila e boro solúvel em água quente, com $r=0,51^{*}$. HOROWITZ \& DANTAS (1973) também observaram tendência de acúmulo de boro nos horizontes mais argilosos de solos pernambucanos. 
Nos trabalhos em que o $\mathrm{CaCl}_{2}$ foi utilizado como extrator do boro solúvel, os resultados obtidos foram semelhantes aos encontrados neste trabalho. Assim, GUPTA (1978) obteve um alto coeficiente de correlação entre boro solúvel em solução de $\mathrm{CaCl}_{2}$ a quente e teor de argila $\left(0,94^{* *}\right)$, fato também observado por ADAMS et al. (1991), usando o mesmo extrator. É interessante ressaltar que, em ambos os trabalhos, foi também utilizada a extração com água quente, sendo que os valores de boro extraído foram mais altos do que aqueles obtidos após extração com solução de cloreto de cálcio. Entretanto, o contrário ocorreu para os coeficientes de correlação com boro solúvel, confirmando a hipótese de que a água quente extrai parte do boro adsorvido aos colóides do solo (OLSON \& BERGER, 1946). Como os autores afirmam que o $\mathrm{CaCl}_{2}$ 0,01 mol/L mostra melhor correlação com teores de boro na planta e sua produção, parece mais importante ainda o efeito da granulometria na disponibilidade de boro às culturas, já que os coeficientes de correlação são, freqüentemente, mais altos.

Embora a grande maioria dos trabalhos aponte para uma correlação positiva entre boro solúvel e os separados do solo, SINGH \& SINHA (1976) não obtiveram correlação significativa entre boro solúvel e teor de argila de mais de duzentas amostras de solos indianos. Nesse estudo, os autores observaram um coeficiente de correlação igual a 0,04 - embora citem que a média dos teores para cada classe de textura avaliada (areia-franca, franco-arenosa, franco-siltosa, franco-argilosa e argila siltosa) aumentou com o grau de finura do material, apesar de as diferenças não terem sido significativas. Em outro estudo semelhante, observou-se um alto coeficiente de correlação positivo $\left(0,75^{* *}\right)$ somente quando se considerou o teor de argila, isoladamente (PARKER \& GARDNER, 1982).

No presente estudo, o efeito mais destacado do teor de argila foi observado no PV, visto que o gradiente textural foi acentuado (Tabela 4), e o teor de boro solúvel aumentou em profundidade, enquanto que os teores de carbono 
orgânico nos horizontes A e B foram praticamente iguais (Tabela 2). Nos demais solos, parece ter havido mais efeito do carbono orgânico do que da textura, já que em três dos latossolos (LRarg, LVmd e LEarg) o boro solúvel foi menor no horizonte subsuperficial, acompanhando um decréscimo nos teores de carbono (Tabelas 2 e 3), uma vez que os teores de argila foram praticamente iguais nas duas profundidades (Tabela 4).

\subsubsection{Análise de regressão múltipla}

A análise conjunta do efeito das dezessete variáveis citadas no ítem 4.4. mostrou que os teores de óxidos de alumínio totais, juntamente com os teores de cálcio e alumínio trocáveis, explicaram $85 \%$ da variação nos teores de boro solúvel. Em relação ao alumínio total, que apresentou o mais alto coeficiente de determinação $\left(r^{2}=0,49\right)$, a tendência foi a mesma da correlação simples, em que o efeito foi positivo significativo a $5 \%$ (Tabela 5). No caso dos cátions trocáveis, entretanto, ocorreu o contrário, pois os coeficientes de correlação simples foram muito baixos e não significativos, enquanto que na análise conjunta cálcio e alumínio representaram aproximadamente $37 \%$ da variação de boro solúvel (Apêndice 1).

Embora se reconheça a importância das análises de regressão múltipla, principalmente em fenômenos nos quais estão envolvidas variáveis interdependentes, é pequeno o número de trabalhos na literatura que exploram essa ferramenta estatística. Mesmo nesses casos, a comparação dos resultados com os obtidos neste trabalho fica dificultada, pois a equação apresentada pelo modelo é válida somente para as condições em que o ensaio foi conduzido, sendo temerosa qualquer conclusão que extrapole os limites do experimento em questão.

A maioria dos trabalhos mostra efeito significativo do $\mathrm{pH}$ e do carbono orgânico no boro extraído com água quente ou com solução centimolar 
de cloreto de cálcio. MILJKOVIC et al. (1966), por exemplo, contabilizaram para a matéria orgânica $69 \%$ da variabilidade do teor de boro solúvel em água quente de trinta e três amostras de solos egípcios, a várias profundidades. RUIZ-NETO et al. (1988) obtiveram efeito semelhante do teor de matéria orgânica $(63 \%)$ e concluíram que a fração orgânica das noventa amostras de solos espanhóis teve efeito mais significativo no teor de boro solúvel do que a fração inorgânica.

O teor de argila aparece na análise conjunta de RUIZ-NETO et al. (1988), enquanto que ELRASHIDI \& O'CONNOR (1982) contabilizam também o efeito dos óxidos, de maneira semelhante ao ocorrido nesse trabalho. Para ELRASHIDI \& O'CONNOR (1982), nenhuma das correlações simples com óxidos foi significativa, embora, na análise conjunta, ambos os teores totais de óxidos, mais o teor de carbono orgânico, respondessem por $98 \%$ da variação no teor de boro solúvel.

Os teores de carbono orgânico e de argila não entraram no modelo de regressão múltipla, muito embora as correlações simples com esses duas propriedades tenham sido significativas. Com objetivo de se agruparem os efeitos do carbono e do teor de argila, foi calculado o parâmetro carbono x argila, resultado da multiplicação dessas duas propriedades do solo. $\mathrm{O}$ artifício de relacionar atributos, através de multiplicações, divisões, somas e subtrações é muito comum, principalmente quando esses novos parâmetros criados entram na análise conjunta. MILJKOVIC et al. (1966) testou os produtos de carbono orgânico com pH e com teor de argila, conseguindo aumento no coeficiente de determinação obtido na equação do modelo de regressão.

No presente estudo, a correlação simples entre o produto carbono $\mathrm{x}$ argila e os teores de boro solúvel foi altamente significativa a $1 \%$ de probabilidade, com um coeficiente igual a 0,78. Um exemplo da boa correspondência entre esses dois atributos é que o maior valor de boro solúvel $\left(0,61 \mathrm{mg} / \mathrm{dm}^{3}\right)$ foi encontrado na amostra com maior valor de carbono $\mathrm{x}$ argila 
(9360, para o horizonte A do LEarg). Analogamente, para o horizonte superficial do $\mathrm{PV}$, foram observados os menores valores de boro solúvel $\left(0,07 \mathrm{mg} / \mathrm{dm}^{3}\right)$ e de carbono $\mathrm{x}$ argila (300). Entretanto, quando esse parâmetro foi incluído na análise conjunta, o coeficiente de determinação total do modelo foi igual a 0,78 , muito embora o produto carbono $\mathrm{x}$ argila explicasse $61 \%$ da variação dos teores de boro solúvel. Como o valor de $\mathrm{r}^{2}$ obtido no modelo de regressão múltipla sem a variável carbono $\mathrm{x}$ argila foi mais alto $(0,85)$, optou-se pela escolha desse último, em que entraram os teores totais de óxido de alumínio e os teores trocáveis de cálcio e alumínio.

\subsection{Boro adsorvido}

\subsubsection{Quantidade adsorvida}

- Como pode ser observado na tabela 6, os valores de boro adsorvido na camada subsuperficial foram mais altos do que no horizonte $\mathrm{A}$, coincidindo com resultados obtidos em dois latossolos argilosos e um podzólico vermelhoamarelo, de Piracicaba, SP (CATANI et al., 1971), entissolos, alfissolos e vertissolos americanos (GOLDBERG \& GLAUBIG, 1986a) e vinte e nove solos canadenses (NICHOLAICHUK et al., 1988). Apesar de a maioria dos trabalhos utilizarem concentrações máximas de boro adicionado bem maiores do que a utilizada neste trabalho, chegando até a $200 \mu \mathrm{g} / \mathrm{mL}$, a ordem de grandeza dos valores de boro adsorvido esteve próxima, se consideradas concentrações semelhantes da solução de boro em equilíbrio.

A quantidade de boro adsorvido, após adição de $2 \mu \mathrm{g} / \mathrm{mL}$ do elemento, foi maior nos solos argilosos, diminuindo bastante nas amostras arenosas e de textura média (Tabela 6). CORREA et al. (1985) utilizaram 
soluções com concentrações em boro iguais às deste trabalho, e mais a de $0,5 \mu \mathrm{g} / \mathrm{mL}$, obtendo maiores valores de boro adsorvido no latossolo roxo argiloso do que no latossolo vermelho-escuro arenoso. Em outro trabalho realizado com solos brasileiros, adicionaram-se até $80 \mu \mathrm{g} / \mathrm{mL}$ de boro a três solos de Piracicaba, tendo-se variado também o $\mathrm{pH}$ dos mesmos. $\mathrm{Na}$ faixa de $\mathrm{pH}$ próxima à dos solos deste trabalho, os valores de boro adsorvido foram semelhantes e também ligados às suas texturas (CATANI et al., 1971).

A adsorção de boro pelos solos foi maior nas maiores concentrações de boro adicionado, mas a porcentagem de boro adsorvido decresceu com o aumento da concentração do elemento em solução, igualmente ao que ocorreu com outros estudos (SNGH, 1971; CATANI et al., 1971; CORREA et al., 1985); KEREN \& GAST 1981; GU \& LOWE, 1990; GOLDBERG \& FORSTER, 1991). Somente no trabalho de CRUZ et al. (1987) foi observado um aumento na porcentagem de boro adsorvido com o aumento na concentração de boro adicionado, que variou de $15 \mathrm{a} 75 \mu \mathrm{g} / \mathrm{mL}$.

\subsubsection{Correlações entre boro adsorvido e atributos químicos dos solos}

\subsubsection{Boro adsorvido $\mathrm{xpH}$}

Não foi observada correlação significativa entre boro adsorvido e pH em nenhuma das concentrações de boro adicionado (Tabela 1A - Apêndice 2). Um dos motivos pode ser o fato de que a retenção de boro em solos tem um valor máximo entre os pHs 7,5 e 8,5 (HNGSTON, 1964; SIMS \& BINGHAM, 1968b; KLUGE \& BEER, 1979), que são valores bem mais altos do que os das amostras utilizadas nesse trabalho. Uma tendência geral encontrada na literatura, e confirmada no presente estudo, é que o efeito isolado do $\mathrm{pH}$ do solo na retenção 
de boro parece ser relativamente pequeno em solos ácidos. HARADA \& TAMAI (1968) estudaram solos japoneses de diferentes formações geológicas, com pH variando de 4,4 a 7,0 e também não obtiveram correlação com boro adsorvido.

A correlação não significativa do boro adsorvido com o $\mathrm{pH}$, na faixa de reação ácida, pode ser devida ao fato de que o elemento está predominantemente na forma de ácido bórico e não na forma de $\mathrm{H}_{4} \mathrm{BO}_{4}{ }^{-}$ (BINGHAM et al., 1971). Ao pH 6,8 - por exemplo - esta forma iônica responde por apenas $0,4 \%$ do total das formas solúveis de boro (EVANS, 1987). Entretanto, a adsorção de boro pode ocorrer sob condições ácidas. Nesse caso, o fenômeno parece ser resultado da adsorção molecular do ácido, como comprovado por SCHALSCHA et al. (1973), que observaram retas praticamente paralelas de retenção do $\mathrm{H}_{3} \mathrm{BO}_{3}$ em solos chilenos derivados de cinzas vulcânicas, com pHs variando de 4,0 a 7,0.

Mesmo trabalhando com pHs na faixa neutra (de 6,0 a 8,0), ELRASHIDI \& O'CONNOR (1982) obtiveram um $\mathbf{r}$ não significativo e bastante pequeno $(0,07)$ para solos americanos com mineralogias semelhantes, enquanto que GU \& LOWE (1990) notaram que a adsorção de boro em ácidos húmicos presentes na matéria orgânica também não foi afetada pelo $\mathrm{pH}$ abaixo de 6,5. Um argumento que reforça a hipótese de que o $\mathrm{pH}$, na faixa de reação ácida, tem efeito pouco significativo na adsorção de boro é o fato de ter-se utilizado neste estudo uma solução relativamente diluída de cloreto de cálcio como eletrólito suporte. Segundo BARROW (1989), a força iônica da solução em equilíbrio influencia o efeito do $\mathrm{pH}$ na quantidade de boro adsorvido pelos solos. Quanto maior a concentração salina da solução, maior o efeito do $\mathrm{pH}$ no sentido de aumentar a quantidade de boro adsorvido. Assim sendo, numa solução de $\mathrm{CaCl}_{2}$ $0,01 \mathrm{~mol} / \mathrm{L}$, o efeito do $\mathrm{pH}$ praticamente inexiste na faixa de reação ácida.

Um número significativo dos trabalhos que mostram correlação significativa entre $\mathrm{pH}$ e boro adsorvido foi desenvolvido em condições de solo 
alcalino, onde a probabilidade de resposta é maior. Assim, observou-se aumento no boro retido por um solo argiloso de Arkansas, EUA, após aumento do $\mathrm{pH}$ de 6,3 a 9,5 (SCOTT et al., 1975). Em outro trabalho, constatou-se, também, um aumento na adsorção de boro em montmorilonita, que teve o $\mathrm{pH}$ aumentado de 7,0 até 11,0 - atingindo um pico no valor de boro adsorvido ao pH 9,7 (KEREN \& GAST, 1981).

\subsubsection{Efeito da aplicação de $\mathrm{CaCO}_{3}$}

A aplicação de carbonato de cálcio promoveu aumento médio de $32 \%$ na quantidade de boro adsorvido, sendo que a extensão do aumento foi variável para cada solo (Tabela 7). Há quase sessenta anos, MIDGLEY \& DUNKLEE (1939) já haviam reportado que adições de carbonatos de cálcio e de magnésio causaram aumento na adsorção de boro em solos ácidos com alto teor de carbono orgânico. A alcalinidade produzida pelos corretivos teve mais influência na fixação de boro do que os cátions trocáveis (OLSON \& BERGER, 1946).

Uma das causas do aumento na adsorção de boro após adição do carbonato de cálcio pode ter sido a precipitação de alumínio na forma de hidróxidos, que adsorvem elevadas quantidades do elemento (HATCHER et al., 1967). Esses autores observaram também que a correlação entre o aumento na adsorção de boro devido à calagem e a diminuição no teor de alumínio trocável foi altamente significativa $(\mathrm{r}=0,98)$.

Outra possível causa para o aumento na porcentagem de boro adsorvido foi a ligação do boro com o carbonato de cálcio, podendo haver ou precipitação de boratos de cálcio, ou substituição do carbono por boro no $\mathrm{CaCO}_{3}$ ou adsorção do boro no $\mathrm{CaCO}_{3}$ (ICHIKUNI \& KIKUCHI, 1972). Num estudo desenvolvido especialmente para observar a adsorção de boro no carbonato, 
obteve-se uma redução de $25 \%$ na quantidade de boro adsorvido por dois entissolos e um alfissolo, após remoção, com uma solução $0,5 \mathrm{~mol} / \mathrm{L}$ de acetato de sódio, da calcita presente nos solos (GOLDBERG \& FORSTER, 1991).

A correlação simples entre boro adsorvido e cálcio trocável não foi estatisticamente significativa (Tabela 1A - Apêndice 2), embora o teor do elemento tenha aumentado, após a calagem, em todos os solos, juntamente com o aumento na quantidade de boro adsorvido (Tabelas 2 e 6). HARADA \& TAMAI (1968) estudaram diversos solos com teores de cálcio bastante variáveis (de 20 a $\left.350 \mathrm{mmol}_{\mathrm{c}^{+} /} / \mathrm{dm}^{3}\right)$, mas também não obtiveram correlação significativa do teor do elemento com a adsorção de boro.

KEREN \& O'CONNOR (1982) estudaram o efeito da variação da concentração do eletrólito suporte do meio na adsorção de boro em ilita e em montmorilonita, concluindo que houve pequeno efeito dos cátions, quando consideradas as forças iônicas usuais da solução de solos $(0,01-0,02)$. Ao se aumentar a força iônica do meio, supõe-se que haja algum aumento na adsorção de boro, já que deve ocorrer compressão no campo elétrico associado com as bordas das partículas de argila, com conseqüente redução na repulsão entre a superfície e o íon adsorvido especificamente (KEREN \& BINGHAM, 1985). Porém, a magnitude no aumento dessa força iônica deveria ser de tal ordem que faria os valores fugirem da faixa normalmente encontrada em solos.

Embora a maioria dos trabalhos aponte para a inexistência de correlação entre cálcio no solo e boro adsorvido, alguns autores especulam o contrário. Após aplicação de $\mathrm{NaOH}$ e $\mathrm{Ca}(\mathrm{OH})_{2}$ em solos cauliníticos do Havaí, observou-se que no tratamento com cálcio houve aumento mais pronunciado no boro adsorvido com o pH (OKAZAKI \& CHAO, 1968). Esta afirmação vai ao encontro da feita por BIGGAR \& FIREMAN (1960), que relataram lixiviação mais rápida de boro em solos tratados com sódio do que com cálcio. 
O tetraborato de sódio é consideravelmente mais solúvel do que o metaborato de cálcio, e assim a formação de boratos de cálcio relativamente insolúveis poderia ser responsável pelo decréscimo na disponibilidade do boro após calagem (BISHOP \& COOK, 1958). Esse mecanismo pode ser expressivo em solos ácidos com alto teor de $\mathrm{Ca}^{2+}$, nos quais é estudada a adsorção de boro, utilizando-se o cloreto de cálcio como eletrólito suporte (EVANS, 1987). Outra possibilidade encontrada na literatura é a formação de uma "ponte" envolvendo argila --- cálcio --- $\mathrm{B}\left(\mathrm{OH}_{4}\right)^{-}$, desde que um material como montmorilonita, por exemplo, esteja presente (GÁRATE et al., 1984).

\subsubsection{Boro adsorvido $\mathrm{x}$ carbono orgânico}

Não houve correlação estatisticamente significativa entre o teor de carbono orgânico e o boro adsorvido, de maneira análoga ao observado por BINGHAM et al. (1971), para solos derivados de cinzas vulcânicas.

Muitos pesquisadores (MIDGLEY \& DUNKLEE, 1939; PARKS \& WHITE, 1952) afirmaram que a matéria orgânica é um dos sítios mais ativos de adsorção de boro. Entretanto, muitos trabalhos mostram resultados diferentes. Por exemplo, dentre sete amostras de solos, observou-se em somente quatro delas um aumento na quantidade de boro adsorvido após a destruição da matéria orgânica, enquanto que nas três demais ocorreu o contrário (HARADA \& TAMAI, 1968). Considera-se que o efeito da matéria orgânica é pouco pronunciado quando seu teor no solo é menor do que $15 \mathrm{~g} / \mathrm{dm}^{3}$ (MEZUMAN \& KEREN, 1981). Estes autores não observaram efeito da destruição da matéria orgânica, cujo teor era $12 \mathrm{~g} / \mathrm{dm}^{3}$, na adsorção de boro por um vertissolo.

A matéria orgânica parece ter importante papel no controle da mobilidade do boro em solos. PARKER \& GARDNER (1982) destacaram esse importante efeito da matéria orgânica, mas não encontraram maior teor de boro 
adsorvido em um molissolo com $40 \mathrm{~g} / \mathrm{dm}^{3}$ de matéria orgânica, quando comparado a outro molissolo com $9 \mathrm{~g} / \mathrm{dm}^{3}$. Segundo os autores, tão importante quanto a quantidade é o conhecimento da natureza da matéria orgânica, pois materiais de naturezas diferentes podem ter sido a causa dos resultados contraditórios obtidos por eles. Estudos feitos após fracionamento da matéria orgânica mostram que a complexação de boro com grupos carboxílicos é favorecida em pHs baixos, enquanto que no meio alcalino foi demonstrada a presença de complexos apenas com o tartarato, que é um ânion que contém o arranjamento glicol (diol) (REBSTOCKOVA \& BARTUSEK, 1977). GU \& LOWE (1990) observaram baixa adsorção de boro em ácidos húmicos em pHs menores do que 6,5, atribuindo este resultado à presença de cálcio no meio, ocupando os sítios de adsorção no ácido.

A literatura tem mostrado que o $\mathrm{pH}$ do meio influencia o efeito da matéria orgânica na adsorção de boro, principalmente porque a afinidade dos adsorventes, sejam orgânicos, sejam inorgânicos, pelo ácido bórico é relativamente baixa (KEREN et al., 1981; YERMTYAHU et al., 1988). Sendo assim, em solos ácidos a fração dos sítios de adsorção ocupada por boro é pequena. Isso pode ter sido uma causa da baixa correlação existente entre carbono orgânico e boro nesse trabalho (menor do que 0,30 - Tabela 1A, do Apêndice 2). Adicionando-se um composto com $214 \mathrm{~g} / \mathrm{kg}$ de substâncias húmicas a um alfissolo de Israel, obtiveram-se misturas de solo + composto com teores de matéria orgânica que variaram de $10 \mathrm{a} 100 \mathrm{~g} / \mathrm{kg}$, e observou-se que a adsorção de boro foi muito baixa em pHs menores do que 7,0, subindo até a um pico no $\mathrm{pH} 8,5 \mathrm{e}$ decrescendo a partir daí (YERMIYAHU et al., 1995). Deve-se complementar que o distrofismo dos solos não ofereceu condições adequadas à atividade microbiana, que promoveria a formação do grupamento diol, responsável pela retenção do boro (RIBEIRO \& BRAGA, 1974). 


\subsubsection{Boro adsorvido $\mathrm{x}$ óxidos de ferro e de alumínio}

As correlações simples entre boro adsorvido e óxidos foram estatisticamente significativas somente para alumínio total e alumínio mal cristalizado. Embora positivas, as correlações com as diversas formas de óxidos de ferro e com o alumínio livre não foram significativas.

Apesar de alguns autores não terem encontrado correlação significativa entre boro adsorvido e os óxidos (RIBEIRO \& BRAGA, 1974; ELRASHIDI \& O'CONNOR, 1982), considera-se que a afinidade do elemento pelo hidróxido de alumínio, por exemplo, é muito maior do que a com minerais de argila (KEREN \& GAST, 1983).

Um coeficiente de correlação mais alto para óxido de alumínio do que para óxido de ferro era esperado, com base na marcante afinidade do boro com grupos OH do hidróxido de alumínio (SIMS \& BINGHAM, 1968a) e na maior adsorção de boro por unidade de massa do que os hidróxidos de ferro (McPHAIL et al., 1972). A correlação com óxido de ferro livre foi um pouco maior do que com ferro total, da mesma forma como foi encontrado por SIMS \& BINGHAM (1968b) e MEZUMAN \& KEREN (1981).

Esperavam-se correlações bem melhores com ferro mal cristalizado, devido à sua maior superfície de exposição em relação às formas cristalizadas (RIBEIRO \& BRAGA, 1974; GOLDBERG \& GLAUBIG, 1985). Entretanto, o efeito conjunto dos teores de carbono e de argila parecem ter mascarado seu efeito na adsorção de boro. Além disso, como citado no ítem 4.5.2., a adsorção de boro foi maior em solos com teores mais altos de ferro até um certo limite, decrescendo a partir daí. Como conseqüência, a distribuição dos pontos seguiu uma equação de segundo grau, tomando a correlação linear não significativa.

Os coeficientes de correlação entre boro adsorvido e óxido de alumínio mal cristalizado foram mais altos do que com alumínio livre, com 
valores próximos ao obtido em solos chilenos de origem vulcânica (SCHALSCHA et al., 1973). Enquanto a superficie específica da gibbsita, que corresponde ao alumínio na forma cristalizada, é $2 \mathrm{~m}^{2} / \mathrm{g}$, a do óxido de alumínio mal cristalizado é $163 \mathrm{~m}^{2} / \mathrm{g}$ (GOLDBERG \& GLAUBIG, 1985). Nesses materiais, o boro liga-se às superfícies hidroxiladas, bloqueando os sítios de polimerização e retardando a cristalização do hidróxido de alumínio (BEYROUTY et al, 1984).

\subsubsection{Correlações entre boro adsorvido e atributos físicos dos solos}

As correlações entre boro adsorvido e atributos físicos dos solos foi altamente significativa na maioria dos casos, exceção feita ao teor de silte (Tabela 8). Para o teor de areia, as correlações foram negativas, com coeficientes praticamente iguais para os separados (areia grossa e areia fina) e para o teor total, significativas a 5\%. Para argila, o coeficiente de correlação foi o mais alto e significativo a $1 \%$ de probabilidade $\left(\mathrm{r}=0,79^{* *}\right)$.

A magnitude dos valores de boro adsorvido (Tabela 6) foi semelhante à observada por CORREA et al. (1985), que estudaram latossolos do Paraná. Nesse estudo, a adsorção de boro no latossolo roxo argiloso foi cinco vezes maior, em média, do que o latossolo vermelho escuro, de textura arenosa, mantendo-se constante a concentração de boro adicionado.

O coeficiente da correlação entre boro adsorvido e teor de argila foi semelhante aos obtidos por GUPTA (1968), SINGH (1971) e ELRASHIDI \& O'CONNOR (1982). Esses autores destacaram que a quantidade de boro adsorvido aumentou com o teor de argila, e que a correlação positiva foi favorecida pela mineralogia semelhante dos solos, de maneira semelhante ao que ocorreu neste trabalho (Figuras 2 a 6 ).

Considera-se que a adsorção de boro em diferentes tipos de argilas está ligada à presença de hidróxidos de ferro e de alumínio, ou nas entrecamadas, 
ou cobrindo as partículas de argila, ou presentes como impurezas (SIMS \& BINGHAM, 1967a). Entretanto, HARADA \& TAMAI (1968) removeram os hidróxidos de vários solos e, mesmo assim, uma considerável adsorção de boro foi ainda observada. Eles também fracionaram o solo nos separados areia, silte e argila, e verificaram que de 73 a $96 \%$ do total de boro adsorvido concentravam-se na fração argila. As diferenças entre os solos ficam bem menores quando a adsorção é feita com base no teor de argila, uma vez que os sítios de adsorção estão localizados, principalmente, nessa fração do solo (MEZEMAN \& KEREN, 1981).

Desse modo, parece procedente a afirmação de que os minerais de argila podem adsorver boro, assim como os hidróxidos, principalmente nas bordas das lâminas silicatadas, que contêm íons não totalmente coordenados (KEREN \& TALPAZ, 1984). A goetita, a gibbsita, a caulinita e também os solos cauliníticos formam complexos de esfera interna com o boro, confirmando a hipótese de adsorção específica do elemento nesses materiais (GOLDBERG et al., 1993a). Tal resultado, entretanto, não foi obtido com a montmorilonita e com solos montmoriloníticos, reforçando a necessidade do conhecimento da mineralogia dos solos e o cuidado que se deve ter ao se extrapolar resultados de solos com carga permanente para as condições de solos tropicais com carga variável.

A correlação entre boro adsorvido e superfície específica foi positiva, de maneira análoga ao que ocorreu com teor de argila, apesar do coeficiente de correlação um pouco menor (Tabela 8). Esse coeficiente esteve próximo ao encontrado por SCHALSCHA et al. (1973) e um pouco mais baixo do que os obtidos por HATCHER et al. (1967) e GOLDBERG \& GLAUBIG (1986a). Os valores de superfície específica são semelhantes ao encontrados por GROHMANN (1970) e ALLEONI \& CAMARGO (1994) para latossolos e podzólicos paulistas, e eram esperados, devido à composição granulométrica dos solos, aos teores de carbono orgânico e à mineralogia oxídica da fração argila. 
A análise conjunta das variáveis mostrou que os teores de argila representaram $62 \%$ da variação nos teores de boro adsorvido (Apêndice 1). Juntamente com a argila, os teores de alumínio livres e de boro solúvel em $\mathrm{CaCl}_{2}$ $0,01 \mathrm{~mol} / \mathrm{L}$ a quente também entraram no modelo, representado pela equação 8 , que teve um alto coeficiente de determinação $(0,93)$. Analogamente ao citado para a análise conjunta dos teores de boro solúvel, a comparação com os resultados obtidos na literatura é difícil. Num dos poucos trabalhos em que é apresentada a equação da análise conjunta, ELRASHIDI \& O'CONNOR (1982) observaram efeito significativo de óxido total de ferro, carbono orgânico e CTC em seu modelo, explicando $98 \%$ dos teores de boro adsorvido.

$\mathrm{O}$ efeito significativo do teor de argila na quantidade de boro adsorvido pelos solos foi destacado na análise conjunta, confirmando o que havia ocorrido na correlação simples, quando o coeficiente de correlação foi alto e significativo a $1 \%$ de probabilidade (Tabela 8 ). A importância da granulometria na adsorção de boro foi discutida no ítem 5.2.3. e confirmada na regressão múltipla. Em relação ao óxido de ferro livre, o efeito foi significativo na regressão múltipla, muito embora o mesmo não tivesse ocorrido na correlação simples. Para ELRASHIDI \& O'CONNOR (1982) ocorreu situação semelhante, e para eles a correlação simples não significativa pode ter sido resultado do pequeno número de amostras estudadas, que representaram um espectro pouco amplo de dados. Quando esses valores entraram na análise conjunta, o efeito passou a ser significativo, confirmando consenso na literatura de que as diversas formas de óxidos de ferro e de alumínio, principalmente os últimos, estão sempre diretamente relacionados à adsorção de boro pelos solos.

Outro atributo que compôs a equação 8 foi o teor de boro solúvel em $\mathrm{CaCl}_{2} \quad 0,01 \mathrm{~mol} / \mathrm{L}$ a quente. Apesar de a correlação simples entre o boro adsorvido aos solos, após adição de $2 \mu \mathrm{g} / \mathrm{mL}$ do elemento, e boro extraído com solução de cloreto de cálcio não ter sido significativa, era de se esperar que a 
quantidade originalmente presente nos solos influenciasse a quantidade de boro adsorvida pelos mesmos, principalmente porque os teores extraídos com $\mathrm{CaCl}_{2}$ $0,01 \mathrm{~mol} / \mathrm{L}$ a quente (entre 0,07 e $0,61 \mathrm{mg} / \mathrm{dm}^{3}$ ) estão numa faixa próxima à quantidade de boro adicionada aos solos. De acordo com HARADA \& TAMAI (1968), que obtiveram resultado semelhante com solos japoneses, parece razoável supor que uma correlação negativa seja encontrada entre os teores de boro solúvel e a quantidade de boro adsorvido.

\subsection{Modelos de Langmuir e Freundlich}

\subsubsection{Adequação dos modelos aos resultados}

Tanto o modelo de Langmuir como o de Freundlich adequaram-se bem aos valores de boro adsorvido pelos solos, em toda faixa estudada (Figuras $12,13,14,15$ e 16 , e tabelas 12 e 13). A maioria dos trabalhos mostra boa concordância dos modelos à adsorção de boro, principalmente para Freundlich (GOLDBERG \& GLAUBIG, 1986a), num amplo espectro de concentração (até $200 \mu \mathrm{g} / \mathrm{mL}$ ), e para Langmuir, quando a concentração do elemento na solução é menor do que $30 \mu \mathrm{g} / \mathrm{mL}$ (EVANS \& SPARKS, 1983). Entretanto, encontram-se trabalhos em que a adequação a Langmuir não foi boa, mesmo em concentrações mais baixas, sendo que a causa dos desvios pareceu ser a liberação de boro pela fase sólida do solo (RHOADES et al., 1970; SCOTT et al., 1975).

A adsorção de boro em solos indianos de diferentes ordens seguiu o modelo de Langmuir no intervalo de 0 a $6 \mu \mathrm{g} / \mathrm{mL}$ de boro (PRASAD, 1978). Concentrações de boro dentro dessa faixa, ou até um pouco mais alta, como as verificadas neste trabalho $(0 \mathrm{a} 16 \mu \mathrm{g} / \mathrm{mL})$ são suficientes para propósitos práticos, pois a ênfase que é dada a concentrações mais altas, em alguns trabalhos, é devida 
a necessidade da prevenção da toxicidade pelo elemento, ao invés de sua deficiência.

No presente trabalho, o modelo de Langmuir representou bem a distribuição dos valores de boro adsorvido na faixa inicial da solução em equilíbrio (até $2 \mu \mathrm{g} / \mathrm{mL}$ ). Na faixa intermediária (4 e $8 \mu \mathrm{g} / \mathrm{mL}$ ), o modelo superestimou a adsorção do elemento, enquanto que na maior concentração $(16 \mu \mathrm{g} / \mathrm{mL})$ o modelo subestimou a quantidade de boro adsorvido. Resultados semelhantes, principalmente com relação à faixa intermediária e à maior concentração, são encontrados na literatura para o boro e também para sulfato e fosfato (SINGH, 1984; MEAD, 1981).

HATCHER \& BOWER (1958) observaram boa justaposição de seus resultados à equação de Langmuir na forma linear até aproximadamente $40 \mu \mathrm{g} / \mathrm{mL}$ de boro, quando então os desvios começaram a ser maiores e explicados pela possível presença de sítios não uniformes de adsorção, chamados de multisítios, principalmente na faixa de $\mathrm{pH}$ entre 6,5 e 7,5. Para SINGH (1964), os limites foram $25 \mu \mathrm{g} / \mathrm{mL}$ para solos argilosos e $30 \mu \mathrm{g} / \mathrm{mL}$ para solos de textura média.

Em quinze amostras de terra oriundas de horizontes superficiais e subsuperficiais de um podzólico vermelho-amarelo e de dois latossolos vermelhos-escuros, o coeficiente de correlação encontrado por CATANI et al. (1971) para o modelo de Freundlich foi significativo a 1\% em quatorze delas, enquanto que para o modelo de Langmuir o coeficiente foi significativo em apenas oito amostras, sendo que para quatro delas a probabilidade foi de $5 \%$, e nas outras três somente $10 \%$. Esses autores utilizaram uma faixa de zero a $80 \mu \mathrm{g} / \mathrm{mL}$ de boro, o que pode ter sido a causa da melhor adequação do modelo de Freundlich, como verificado também em estudo até $100 \mu \mathrm{g} / \mathrm{mL}$ (ELRASHIDI \& O’CONNOR, 1982) e até $60 \mu \mathrm{g} / \mathrm{mL}$ (NICHOLAICHUK et al., 1988). 
Os valores das constantes de Langmuir e de Freundlich foram semelhantes aos encontrados na literatura. Entretanto, a comparação dos resultados é difícil, pois as constantes variam de acordo com o intervalo utilizado para concentração em equilíbrio. A estimativa de adsorção máxima de um solo argiloso, no modelo de Langmuir, variou de 31,9 para $43,7 \mu \mathrm{g} / \mathrm{g}$, quando as faixas de concentração de boro variaram de 0 a 8 para 0 a $32 \mu \mathrm{g} / \mathrm{mL}$ (HATCHER \& BOWER, 1958). Em um solo classificado como "terra rossa", a variação foi ainda maior, pois a adsorção máxima passou de 32 para $79 \mu \mathrm{g} / \mathrm{g}$, em faixas de concentração que variaram de 0 a 6 para 0 a $35 \mu \mathrm{g} / \mathrm{mL}$ de boro adicionado (HADAS \& HAGIN, 1972).

A maioria dos trabalhos em que são comparadas as adsorções máximas estimadas pelo modelo de Langmuir demonstram que os valores são normalmente subestimados, principalmente em concentrações abaixo de $50 \mu \mathrm{g} / \mathrm{mL}$. Entretanto, deve-se considerar o aspecto qualitativo dessa estimativa, pois ela permite a comparação entre solos de uma mesma região que não se diferenciam quanto à mineralogia, como é o caso deste trabalho, possibilitando a previsão do comportamento do elemento em termos de adsorção (CUNHA, 1989).

Outro fator que dificulta a comparação dos resultados é a possibilidade de ocorrerem valores diferentes dentro de uma mesma classe de solo. Sete amostras de latossolos vermelho-escuros distróficos, textura argilosa, tiveram estimativas de adsorção máxima variando de 8,2 a 34,1 $\mu \mathrm{g} / \mathrm{g}$ (RIBEIRO \& BRAGA, 1974), enquanto que em seis solos classificados como Brunsolic Gray Brown Luvisol as adsorções máximas variaram de 56,2 a 171,2 $\mu \mathrm{g} / \mathrm{g}$ (EVANS, 1987).

Como os resultados foram semelhantes para ambos os modelos, há generalizada concordância na literatura para se optar pelo deste exigir apenas dois pontos para determinação da constante $\mathbf{K}$, já que a construção da curva de 
logaritmo de boro adsorvido versus logaritmo da concentração de boro em equilíbrio produz una reta. A equação de Langmuir, por outro lado, precisa de pelo menos quatro pontos para obtenção da isoterma (MEAD, 1981).

5.3.2. Correlações entre as constantes dos modelos e atributos dos solos

\subsubsection{Adsorção máxima}

A adsorção máxima estimada pelo modelo de Langmuir apresentou o maior número de correlações significativas com atributos dos solos (Tabela 11).

As correlações entre adsorção máxima e $\mathrm{pH}$ foram muito baixas (Tabela 2A - Apêndice 2), devido aos valores contrastantes de Admáx em amostras com pHs próximos e também às amostras com $\mathrm{pHs}$ diferentes e adsorções máximas próximas, como apresentado no ítem 4.6.1. Esse resultado foi diferente do obtido por RIBEIRO \& BRAGA (1974), que observaram aumento na adsorção máxima de boro em latossolos, em que o $\mathrm{pH}$ em $\mathrm{H}_{2} \mathrm{O}$ variou de 4,4 a 6,2. O mesmo ocorreu com EVANS (1987), que obteve um $\mathbf{r}$ igual a $0,54^{*}$ na correlação de adsorção máxima de boro com $\mathrm{pH}$ de solos canadenses. Para argilominerais puros, como caulinita, ilita e montmorilonita, encontrou-se maior efeito do $\mathrm{pH}$ na faixa de reação alcalina (HINGSTON, 1964), enquanto que nenhum efeito foi verificado para treze solos indianos (PRASAD, 1978) e para quatorze solos americanos (JN et al., 1981).

As demais correlações da adsorção máxima de Langmuir com atributos químicos de rotina não foram significativas, contrariando resultados obtidos para solos semelhantes, em condições brasileiras (RIBEIRO \& BRAGA, 1974). Assim, nem a correlação com o teor de cálcio trocável foi positiva, nem foram negativas as correlações com alumínio trocável e sua saturação - $\mathrm{m} \%$ (Tabela 2A - Apêndice 2). 
Em relação ao carbono orgânico, o coeficiente foi igual a 0,38 e não significativo. Outros autores também não encontraram correlação entre esses atributos na faixa de reação ácida (RIBEIRO \& BRAGA, 1974; EVANS, 1987; JIN et al., 1988), enquanto que, somente em condições alcalinas, foi observada alta correlação positiva para vinte solos canadenses (EVANS, 1987) e para o ácido húmico (GU \& LOWE, 1990).

Os teores de óxidos totais, livres e mal cristalizados tiveram alta correlação positiva com a adsorção máxima de boro, sendo que os coeficientes de correlação foram os mais altos desse trabalho (Tabela 11). Esses resultados mostram a tendência de aumento da capacidade adsortiva de boro pelos solos com o teor de óxidos, seguindo um modelo linear, e realçam sua elevada importância no processo de adsorção do elemento, como observado por diversos autores (SIMS \& BINGHAM, 1968a; BINGHAM et al., 1971; GOLDBERG \& GLAUBIG, 1988; JIN et al., 1988). Em alguns trabalhos, porém, foi destacada a importância dos óxidos na adsorção de boro, mas não se obtiveram correlações significativas com sua adsorção máxima (RIBEIRO \& BRAGA, 1974; PRASAD, 1978).

As correlações da adsorção máxima com atributos físicos foram todas altamente significativas a $1 \%$ de probabilidade. O coeficiente da correlação com teor de argila (Tabela 11) foi mais alto do que o obtido por PRASAD (1978), mesmo considerando-se um menor número de amostras, e mais baixo do que o encontrado por JIN et al. (1988). Adsorções mais altas de boro em solos de textura mais fina foram também observadas em solos indianos (SINGH, 1964), israelenses (MEZUMAN \& KEREN, 1981) e latossolos brasileiros (CORREA et al., 1985). Em um dos raros trabalhos em que a correlação entre adsorção máxima de boro e teor de argila não foi significativa, o coeficiente de correlação foi igual a -0,14 (RIBEIRO \& BRAGA, 1974). 
Outra propriedade que apresentou alta correlação positiva $(\mathrm{r}=$ 0,86**) com a adsorção máxima foi a superfície específica (Tabela 11), confirmando tendência observada há mais de trinta anos (HATCHER \& BOWER, 1958; HATCHER et al., 1967). Coeficientes altamente significativos (entre 0,93 e $0,96)$ foram verificados em solos americanos, com diferentes mineralogias (GOLDBERG \& GLAUBIG, 1986a; JIN et al., 1988). Apesar de o número de trabalhos em que é determinada a superfície específica ser pequeno, é importante destacar que essa propriedade apresentou alta correlação tanto com boro solúvel, como boro adsorvido e adsorção máxima. Assim sendo, sua utilização deveria ser incrementada em trabalhos relacionados à adsorção de elementos e/ou compostos, pois trata-se de uma propriedade de fácil determinação em laboratório e que representa a área disponível para adsorção por unidade de massa do material.

$\mathrm{O}$ artifício do uso dos parâmetros carbono/argila e óxidos/argila não promoveu aumento nos coeficientes das correlações com a adsorção máxima de boro. Pelo contrário, houve diminuição nos valores de $\mathbf{r}$, sendo que a correlação com o parâmetro Al livre / argila teve coeficiente não significativo, embora, individualmente, ambos os atributos tivessem correlação significativa com adsorção máxima. Desse modo, as vantagens apontadas por LAVERDIÈRE \& KARAM (1984) para adsorção de fosfato, na razão de carbono e óxido por argila, não foram observadas para adsorção de boro, sendo então preferidas as correlações com os atributos individualmente.

A análise de regressão múltipla mostrou que a variação na adsorção máxima dos solos foi quase que totalmente explicada pelos teores de óxidos de ferro livres, com coeficiente de determinação igual a 94\% (Apêndice 1). Na equação 9 aparece também o teor de cálcio trocável, contribuindo com $2 \%$ do $\mathrm{r}^{2}$ total do modelo. A influência marcante do teor de ferro livre confirma tendência observada na correlação simples, em que o coeficiente foi igual a 0,97 e altamente significativo a $1 \%$ de probabilidade, confirmando os resultados de MEZUMAN \& 
KEREN (1981) que, trabalhando com grupos de solos com teores semelhantes de carbono orgânico e argila, encontraram uma adsorção máxima de boro $50 \%$ maior naquele em que o teor de óxidos livres era três vezes mais alto.

\subsubsection{Demais correlações}

A constante $\mathbf{K}$ de Freundlich apresentou correlações significativas bastante semelhantes às encontradas para a adsorção máxima estimada pelo modelo de Langmuir (Tabela 11). Somente para os óxidos de ferro e de alumínio, que se correlacionaram com a constante de Langmuir, não houve a mesma tendência no modelo de Freundlich, sendo significativa somente a correlação com alumínio total. No caso dos óxidos, a divisão pelo teor de argila fez as correlações com ferro total e alumínio livre tornarem-se significativas a 1 e a $5 \%$, respectivamente.

A correlação entre a constante $\mathbf{K}$ de Freundlich e a adsorção máxima de Langmuir não foi significativa $(r=0,50)$, principalmente porque o LRarg teve os maiores valores de adsorção máxima, enquanto que no modelo de Freundlich os maiores valores de $\mathbf{K}$ foram do LEarg (Tabela 10). Entretanto, analisando-se mais cuidadosamente a figura 7 , em que aparecem as curvas de adsorção do LRarg, não se notam as curvaturas maiores observadas para os demais solos (Figuras 8, 9, 10 e 11), e isso pode ter causado menores valores de $\mathbf{K}$, no modelo de Freundlich, mas maiores valores de $\mathbf{b}$, que corresponde ao componente exponencial dessa equação (Tabela 10). Como conseqüência, as constantes K (Freundlich) e adsorção máxima (Langmuir) não se correlacionaram significativamente.

Se for feita a correlação entre as variáveis, retirando-se o LRarg, o coeficiente de correlação passa a ser altamente significativo $\left(\mathrm{r}=0,98^{* *}\right)$, confirmando a hipótese de MEAD (1981), de que a constante de Freundlich dá 
uma medida relativa da capacidade adsortiva do solo. Esse autor obteve para fosfato um valor de adsorção máxima cerca de 2,5 vezes maior do que a constante $\mathrm{K}$ de Freundlich, enquanto que neste trabalho a adsorção máxima foi três vezes maior. Resultado semelhante foi obtido para adsorção de zinco, sendo o fator entre as constantes igual a 4 (CUNHA, 1989).

A constante $\mathbf{K}$ de Langmuir, que dá idéia da afinidade do adsorvente por boro, correlacionou-se apenas com os teores de ferro total e mal cristalizado, e com o teor de alumínio livre (Tabela 11). Diferentemente do observado por BIGGAR \& FIREMAN (1960) e NICHOLAICHUK et al. (1988), não houve correlação positiva com o teor de argila.

Apenas três correlações simples entre a capacidade tampão máxima (CTM) e atributos dos solos foram significativas (alumínio mal cristalizado, argila e o parâmetro alumínio livre / argila). $\mathrm{Na}$ análise conjunta das variáveis, as diversas formas de óxidos de alumínio representaram 95\% dos valores de CTM, sendo que $53 \%$ foram devidos somente ao alumínio mal cristalizado, confirmando que o conceito de poder tampão de solos está intimamente ligado à area de exposição do material, que é maior nos materiais não cristalizados (Apêndice 1). As demais formas de alumínio responderam por $42 \%$, enquanto que o $\mathrm{pH}$ e o teor de ferro livre participaram do modelo (equação 10), com contribuições menores, na faixa de $2 \%$, porém significativas. 


\section{CONCLUSÕES}

Os resultados obtidos neste trabalho permitem concluir que:

- $\mathrm{O}$ boro solúvel em solução de $\mathrm{CaCl}_{2} \quad 0,01 \mathrm{~mol} / \mathrm{L}$ a quente apresentou alta correlação linear simples com os atributos físicos do solo, exceção feita ao teor de silte. Foram também significativas as correlações com a CTC e o óxido de alumínio total dos cinco solos e com o teor de carbono orgânico dos latossolos. $\mathrm{Na}$ análise conjunta, alumínio total, cálcio trocável e alumínio trocável foram as variáveis que se correlacionaram significativamente com boro solúvel, explicando $85 \%$ de sua variação.

- A porcentagem de boro adsorvido pelos latossolos argilosos foi superior à do podzólico vermelho-amarelo que, por sua vez, foi superior à dos latossolos de textura média. A aplicação de carbonato de cálcio promoveu aumento na quantidade de boro adsorvido por todos os solos, sendo mais pronunciado o efeito nos latossolos de textura média.

- Os teores totais e mal cristalizados de alumínio apresentaram os mais altos coeficientes de correlação com o boro adsorvido pelos solos. Analogamente ao que ocorreu com o boro solúvel, as correlações simples com areia, argila e superfície específica foram altamente significativas. Na regressão múltipla, os teores de argila, de óxido de alumínio livre e de boro solúvel correlacionaram-se significativamente com o boro adsorvido pelos solos, com alto coeficiente de determinação $(0,93)$. 
- A isoterma de Freundlich teve um somatório de desvios um pouco menor do que a de Langmuir. Os maiores desvios entre os valores obtidos em laboratório e os estimados pelos modelos apareceram nos solos de textura argilosa. Nesses solos foram encontradas as maiores estimativas de adsorção máxima pelo modelo de Langmuir, que apresentaram correlação simples altamente significativa com os teores de óxidos de ferro e de alumínio totais, livres e mal cristalizados, e com todos os atributos físicos, inclusive o teor de silte. Na análise conjunta, o teor de óxido de ferro livre foi o principal responsável pela variação nos valores de adsorção máxima, resspondendo por $94 \%$ do modelo. 


\section{REFERÊNCIAS BIBLIOGRÁFICAS}

ADAMS, J.A.; HAMZAH, Z.; SWIFT, R.S. Availability and uptake of boron in a group of pedogenetically-related Canterbury, New Zealand soils. Australian Journal of Soil Research, Melboume, 29: 415-23, 1991.

ALLEONI, L.R.F. \& CAMARGO, O.A. Atributos físicos de latossolos ácricos do norte paulista. Scientia Agricola, Piracicaba, 51: 321-6, 1994.

BARROW, N.J. Reactions with variable-charge soils. Dordrecht, Martinus Nijhoff Publishers, 1987. 191p.

BARROW, N.J. Testing a mechanistic model. $\mathrm{X}$. The effect of $\mathrm{pH}$ and electrolyte concentration on borate sorption by a soil. Journal of Soil Science, Oxford, 40: 427-35, 1989.

* BATAGLIA, O.C. \& RAIJ, B. van. Eficiência de extratores na determinação de B em solos. Revista brasileira de Ciência do Solo, Campinas, 14: 25-31, 1990.

BERGER, K.C. \& PRATT, P.F. Advances in secondary and micronutrient fertilization. In: MALCOM, H.M.; BRIDGER, G.L.; NELSON, L.B., ed. Fertilizers technology and usage. Madison, Soil Science Society of 
America, 1963. p. 287-340.

BERGER, K.C. \& TRUOG, E. Boron deficiences as revealed by plants and soil tests. Journal of the American Society of Agronomy, Geneva, 32: 297-301, 1940.

BEYROUTY, C.A.; SCOYOC, G.E. van; FELDKAMP, J.R. Evidence supporting adsorption of boron on synthetic aluminum hydroxides. Soil Science Society of America Journal, Madison, 48: 284-7, 1984.

BIGGAR, J.W. \& FIREMAN, M. Boron adsorption and release by soils. Soil Science Society of America Proceedings, Madison, 24: 115-9, 1960.

BINGHAM, F.T. Boron. In: PAGE, A.L.; MILLER, R.H.; KEENEY, D.R., ed. Methods of Soil Analysis, Part 2. Chemical and Microbiological Properties. Madison, American Society of Agronomy, 1982. cap. 25, p. 431-47.

BINGHAM, F.T.; PAGE, A.L.; COLEMAN, N.T.; FLACH, K. Boron adsorption characteristics of selected amorphous soils from Mexico and Hawaii. Soil Science Society of America Proceedings, Madison, 35: 546-50, 1971.

BISHOP, R.F. \& COOK, R.L. Laboratory and greenhouse studies on effect of lime and other amendments on water soluble boron in soil. Canadian Journal of Soil Science, Ottawa, 38: 27-35, 1958.

BLADEL, R. van \& MOREALE, A. Adsorption of herbicide-derivied pchloroaniline residues in soils: a predcitive equation. Journal of Soil Science, Oxford, 28: 93-102, 1977. 
BOHN, H.L.; McNEAL, B.L.; O’CONNOR, G.A. Soil Chemistry. New York, John Wiley \& Sons, 1979. 329 p.

BRASIL SOBRINHO, M.O.C. Levantamento do teor de boro em alguns solos do Estado de São Paulo. Piracicaba, 1965. 135p. (Livre-Docência - Escola Superior de Agricultura "Luiz de Queiroz" / USP).

CAMARGO, O.A. Reações e interações de micronutrientes no solo. In: FERREIRA, M.E.F. \& CRUZ, M.C.P.C., coord. Micronutrientes na agricultura. Piracicaba, Potafos, 1991. cap. 5, p. 243-72.

CAMARGO, O.A.; MONIZ, A.C.; JORGE, J.A.; VALADARES, J.M.A.S. Métodos de análise química, mineralógica e fisica de solos do Instituto Agronômico de Campinas. Campinas, IAC, 1986. 94p. (Boletim Técnico, 106).

CARTWRIGHT, B.; TILLER, K.G.; ZARCINAS, B.A.; SPOUNCER, L.R. The chemical assessment of the boron status of soils. Australian Journal of Soil Research, Melboume, 21:321-32, 1983.

CASAGRANDE, J.C. O boro em solos do municipio de Piracicaba. Piracicaba, 1978. 122p. (Mestrado - Escola Superior de Agricultura "Luiz de Queiroz" / USP).

CASAGRANDE, J.C. Avaliação de um modelo de complexação de superficie para adsorção de fosfato em solos ácricos do norte paulista. Piracicaba, 1993. 97p. (Doutorado - Escola Superior de Agricultura "Luiz de Queiroz" ( USP). 
CATANI, R.A.; ALCARDE, J.C.; KROLL, F.M. A adsorção de boro pelo solo. Anais da ESALQ, Piracicaba, 28: 189-98, 1971.

CIHACEK, J.L. \& BREMNER, J.M. A simplified ethylene glycol monoethyl procedure for assesment of soil surface area. Soil Science Society of America Journal, Madison, 43: 821-2, 1979.

CORREA, A.E.; PAVAN, M.A.; MIYAZAWA, M. Aplicação de boro no solo e respostas do cafeeiro. Pesquisa Agropecuária Brasileira, Brasília, 20(2): 177-81, 1985.

COTTON, A.F. \& WILKINSON, G. Advanced inorganic chemistry. New York, John Wiley, 1972.

CRUZ, M.C.P. \& FERREIRA, M.E. Seleção de métodos para avaliação do boro disponível em solo. Pesquisa Agropecuária Brasileira, Brasília, 19: 145764, 1984.

赎CRUZ, M.C.P.; NAKAMURA, A.M.; FERREIRA, M.E. Adsorção de boro pelo solo: efeito da concentração e do pH. Pesquisa Agropecuária Brasileira, Brasília, 22: 621-6, 1987.

CUNHA, R.C.A. Retenção e movimento de zinco em solos do estado de São Paulo. Piracicaba, 1989. 115p. (Mestrado - Escola Superior de Agricultura "Luiz de Queiroz" / USP). 
DANTAS, J.P. Boro. In: FERREIRA, M.E.F. \& CRUZ, M.C.P.C., coord. Micronutrientes na agricultura. Piracicaba, Potafos, 1991. cap. 5, p. 113130.

ELSEEWI, A.A. \& ELMALKY, A.E. Boron distribution in soils and waters of Egypt. Soil Science Society of America Journal, Madison, 43: 297-300, 1979.

ELRASHIDI, M.A. \& O'CONNOR, G.A. Boron sorption and desorption in soils. Soil Science Society of America Journal, Madison, 46: 27-31, 1982.

EVANS, C.M \& SPARKS, D.L. On the chemistry and mineralogy of boron in pure and mixed systems: a review. Communications in Soil Science and Plant Analysis, New York, 14(19): 827-46, 1983.

EVANS, L.J. Retention of boron by agricultural soils from Ontario. Canadian Journal of Soil Science, Ottawa, 67: 33-42, 1987.

FONTES, M.P.F. Vermiculita ou esmectita com hidróxi nas entrecamadas: proposição de nomenclatura. Boletim Informativo da Sociedade Brasileira de Ciência do Solo, Campinas, 15(1): 24-8, 1990.

GÁRATE, A.; MEYER, B.; SANCHEZ-ANDREU, J. Influence of saturating cation on boron adsorption capacity of monmorillonite. Agrochimica, Madrid, 28: 140-7, 1984. 
GESTRING, W.D. \& SOLTANPOUR, P.N. Boron analysis in soil extracts and plant tissue by plasmas emission spectroscopy. Communications in Soil Science and Plant Analysis, New York, 12(8): 733-42, 1981.

GOLDBERG, S. \& FORSTER, H.S. Boron adsorption on calcareous soils and reference calcites. Soil Science, Baltimore, 152: 304-10, 1991.

GOLDBERG, S. \& GLAUBIG, R.A. Boron adsorption on aluminum and iron oxide minerals. Soil Science Society of America Journal, Madison, 49: 1374-9, 1985.

GOLDBERG, S. \& GLAUBIG, R.A. Boron adsorption on California soils. Soil Science Society of America Journal, Madison, 50: 1173-6, 1986a.

GOLDBERG, S. \& GLAUBIG, R.A. Boron adsorption and silicon release by the clay minerals kaolinite, montmorillonite, and illite. Soil Science Society of America Journal, Madison, 50: 1442-8, $1986 \mathrm{~b}$.

GOLDBERG, S. \& GLAUBIG, R.A. Boron adsorption on an aluminum oxide. Soil Science Society of America Journal, Madison, 52: 87-91, 1988.

GOLDBERG, S.; FORSTER, H.S.; HEICK, E.L. Boron adsorption mechanisms on oxides, clay minerals, and soils, inferred from ionic strenght effects. Soil Science Society of America Journal, Madison, 57: 704-8, 1993.

GRIFFIN, R.A. \& BURAU, R.G. Kinetic and equilibrium studies of boron desorption from soil. Soil Science Society of America Proceedings, 
Madison, 38: 892-7, 1974.

GROHMANN, F. A superficie específica e sua correlação com propriedades fisicas e fisico-químicas do solo. Piracicaba, 1970. 52p. (Doutorado Escola Superior de Agricultura "Luiz de Queiroz" / USP).

GU, B. \& LOWE, L.E. Studies on the adsorption of boron on humic acids. Canadian Journal of Soil Science, Ottawa, 70: 305-11, 1990.

* GUPTA, U.C. Relationship of total and hot-water soluble boron, and fixation of added boron, to properties of podzol soils. Soil Science Society of America Proceedings, Madison, 32: 45-8, 1968.

GUPTA, U.C. \& MacLEOD, J.A. Influence of calcium and magnesium sources on boron uptake and yield of alfalfa and rutabagas as related to soil $\mathrm{pH}$. Soil Science, Baltimore, 124: 279-84, 1977.

GUPTA, U.C.; JAME, Y.W.; CAMPBELL, C.A.; LEYSHON, A.J.; NICHOLAICHUK, W. Boron toxicity and deficiency: a review. Canadian Journal of Soil Science, Ottawa, 65:381-409, 1985.

GUPTA, S.K. Effect of soil-properties on the extractable boron contents. Schweizerische landwirtschaftliche Forschung, Bern, 17(1/2): 45-50, 1978.

HADAS, A. \& HAGIN, J. Boron adsorption by soils as influenced by potassium. Soil Science, Baltimore, 113: 189-93, 1972. 
HADDAD, K.S. \& KALDOR, C.J. Effect of parent material, natural available soil boron, and applied boron and lime on the growth and chemical composition of leucerne on some acidic soils of the Central Tablelands of the New South Wales. Australian Journal of Experimental Agricultural and Animal Husbandry, Melbourne, 22:317-28, 1982.

HADDAD, K.S. \& KALDOR, C.J. Boron suplying power, boron adsorption capacity and productivity of some acidic soils of the Central Tablelands of the New South Wales. Australian Journal of Experimental Agricultural and Animal Husbandry, Melbourne, 24: 120-25, 1984.

HARADA, T. \& TAMAI, M. Some factors affecting behaviour of boron in soil. I. Some soil properties affecting boron adsorption of soil. Soil Science and Plant Nutrition, Tokyo, 14: 215-24, 1968.

HARTER, R.D. \& BAKER, D.E. Applications and misapplications pf the Langmuir equation to soil adsorption phenomena. Soil Science Society of America Journal, Madison, 41: 1077-80, 1979.

HATCHER, J.T. \& BOWER, C.A. Equilibria and dynamics of boron adsorption by soils. Soil Science, Baltimore, 85: 319-23, 1958.

HATCHER, J.T.; BOWER, C.A.; CLARCK, M. Adsorption of boron by soils as influenced by hidroxialuminum and surface area. Soil Science, Baltimore, 104: 422-6, 1967. 
HEILMAN, M.D.; CARTER, D.L.; GONZALEZ, C.L. The ethylene glycol monoethyl (EGME) technique for determining soil-surface area. Soil Science, Baltimore, 100: 409-13, 1965.

HINGSTON, F.J. Reaction between boron and clays. Australian Journal of Soil Research, Melbourne, 2:83-95, 1964.

HOROWITZ, A. \& DANTAS, H.S. Boro disponível nos solos da zona Litoral Mata de Pernambuco. Pesquisa Agropecuária Brasileira, Rio de Janeiro, 8: 163-8, 1973.

ICHIKUNI, M. \& KIKUCHI, K. Retention of boron by travertines. Chemical Geology, Amsterdam, 9: 13-21, 1972.

JIN, J.; MARTENS, D.C.; ZELASNY, L.W. Distribution and plant availability of soil boron fractions. Soil Science Society of America Journal, Madison, 51: 1228-31, 1987.

JIN, J.; MARTENS, D.C.; ZELASNY, L.W. Plant availability of applied and native boron in soils with diverse properties. Plant and Soil, Dordrecht, 105: 127-32, 1988.

KEREN, R. \& BINGHAM, F.T. Boron in water, soils, and plants. Advances in Soil Science, New York, 1:229-76, 1985.

KEREN, R. \& GAST, R.G. Effects of wetting and drying, and of exchangeable cations, on boron adsorption and releáse by montmorillonite. Soil Science Society of America Journal, Madison, 45: 478-82, 1981. 
KEREN, R. \& GAST, R.G. pH-dependent boron adsorption by montmorillonite hidroxi-aluminum complexes. Soil Science Society of America Journal, Madison, 47: 1116-21, 1983.

KEREN, R. \& MEZUMAN, U. Boron adsorption by clay minerals using a phenomenological equation. Clays and Clay Mineralogy, New York, 29: 198-204, 1981.

KEREN R. \& O'CONNOR, G.A. Effect of exchangeable ions and ionic strength on boron adsorption by montmorillonite and illite. Clays and Clay Mineralogy, New York, 30: 341-6, 1982.

KEREN, R. \& TALPAZ, H. Boron adsorption by montmorillonite as affected by particle size. Soil Science Society of America Journal, Madison, 48: 555$9,1984$.

KEREN, R.; GAST, R.G.; BAR-YOSEF, B. pH-dependent boron adsorption by Na-montmorillonite. Soil Science Society of America Journal, Madison, 45: 45-8, 1983.

KLUGE, R \& BEER, K. The effect of $\mathrm{pH}$ on boron adsorption by aluminum hidroxide gel, clay minerals and soils. Archiv. Acker-und Pflanzembau und Bodenkunde, Berlin, 23(5): 279-87, 1979.

KRAUSKOPF, K.B. Introdução à geoquímica. São Paulo, USP/Polígono, 1972. v. 2. 605 p. 
KRAUSKOPF, K.B. Geochemistry of micronutrients. In: MORTVEDT, M.G. \& LINDSAY, W.L., ed. Micronutrients in agriculture. Madison, Soil Science Society of America, 1973. p. 7-36.

LAVERDIÈRE, M.R. \& KARAM, A. Sorption of phosphorus by some surface soils from Quebec in relation to their properties. Communications in Soil Science and Plant Analysis, New York, 15: 1215-30, 1984.

LEMOS, R.C. \& SANTOS, R.D. Manual de descrição e coleta de solo no campo. Campinas, Sociedade Brasileira de Ciência do Solo / Serviço Nacional de Levantamento e Conservação do Solo, 1984. 46p.

LINDSAY, W.L. Inorganic phase equilibria of micronutrients in soils. In: MORTVEDT, J.J.; GIORDANO, P.M.; LINDSAY, W.L., ed. Micronutrients in agriculture. Madison, Soil Science Society of America, 1972. p.41-57.

MALAVOLTA, E. Elementos de nutrição mineral de plantas. São Paulo, Ceres, 1980. 251p.

MANDAL, B.; ADHIKARI, T.K.; DE, D.K. Effect of lime and organic matter application on the availability of added boron in acidic alluvial soils. Communications in Soil Science and Plant Analysis, New York, 24: 192535, 1993. 
MARCONI, A.; FREIRE, O.; ABRAHÃO, I.O.; BRASIL SOBRINHO, M.O.C. Boro nos minerais, rochas, solos e plantas. Revista de Agricultura, Piracicaba, 55: 33-9, 1980.

MARZADORI, C.; VITTORI ANTISARI, L.; CIAVATTA, C.; SEQUI, P. Soil organic matter influence on adsorption and desorption of boron. Soil Science Society of America Journal, Madison, 55: 1582-5, 1991.

McPHAIL, M.; PAGE, A.L.; BINGHAM, F.T. Adsorption interactions of monosilicic and boric acid on hydrous oxides of iron and aluminum. Soil Science Society of America Proceedings, Madison, 36: 510-14, 1972.

MEAD, J.A. A comparison of the Langmuir, Freundlich and Temkin equations to describe phosphate adsorption properties. Australian Journal of Soil Research, Melbourne, 19: 333-42, 1981.

MEZUMAN, U. \& KEREN, R. Boron adsorption by soils using a phenomenological adsorption equation. Soil Science Society of America Journal, Madison, 45: 722-6, 1981.

MIDGLEY, A.R. \& DUNKLEE, D.E. The effect of lime on the fixation of borates in soils. Soil Science Society of America Proceedings, Madison, 4: 302-7, 1939.

MLJKOVIC, N.S.; MATTHEWS, B.C.; MLLER, M.H. The available boron content of the genetic horizons of some Ontario soils. I. The relationship between watwr-aoluble boron and other soil properties. Canadian Journal of Soil Science, Ottawa, 46:133-8, 1966. 
NICHOLAICHUK, W.; LEYSHON, A.J.; JAME, Y.W.; CAMPBELL, C.A. Boron and salinity survey of irrigation projects and the boron adsorption characteristics of some Saskatchewan soils. Canadian Journal of Soil Science, Ottawa, 68: 77-90, 1988.

OKAZAKI, E. \& CHAO, T.T. Boron adsorption and desorption by some Hawaiian soils. Soil Science, Baltimore, 105: 255-9, 1968.

OLSON, R.V. \& BERGER, K.C. Boron fixation as influenced by $\mathrm{pH}$, organic matter content, and other factors. Soil Science Society of America Proceedings, Madison, 11:216-20, 1946.

PARKER, D.R. \& GARDNER, E.H. The determination of hot-water-soluble boron in some acid Oregon soils using a modified azometine-H procedure. Communications in Soil Science and Plant Analysis, New York, 12: 1311$22,1981$.

PARKER, D.R. \& GARDNER, E.H. Factors affecting the mobility and plant availability of boron in some Western Oregon soils. Soil Science Society of America Journal, Madison, 46: 573-8, 1982.

PARKS, R.Q. \& SHAW, B.T. Possible mechanisms of boron fixation in soil: I. Chemical. Soil Science Society of America Proceedings, Madison, 6: 219$23,1941$.

PARKS, W.L. \& WHITE, J.L. Boron retention by clay and humus systems saturated with various cations. Soil Science Society of America Proceedings, Madison, 16: 29.8-30, 1952. 
PINYERD, C.A.; ODOM, J.W.; LONG, F.L.; DANE, J.H. Boron movement in a Norfolk loamy sand. Soil Cience, Baltimore, 137: 428-33, 1984.

PRASAD, M. Extent of boron adsorption and its relationship to soil properties in some West Indian soils. Communications in Soil Science and Plant Analysis, New York, 9: 203-14, 1978.

RAIJ, B. van. Geoquímica de micronutrientes. In: FERREIRA, M.E.F. \& CRUZ, M.C.P.C., coord. Micronutrientes na agricultura. Piracicaba, Potafos, 1991. cap. 4, p. 99-111.

RAIJ, B. van. Conceitos fundamentais na interpretação da análise do solo. In: PEREIRA, J.R. \& FARIA, C.M.B., ed. Fertilizantes: insumo básico para agricultura e combate à fome. Anais do Simpósio. Petrolina, EMBRAPACPATSA / SBCS, 1995. p. 34-50.

RAIJ, B. van; SILVA, N.M.; BATAGLIA, O.C.; QUAGGIO, J.A.; HIROCE, R.; CANTARELLA, H.; BELLINAZZI JÚNIOR, R.; DECHEN, A.R.; TRANI, P.E. Recomendações de adubação e calagem para o Estado de São Paulo. Campinas, Instituto Agronômico, 1985. 107p. (Boletim Técnico, 100).

RANKAMA, K. \& SAHAMA, T.G. Geoquímica. Madrid, Aguilar, 1962. 862p.

RATNER-ZOMAR, Y.; BANIN, A.; CHEN, Y. Oven drying as a pretreatment for surface area determinations of soils and clays. Soil Science Society of America Journal, Madison, 47: 1056-8, 1983. 
REBSTOCKOVA, M. \& BARTUSEK, M. Reactions of boric acid with oxalic, glycolic and tartaric acids. Collection Czechoslov. Chem. Commun, 42: 627-36, 1977.

RESENDE, M. \& SANTANA, D.P. Uso das relações ki e kr na estimativa da mineralogia para classificação dos latossolos. In: REUNIÃO DE CLASSIFICAÇÃO, CORRELAÇÃO DE SOLOS E INTERPRETAÇÃO DE APTIDÃO AGRÍCOLA, 3., Rio de Janeiro, EMBRAPA/SNLCS, 1988. p.225-32. (EMBRAPA. Documentos SNLCS, 12).

RHOADES, J.D.; INGVALSON, R.D.; HATCHER, J.T. Laboratory determination of leaching soil boron. Soil Science Society of America Proceedings, Madison, 34: 871-5, 1970.

RIBEIRO, A.C. \& BRAGA, J.M. Adsorção do boro pelo solo. Experientiae, Viçosa, 17(12): 293-310, 1974.

RUIZ-NETO, A.; BARAHONA, E.; JAIME, S.; AGULAR, A. Relations between $B$ (total and available) and several constituents of cultivated soils. Anales de Edafologia y Agrobiologia, Madrid, 47: 1281-8, 1988.

RUY, V.M. Contribuição para o estudo do boro disponível em solos. Piracicaba, 1986. 104p. (Mestrado - Escola Superior de Agricultura "Luiz de Queiroz" / USP).

SANTOS, H.L.; BRAGA, J.M.; REZENDE, M.; CHAVES, J.R.P. Efeito do zinco, boro, molibdênio e calagem na produção de soja perene (Glycine 
javanica) cultivada em solos de cerrado em condições de casa-de vegetação. Revista Ceres, Viçosa, 27: 99-111, 1980.

SARABIA, W.A.T. Avaliação dos teores de zinco e boro "disponíveis" em latossolos do Triângulo Mineiro. Viçosa, 1982. 61p. (Mestrado Universidade Federal de Viçosa).

SCHALSCHA, E.B.; BINGHAM, F.T.; GALINDO, G.G.; GALVAN, H.P. Boron adsorption by volcanic ash soils in Southern Chile. Soil Science, Baltimore, 116(2): 70-6, 1973.

SCOTT, H.D.; BEASLEY, S.D.; THOMPSON, L.F. Effect of lime on boron transport to and uptake by cotton. Soil Science Society of America Proceedings, Madison, 39: 1116-21, 1975.

SHANI, U.; DUDLEY, L.M.; HANKS, R.J. Model of boron movement in soils. Soil Science Society of America Journal, Madison, 56: 1365-70, 1992.

SHARPLEY, A.N. Effect of soil properties on the kinetics of phosphorus desorption. Soil Science Society of America Journal, Madison, 47: 426-67, 1983.

SHUMWAY, J.S. \& JONES, J.P. Boron adsorption isotherm: a method to estimate boron fertilizer requirement. Communications in Soil Science and Plant Analysis, New York, 3: 477-85, 1972. 
SIMS, J.R. \& BINGHAM, F.T. Retention of boron by layer silicates, sesquioxides and soil materials: I. Layer silicates. Soil Science Society of America Proceedings, Madison, 31: 728-32, 1967.

SIMS, J.R. \& BINGHAM, F.T. Retention of boron by layer silicates, sesquioxides and soil materials: II. Sesquioxides. Soil Science Society of America Proceedings, Madison, 32:364-9, 1968a.

SIMS, J.R. \& BINGHAM, F.T. Retention of boron by layer silicates, sesquioxides and soil materials: III. Iron and aluminum-coated layer silicates and soil materials. Soil Science Society of America Proceedings, Madison, 32: 369-73, $1968 b$.

SINGH, B.R. Sulfate sorption by acid forest soils: 1. Sulfate adsorption isotherms and comparison of different adsorption equations in describing sulfate adsorption. Soil Science, Baltimore, 138: 189-97, 1984.

SINGH, K.P. \& SINHA, H. Availability of boron in relation to certain soil properties. Journal of Indian Soil Science Society, New Dehli, 24: 403-8, 1976.

SINGH, M. Equilibrium adsorption of boron in soils and clays. Geoderma, Amsterdan, 5: 209-17, 1971.

SINGH, S.S. Boron adsorption equilibrium in soils. Soil Science, Baltimore, 98: 383-7, 1964. 
SPOSITO, G. On the use of the Langmuir equation in the interpretation of "adsorption" phenomena. II. The "two-surface" Langmuir equation. Soil Science Society of America Journal, Madison, 46: 1174-52, 1982.

VANDERLEY, J.C. Boro em materiais de três solos do município de Lavras, Estado de Minas Gerais. Lavras, 1984. 96p. (Mestrado - Escola Superior de Agricultura de Lavras).

VEITH, J.A. \& SPOSITO, G. On the use of Langmuir equation in the interpretation of "adsorption" phenomena. Soil Science Society of America Journal, Madison, 41: 697-702, 1977.

WEAR, J.I. Boron. In: BLACK, C.A.; EVANS, D.D.; WHITE, J.L.; EISMINGER, L.E.; CLARCK, F.E., ed. Methods of soil analysis. Part2. Chemical and microbiologycal properties. Madison, American Society of Agronomy, 1965. p. 1059-63. (Agronomy, 9).

WEAR, J.I. \& PATTERSON, R.M. Effect of soil $\mathrm{pH}$ and textura on the availability of water-soluble boron in the soil. Soil Science Society of America Proceedings, Madison, 26: 344-6, 1962.

WILSON, C.M., LOVVORNE, R.L.; WOODHOUSE JUNIOR, W.W. Movement and accumulation of water soluble boron within the soil profile. Agronomy Journal, Madison, 43: 363-7, 1951.

YERMIYAHU, U.; KEREN, R.; CHEN, Y. Boron adsorption on composted organic matter. Soil Science Society of America Journal, Madison, 52: 1309-13, 1988. 
YERMIYAHU, U.; KEREN, R.; CHEN, Y. Boron adsorption by soil in the presence of composted organic matter. Soil Science Society of America Journal, Madison, 59: 405-0, 1995.

ZULLO JÚNIOR, J. \& ARRUDA, F.B. Programa computacional para ajuste de equações em dados experimentais. Campinas, Instituto Agronômico, 1986. 23p. (Boletim Técnico, 113). 


\section{APÊNDICE 1}

No Apêndice 1 são apresentados os quadros de análise da variância e os resumos informativos dos relatórios de saída do programa SAS, para as análises de regressão múltipla empregadas para boro solúvel em $\mathrm{CaCl}_{2} 0,01 \mathrm{~mol} / \mathrm{L}$ a quente (Bs), boro adsorvido após adição de uma solução $2 \mu \mathrm{g} / \mathrm{mL}$ em boro (Bads), adsorção máxima estimada pelo modelo de Langmuir (Admáx) e capacidade tampão máxima (CTM), correspondente ao produto entre as constante $\mathrm{K}$ e $\mathrm{b}$ de Langmuir.

1) Stepwise Procedure for Dependent Variable Bs (boro solúvel)

$\begin{array}{cccccc}\text { Variable } & \begin{array}{c}\text { Parameter } \\ \text { Estimate }\end{array} & \begin{array}{c}\text { Standard } \\ \text { Error }\end{array} & \text { Sum of Squares } & \text { F } & \text { Prob }>\text { F } \\ & & & & & \\ \text { Intercept } & -0.09186797 & 0.07495924 & 0.00735196 & 1.50 & 0.2663 \\ \text { Ca } & 0.00662109 & 0.00272779 & 0.02883784 & 5.89 & 0.0514 \\ \text { Al } & 0.00744609 & 0.00196346 & 0.07039464 & 14.38 & 0.0090 \\ \text { Alt } & 0.00169208 & 0.00037038 & 0.10216083 & 20.87 & 0.0038\end{array}$

Summary of Stepwise Procedure for Dependent Variable Bs

$\begin{array}{cccccc} & \begin{array}{c}\text { Variable } \\ \text { Step }\end{array} & \begin{array}{c}\text { Partial } \\ \text { Entered }\end{array} & \begin{array}{c}\text { Model } \\ \mathrm{r}^{2}\end{array} & \mathrm{r} & \text { Prob>F } \\ & & & & & \\ 1 & \text { Alt } & 0.4885 & 0.4885 & 7.6411 & 0.0245 \\ 2 & \text { Al } & 0.2240 & 0.7125 & 5.4529 & 0.0522 \\ 3 & \text { Ca } & 0.1424 & 0.8549 & 5.8917 & 0.0514\end{array}$


2) Stepwise Procedure for Dependent Variable Bads (boro adsorvido)

$\begin{array}{ccccrr}\text { Variable } & \begin{array}{c}\text { Parameter } \\ \text { Estimate }\end{array} & \begin{array}{c}\text { Standard } \\ \text { Error }\end{array} & \text { Sum of Squares } & \text { F } & \text { Prob }>\mathrm{F} \\ & & & & & \\ \text { Intercept } & 1.65138917 & 0.32459789 & 4.29046616 & 25.88 & 0.0022 \\ \mathrm{Al}_{\mathrm{d}} & -0.11546503 & 0.02166414 & 4.70885132 & 28.41 & 0.0018 \\ \text { Bsol } & -3.03207589 & 1.31857791 & 0.87652747 & 5.29 & 0.0611 \\ \text { Argila } & 0.00823046 & 0.00104132 & 10.35557751 & 62.47 & 0.0002\end{array}$

Summary of Stepwise Procedure for Dependent Variable Bads

\begin{tabular}{|c|c|c|c|c|c|}
\hline Step & $\begin{array}{l}\text { Variable } \\
\text { Entered }\end{array}$ & $\begin{array}{c}\text { Partial } \\
\mathrm{r}^{2}\end{array}$ & $\underset{r^{2}}{\text { Model }}$ & $\mathrm{F}$ & Prob $>F$ \\
\hline 1 & Argila & 0.6171 & 0.6171 & 12.8949 & 0.0071 \\
\hline & $\mathrm{Al}_{\mathrm{d}}$ & 0.2590 & 0.8761 & 14.6365 & 0.0065 \\
\hline 2 & Bsol & 0.0580 & 0.9342 & 5.2877 & 0.0611 \\
\hline
\end{tabular}

3) Stepwise Procedure for Dependent Variable Admáx (adsorção máxima)

$\begin{array}{cccrrr}\text { Variable } & \begin{array}{c}\text { Parameter } \\ \text { Estimate }\end{array} & \begin{array}{c}\text { Standard } \\ \text { Error }\end{array} & \text { Sum of Squares } & \text { F } & \text { Prob }>F \\ & & & & & \\ \text { Intercept } & 1.27606046 & 0.88392852 & 2.81539126 & 2.08 & 0.1921 \\ \mathrm{Ca} & 0.07770415 & 0.04285155 & 4.44207472 & 3.29 & 0.1127 \\ \mathrm{Fe}_{\mathrm{d}} & 0.06640802 & 0.00530008 & 212.08367612 & 156.99 & 0.0001\end{array}$


Summary of Stepwise Procedure for Dependent Variable Admáx

$\begin{array}{cccccc}\text { Step } & \begin{array}{c}\text { Variable } \\ \text { Entered }\end{array} & \begin{array}{c}\text { Partial } \\ \mathrm{r}^{2}\end{array} & \begin{array}{c}\text { Model } \\ \mathrm{r}^{2}\end{array} & \mathrm{~F} & \text { Prob>F } \\ & & & & & \\ 1 & \mathrm{Fe}_{\mathrm{d}} & 0.9438 & 0.9438 & 134.2478 & 0.0001 \\ 2 & \mathrm{Ca} & 0.0180 & 0.9617 & 3.2882 & 0.1127\end{array}$

4) Stepwise Procedure for Dependent Variable CTM (capacidade tampão máxima)

$\begin{array}{cccccc}\text { Variable } & \begin{array}{c}\text { Parameter } \\ \text { Estimate }\end{array} & \begin{array}{c}\text { Standard } \\ \text { Error }\end{array} & \text { Sum of Squares } & \mathrm{F} & \text { Prob>F } \\ & & & & & \\ \text { Intercept } & -2.10161633 & 0.29345076 & 0.64536430 & 51.29 & 0.0020 \\ \mathrm{pH} & 0.56085182 & 0.06502803 & 0.93597367 & 74.39 & 0.0010 \\ \mathrm{Al}_{\mathrm{t}} & 0.02585243 & 0.00132106 & 4.81865281 & 382.96 & 0.0001 \\ \mathrm{Al}_{\mathrm{d}} & -0.15600070 & 0.00873641 & 4.01195327 & 318.85 & 0.0001 \\ \mathrm{Fe}_{\mathrm{o}} & -0.58658646 & 0.08019100 & 0.67325779 & 53.51 & 0.0019 \\ \mathrm{Al}_{\mathrm{o}} & 4.95166599 & 0.19458323 & 8.14817647 & 647.58 & 0.0001\end{array}$

Summary of Stepwise Procedure for Dependent Variable CTM

$\begin{array}{cccccc}\text { Step } & \begin{array}{c}\text { Variable } \\ \text { Entered }\end{array} & \begin{array}{c}\text { Partial } \\ \mathrm{r}^{2}\end{array} & \begin{array}{c}\text { Model } \\ \mathrm{r}^{2}\end{array} & \mathrm{~F} & \text { Prob>F } \\ & & & & & \\ 1 & \mathrm{Al}_{\mathrm{o}} & 0.5317 & 0.5317 & 9.0843 & 0.0167 \\ 2 & \mathrm{Al}_{\mathrm{d}} & 0.2303 & 0.7620 & 6.7728 & 0.0353 \\ 3 & \mathrm{Al}_{\mathrm{t}} & 0.1905 & 0.9525 & 24.0632 & 0.0027 \\ 4 & \mathrm{pH} & 0.0227 & 0.9752 & 4.5791 & 0.0853 \\ 5 & \mathrm{Fe}_{\mathrm{o}} & 0.0231 & 0.9983 & 53.5073 & 0.0019\end{array}$




\section{APÊNDICE 2}

Tabela 1A. Coeficientes de correlação não significativos entre boro adsorvido após adição de solução $2 \mu \mathrm{g} / \mathrm{mL}$ de boro e diversos atributos dos solos.

\begin{tabular}{cc}
\hline Atributo & Coeficiente de correlação \\
\hline pH & $-0,04$ \\
Carbono & 0,29 \\
Cálcio & $-0,01$ \\
Magnésio & $-0,01$ \\
Potássio & $-0,18$ \\
Alumínio & 0,12 \\
H + Al & 0,39 \\
CTC efetiva & 0,03 \\
CTC total & 0,39 \\
V \% & $-0,18$ \\
m \% & 0,12 \\
Boro solúvel & 0,49 \\
\hline
\end{tabular}


Tabela 2A. Coeficientes de correlação não significativos entre constantes dos modelos de Langmuir e de Freundlich e alguns atributos e parâmetros dos solos.

\begin{tabular}{cccccc}
\hline Atributo / parâmetro & \multicolumn{3}{c}{ Langmuir } & \multicolumn{2}{c}{ Freundlich } \\
\cline { 2 - 6 } & $\mathrm{K}$ & $\mathrm{b}$ & $\mathrm{CTM}^{*}$ & $\mathrm{~K}$ & $\mathrm{~b}$ \\
\cline { 2 - 6 } & & \multicolumn{2}{c}{ Coeficiente de correlação } \\
pH & 0,08 & 0,05 & $-0,06$ & $-0,05$ & $-0,18$ \\
Carbono & 0,01 & 0,38 & 0,27 & 0,27 & 0,21 \\
Cálcio & 0,21 & $-0,19$ & 0,07 & $-0,01$ & $-0,19$ \\
Magnésio & 0,07 & $-0,08$ & 0,03 & $-0,02$ & $-0,03$ \\
Potássio & $-0,42$ & 0,29 & $-0,35$ & $-0,22$ & 0,29 \\
Alumínio & $-0,09$ & $-0,03$ & 0,05 & 0,09 & 0,09 \\
H + Al & $-0,23$ & 0,42 & 0,26 & 0,34 & 0,32 \\
CTC efetiva & 0,07 & $-0,18$ & 0,04 & $-0,01$ & $-0,06$ \\
CTC total & $-0,16$ & 0,33 & 0,28 & 0,34 & 0,25 \\
V\% & 0,25 & $-0,35$ & $-0,09$ & $-0,18$ & $-0,28$ \\
m \% & $-0,09$ & $-0,01$ & 0,08 & $-0,12$ & $-0,01$ \\
\hline
\end{tabular}

* Capacidade tampão máxima 
Tabela 3A. Parâmetros obtidos a partir da razão entre alguns atributos e o teor de argila (arg = argila; $\mathrm{C}$ = carbono; $\mathrm{Fe}_{\mathrm{t}}$ e $\mathrm{Al}_{\mathrm{h}}, \mathrm{Fe}_{\mathrm{d}}$ e $\mathrm{Al}_{\mathrm{d}}, \mathrm{Fe}_{\mathrm{o}}$ e $\mathrm{Al}_{\mathrm{o}}=$ óxidos de ferro e de alumínio totais, livres e mal cristalizados, respectivamente).

\begin{tabular}{|c|c|c|c|c|c|c|c|c|}
\hline \multicolumn{2}{|c|}{ Solo/ camada } & \multirow{2}{*}{$\begin{array}{l}\text { C/arg } \\
0,0147\end{array}$} & \multirow{2}{*}{$\begin{array}{c}\mathrm{Fe}_{\mathrm{t}} / \mathrm{arg} \\
0,5344\end{array}$} & \multirow{2}{*}{$\begin{array}{c}\mathrm{Al}_{\mathrm{p}} / \mathrm{arg} \\
0,3098\end{array}$} & \multirow{2}{*}{$\begin{array}{c}\mathrm{Fe}_{\mathrm{d}} / \mathrm{arg} \\
0,3410\end{array}$} & \multirow{2}{*}{$\begin{array}{c}\mathrm{Al}_{\mathrm{d}} / \mathrm{arg} \\
0,0597\end{array}$} & \multirow{2}{*}{$\begin{array}{c}\mathrm{Fe}_{\mathrm{o}} / \mathrm{arg} \\
0,0056\end{array}$} & \multirow{2}{*}{$\begin{array}{c}\mathrm{Al}_{\mathrm{o}} / \mathrm{arg} \\
0,0011\end{array}$} \\
\hline LR arg & A & & & & & & & \\
\hline & $\mathrm{A}^{*}$ & 0,0229 & - & - & - & - & - & - \\
\hline & B & 0,0104 & 0,5089 & 0,2821 & 0,3104 & 0,0430 & 0,0067 & 0,0010 \\
\hline \multirow[t]{3}{*}{$\mathrm{PV} \mathrm{a} / \mathrm{m}$} & A & 0,0833 & 0,3833 & 0,4833 & 0,1667 & 0,0867 & 0,0117 & 0,0033 \\
\hline & $\mathrm{A}^{*}$ & 0,0833 & - & - & - & - & - & - \\
\hline & B & 0,0118 & 0,1382 & 0,3353 & 0,0794 & 0,0191 & 0,0029 & 0,0009 \\
\hline \multirow[t]{3}{*}{ LV md } & A & 0,0714 & 0,1286 & 0,3071 & 0,1214 & 0,0557 & 0,0071 & 0,0033 \\
\hline & $\mathrm{A}^{*}$ & 0,0643 & - & - & - & - & - & - \\
\hline & B & 0,0250 & 0,1050 & 0,2150 & 0,1000 & 0,0650 & 0,0035 & 0,0025 \\
\hline \multirow[t]{3}{*}{ LE arg } & A & 0,0180 & 0,2319 & 0,2486 & 0,1667 & 0,0253 & 0,0033 & 0,0008 \\
\hline & $\mathrm{A}^{*}$ & 0,0167 & - & $=$ & - & - & - & - \\
\hline & B & 0,0120 & 0,2320 & 0,2389 & 0,1920 & 0,0277 & 0,0028 & 0,0017 \\
\hline \multirow[t]{3}{*}{ LE md } & A & 0,0529 & 0,1412 & 0,3529 & 0,1176 & 0,0765 & 0,0059 & 0,0018 \\
\hline & $\mathrm{A}^{*}$ & 0,0529 & - & - & - & - & - & - \\
\hline & B & 0,0227 & 0,1318 & 0,3636 & 0,1045 & 0,0532 & 0,0045 & 0,0014 \\
\hline
\end{tabular}

* Horizonte A com calcário 